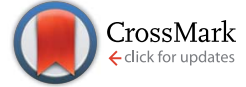

Cite this: RSC Adv., 2017, 7, 9194

\title{
Recent studies of the synthesis, functionalization, optoelectronic properties and applications of dibenzophospholes
}

\begin{abstract}
Paulina Hibner-Kulicka, ${ }^{\text {ab }}$ John Arthur Joule, ${ }^{c}{ }^{\prime}$ Joanna Skalik ${ }^{a}$ and Piotr Bałczewski*ad
The first dibenzophospholes were described in the 1950s, but only recently have they gained greater importance, due to their use in organic electronics and the possibility of designing new $\pi$-conjugated, optoelectronic materials that incorporate these heterocycles. Our comprehensive review covering a period of 15 years (2001-2016), includes methods of synthesis of these compounds, methods for their functionalization, a description of their optoelectronic properties and their first use in optoelectronic devices. The review represents the current state of knowledge in this field and shows the great potential of simple and functionalized dibenzophospholes. The work described in this review suggests that dibenzophospholes should also be investigated more intensively as single materials, as well as in structural combinations with other $\pi$-extended conjugated aromatic and heteroaromatic systems containing phosphorus, nitrogen, silicon or sulfur atoms.
\end{abstract}

Received 4th November 2016 Accepted 23rd January 2017

DOI: 10.1039/c6ra26333j

rsc.li/rsc-advances

\section{Introduction}

Interest in $\pi$-conjugated compounds has increased greatly following the investigations of Heeger, MacDiarmid and Shirakawa, ${ }^{1}$ that led to the award of the Chemistry Nobel Prize in 2000. There followed a period of dynamic development in the field of synthesis and studies on the properties of oligomeric and polymeric systems applicable to flexible, lightweight and low-cost electronic devices. A great deal of attention has been paid not only to structural modifications, but also to \begin{abstract}
Protection and Biotechnology, The Faculty of Mathematics and Natural Sciences, Armii Krajowej 13/15, 42-201 Czestochowa, Poland. Tel: +48343784100

${ }^{a}$ Department of Heteroorganic Chemistry, Centre of Molecular and Macromolecular Studies, Polish Academy of Sciences, Sienkiewicza 112, 90-363 Łódź, Poland. E-mail: pbalczew@cbmm.lodz.pl; Fax: +48 4268471 26; Tel: +48 426847126

${ }^{b}$ Department of Molecular Physics, Technical University of Łódź, Żeromskiego 116, 90924 Lódź, Poland. Fax: +484263132 18; Tel: +48426313205

The School of Chemistry, The University of Manchester, Manchester M13 9PL, UK IJan Dlugosz University in Czestochowa, Institute of Chemistry, Environmental
\end{abstract}

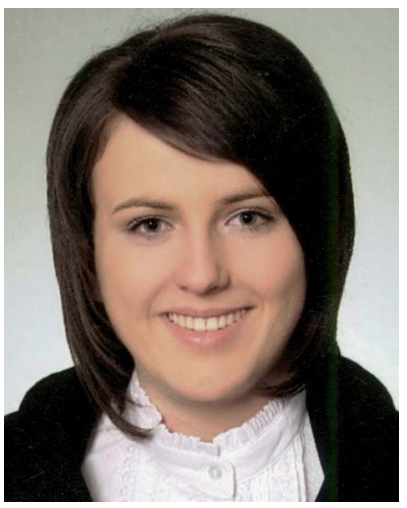

Paulina Hibner-Kulicka received her BSc in chemistry from the Jan Dtugosz University in Czestochowa, Poland. Within an Erasmus program with the University of Caen-Normandy (ENSICAEN), France, she was involved in the synthesis of ladder-type heteroacenes as materials for light-emission and charge transport. She graduated (MSc) from the University of Eódz, in the area of chemistry and nanotechnology of new materials in collaboration with the Centre of Molecular and Macromolecular Studies, Polish Academy of Science, tódź (Prof. P. Batczewski). Currently, she is a PhD student working on photovoltaic and OLED device fabrication at tódź University of Technology, Poland.

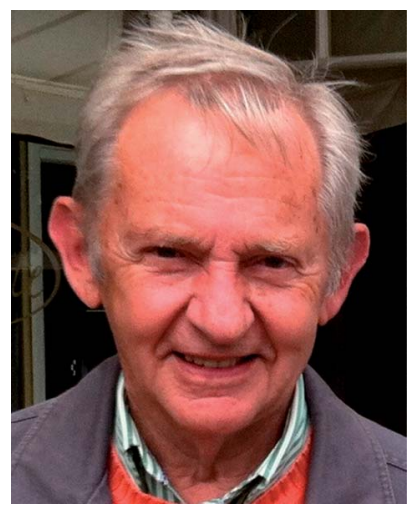

John Joule grew up and went to school in Llandudno, Wales, moving to the University of Manchester for BSc, MSc, and $\mathrm{PhD}$ degrees, the last with $\mathrm{Dr}$ George F. Smith. Following postdoctoral studies with Richard $K$. Hill (Princeton) and Carl Djerassi (Stanford) he returned to Manchester for an academic career of 41 years. His research there produced more than 230 papers on aspects of heterocyclic chemistry, especially indoles and quinoxalines and pteridines related to the molybdenum cofactor. His textbook 'Heterocyclic Chemistry' co-authored originally with George Smith and latterly with Keith Mills, his one-time PhD student, is now in its $5^{\text {th }}$ Edition. 

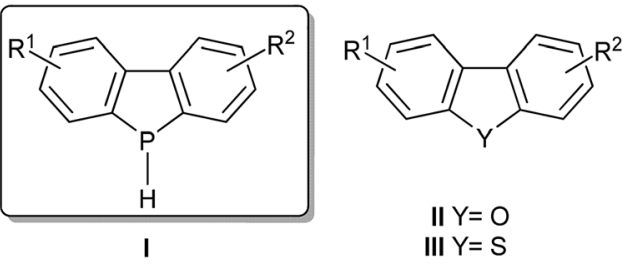

II $Y=O$

III $Y=S$

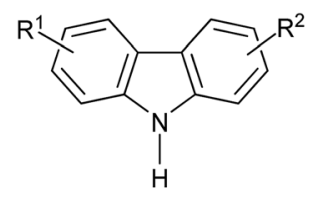

IV

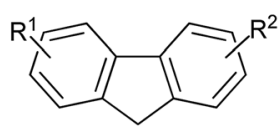

V

Scheme 1

supramolecular organization of such compounds to achieve optimal properties of the final materials. The use of conjugated polyaromatic, polyacetylenic, polyolefinic compounds and fused aromatic systems, as well as their structural combinations, not only guarantees satisfactory properties and excellent stability of these compounds, but also the possibility for their easy chemical functionalization using modern synthetic tools. A disadvantage of the systems containing aromatic building blocks has often been a too high degree of aromaticity, which inhibits an easy electron delocalization along the conjugated rings when in an oxidized state. ${ }^{2-4}$

Therefore, this type of molecular system requires a beneficial incorporation of heteroaromatic rings, for example fivemembered pyrrole, thiophene or furan, possessing lower aromatic stabilization energies ( $\mathrm{ASE}_{\text {calc }}: 20.57,18.57,14.77 \mathrm{kcal}$ $\mathrm{mol}^{-1}$, respectively) than a benzene ring. The aromatic character of the phosphole ring $\left(\mathrm{ASE}_{\text {calc }}=3.2 \mathrm{kcal} \mathrm{mol}^{-1}\right.$ ) is relatively low due to the pyramidal geometry of the phosphorus atom. Overlap between the lone pair and the diene unit is thus limited, resulting in a lower aromatic character compared with other five-membered heterocycles with nitrogen, sulfur or oxygen. The low aromatic character allows hyperconjugation of the endocyclic $4-\pi$-electron system with the exocyclic P-R bond. Closely related dibenzophospholes I (Scheme 1) and their derivatives, being further examples of such fused heterocyclic systems, have been used successfully, alone or as building blocks, for preparation of more complex $\pi$-conjugated systems useful as electronic and optoelectronic materials. However, they are still an underestimated group of compounds in this field.

Dibenzophospholes I together with dibenzofurans II, dibenzothiophenes III and carbazoles IV belong formally to a family of heteroanalogs of fluorene $\mathbf{V}$, or to be more precise, the fluorene anion (Scheme 1).

Important reviews by Réau, ${ }^{5}$ Baumgartner ${ }^{6,7}$ and Hissler ${ }^{8,9}$ serve as brief introductions to phospholes and other organophosphorus derivatives in the molecular electronics context. Hissler's reviews focus mainly on nonfused phospholes and diheteroaromatic derivatives of phospholes fused to thiophene, pyrrole, furan, pyridine moieties and other P-derivatives with a particular emphasis on incorporation into electronic devices while the (micro)reviews by Réau and Baumgartner focus on development of phosphole-containing oligo- and polythiophene materials. A 2015 review by Gouygou ${ }^{10}$ discussed phospholebased ligands, including dibenzophospholes, which have potential in metal and organocatalysed reactions. ${ }^{10}$

In our comprehensive review, we summarise the literature on the newest methods of synthesis and functionalisation of the dibenzophospholes as well as their applications as optoelectronic materials (Fig. 1). This work continues the comprehensive coverage in a previous review devoted to synthesis of dibenzophospholes by Aitken in $2001^{11}$ and thus it deals with work from the years 2001-2016.

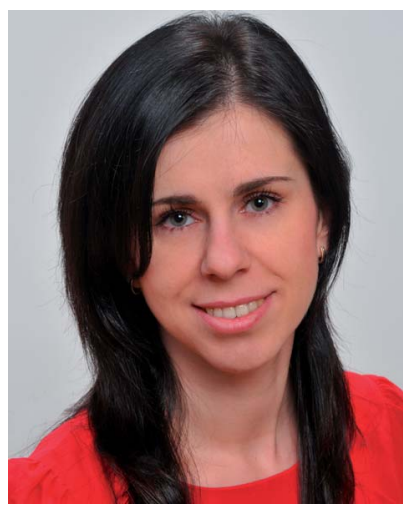

Joanna Skalik graduated from the Jan Dtugosz University in Czestochowa, Faculty of Mathematics and Natural Sciences (2008). She received her PhD with distinction at the Center of Molecular and Macromolecular Studies, Polish Academy of Sciences (CMMS, PAS) (2015). Since 2008, she has been a member of the scientific staff in the group of Prof. Piotr Batczewski at the Department of Heteroorganic Chemistry, CMMS, PAS. She is a co-author of several patents, original and review articles, and chapters in books (Organophosphorus Chemistry, RSC, vol. 40-42, 44, 46). She is actively involved in the realization of Polish national and European research projects.

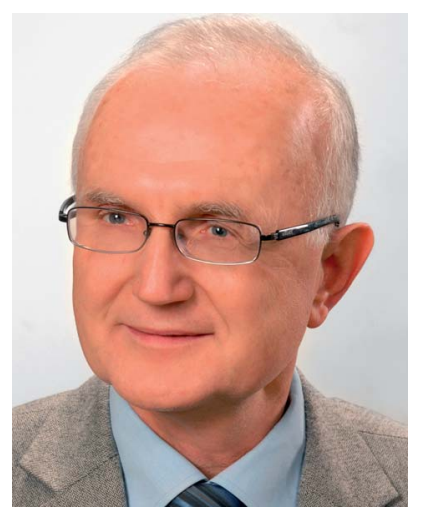

Piotr Bałczewski studied chemistry at the Technical University of $\mathrm{Eodz}$. $\mathrm{MSc} / \mathrm{PhD}$ theses ( $\mathrm{P} / \mathrm{S} / \mathrm{Si}$ and cyclopentanoid chemistry) were with Prof. M. Mikołajczyk at the Centre of Molecular and Macromolecular Studies (CM \& MS), Polish Academy of Sciences (PAS), tódź. Doctoral studies at the Warsaw PAS, Institute of Organic Chemistry, then a postdoctoral period at Manchester University (UK) in alkaloid chemistry (Prof. J. A. Joule) led to habilitation and appointment as full professor at CM \& MS PAS, Eódź. He currently leads materials research groups at $C M \& M S P A S$, Lodź and the J. Dtugosz University in Czestochowa, and is currently Vice-President of the Polish Chemical Society. 


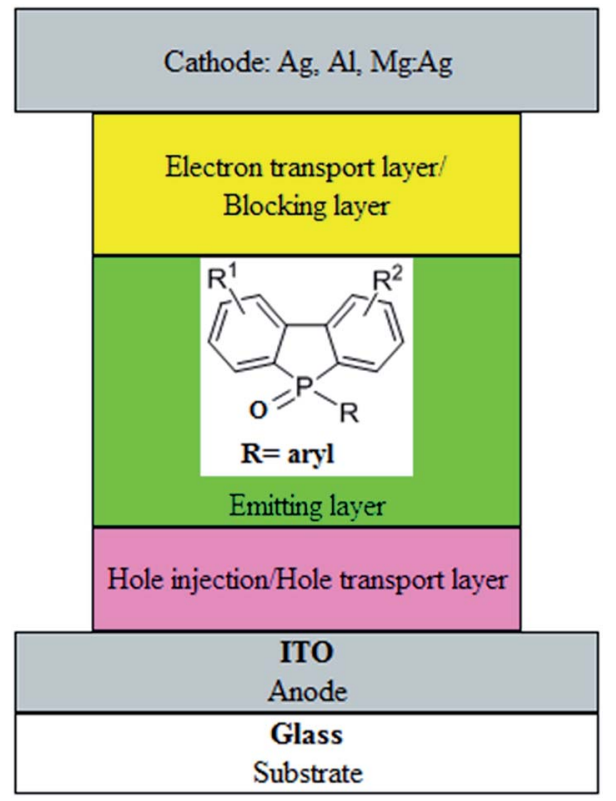

Fig. 1 The application dibenzophospholes in construction of various OLED devices.

Although the first dibenzophospholes were described in the 1950s, in recent times, these interesting compounds have gained importance due to the possibility of using them in new $\pi$-conjugated materials. The presence of the two flanking benzene rings in a dibenzophosphole gives the system several advantages over monocyclic phospholes in the context of incorporation into molecular electronics roles. The synthesis and synthetic manipulation of the tricyclic system allows adjustment of overall electronic structure by the introduction and manipulation of benzene-ring substituents. In particular, the linking of dibenzophosphole units to other electronically active components or its incorporation into polymer chains is facilitated by the benzene-ring units.

An important advantage of dibenzophospholes is their high resistance to thermal decomposition. For example, the temperature of thermal decomposition for dibenzophosphole is $365{ }^{\circ} \mathrm{C}$, while for the phospholes and dithienophospholes thermal decomposition temperatures are between 200 and $300{ }^{\circ} \mathrm{C} .{ }^{12}$

Dibenzophospholes and analogous tricyclic, dithienophospholes, are each well delocalized over the entire molecule and possess a smaller HOMO-LUMO gap than any of the component rings. Consequently the dibenzophospholes represent an independent class of compounds and should not be considered as classic, monocyclic phospholes. The dithienophosphole system, developed by Baumgartner et al., ${ }^{13-18}$ also possesses some advantages with respect to wavelength, intensity, especially tunability, as well as optical and thermal stability.

In this context, dibenzophospholes can be regarded as complementary optoelectronic materials and it is interesting to make a comparison of some selected properties of non-fused phospholes, fused dibenzophospholes and dithienophospholes, such as ranges of light absorption and light emission maxima, and luminescence quantum efficiencies. Thus for phospholes, the data are $350-450 \mathrm{~nm}, 450-620 \mathrm{~nm}$, up to 0.143 , for dibenzophospholes the significantly different values are $290-365 \mathrm{~nm}$, $360-490 \mathrm{~nm}$, up to 0.98 , and for dithienophospholes the values are $330-420 \mathrm{~nm}, 415-630 \mathrm{~nm}$, up to $0.90 .^{17,18}$

The first described dibenzophosphole (IUPAC, CAS: $5 \mathrm{H}^{-}$ benzo[b]phosphindole]) was 5 -phenyl substituted derivative $\mathbf{1},{ }^{19}$ obtained by Wittig in 1953, in low yield from a thermal decomposition of pentaphenylphosphorane $\mathrm{Ph}_{5} \mathrm{P}$. Other early methods, most of which were also elaborated by Wittig and coworkers, involved reactions of $\mathrm{Ph}_{5} \mathrm{P}, \mathrm{Ph}_{3} \mathrm{P}$, and $\mathrm{Ph}_{4} \mathrm{P}^{+} \mathrm{X}^{-}(\mathrm{X}=$ $\mathrm{Cl}, \mathrm{Br}), \mathrm{Ph}_{3} \mathrm{P}(\mathrm{O})$, with both weak (Py) and strong bases (PhMet, $\left.\mathrm{Et}_{2} \mathrm{NMet} ; \mathrm{Met}=\mathrm{Li}, \mathrm{Na}\right)^{20-23}$ as well as the reaction of $\mathrm{Ph}_{3} \mathrm{P}$ with benzyne (Scheme 2). ${ }^{24}$

The phosphorus atom in dibenzophospholes offers the possibility of expanding its valency and forming new bonds to $\mathrm{O}, \mathrm{S}, \mathrm{Se}, \mathrm{B}, \mathrm{N}, \mathrm{P}, \mathrm{Cl}, \mathrm{C}$ and metals in derivatives $\mathbf{2 ,} 3$ and 6-8. Dibenzophospholes possessing ionic structures, like the cation $\mathbf{4}$ and the anion $\mathbf{9}$ are also known. The phosphorane structure 5 containing two dibenzophosphole units was reported for the first time by Hellwinkel in $1960 .{ }^{25}$

\section{Synthesis of dibenzophospholes}

\subsection{From $\mathrm{PH}_{3}$ and derivatives}

In the years 2001-2015, new methods of synthesis of dibenzophospholes have been elaborated starting from $\mathrm{PH}_{3}$ and its derivatives. Stelzer, Sheldrick et al. obtained 5-phenyl-2,2'-bis(sulfonato)- $5 H$-dibenzophosphole dipotassium salt $\mathbf{1 1}$ by reaction of primary phenylphosphine with $5,5^{\prime}$-bis(sulfonato)-2, $2^{\prime}$ difluoro-1,1'-biphenyl dipotassium salt $\mathbf{1 0}$ in superbasic medium DMSO/KOH in $60 \%$ yield (Scheme 3 ). ${ }^{26}$

This research group also obtained the P-unsubstituted dibenzophosphole 14 by reaction of $5,5^{\prime}$-bis(sulfonato)-2,2'difluoro-1,1'-biphenyl disodium salt 12 with $\mathrm{NaPH}_{2}$ in liquid ammonia. In this reaction, the trisodium salt $\mathbf{1 3}$ was formed first, which upon acidification with aqueous $\mathrm{HCl}$ under aerobic conditions gave the dibenzophosphole disalt $\mathbf{1 4}$ accompanied by its dimer 15 (Scheme 4 ). ${ }^{26}$

Various bridged dibenzophospholes 17-21 have been obtained by a radical phosphanylation. An example of this approach is the reaction of tetrabromobiphenyls $16(\mathrm{R}=\mathrm{H}, \mathrm{Ph})$ with $\left(\mathrm{Me}_{3} \mathrm{Sn}\right)_{2} \mathrm{PPh}$ in benzene or trifluoromethylbenzene, in the presence of V-40 (1,1'-azobis(cyclohexane-1-carbonitrile)) as a radical initiator followed by a subsequent oxidation of the corresponding intermediate with $\mathrm{H}_{2} \mathrm{O}_{2}$. In this process, two cis/ trans isomers 17 and 18 were formed in a ratio of $1.0: 1.1$ in $10 \%$ and $11 \%$ yields, in benzene and in the same ratio in $27 \%$ and $29 \%$ yields in trifluoromethylbenzene, respectively. Interestingly, the dibenzophosphole 19 precipitated pure, in $40 \%$ yield, by stirring the crude reaction mixture at room temperature overnight. The radical phosphanylation of the biphenyl 16 $(\mathrm{R}=$ aryl $)$ led to formation of 4,4'-diaryl-substituted bis(phosphoryl)-bridged biphenyls 20 and 21 in $22 \%$ and $13 \%$ yields, respectively (Scheme 5). ${ }^{27}$ 


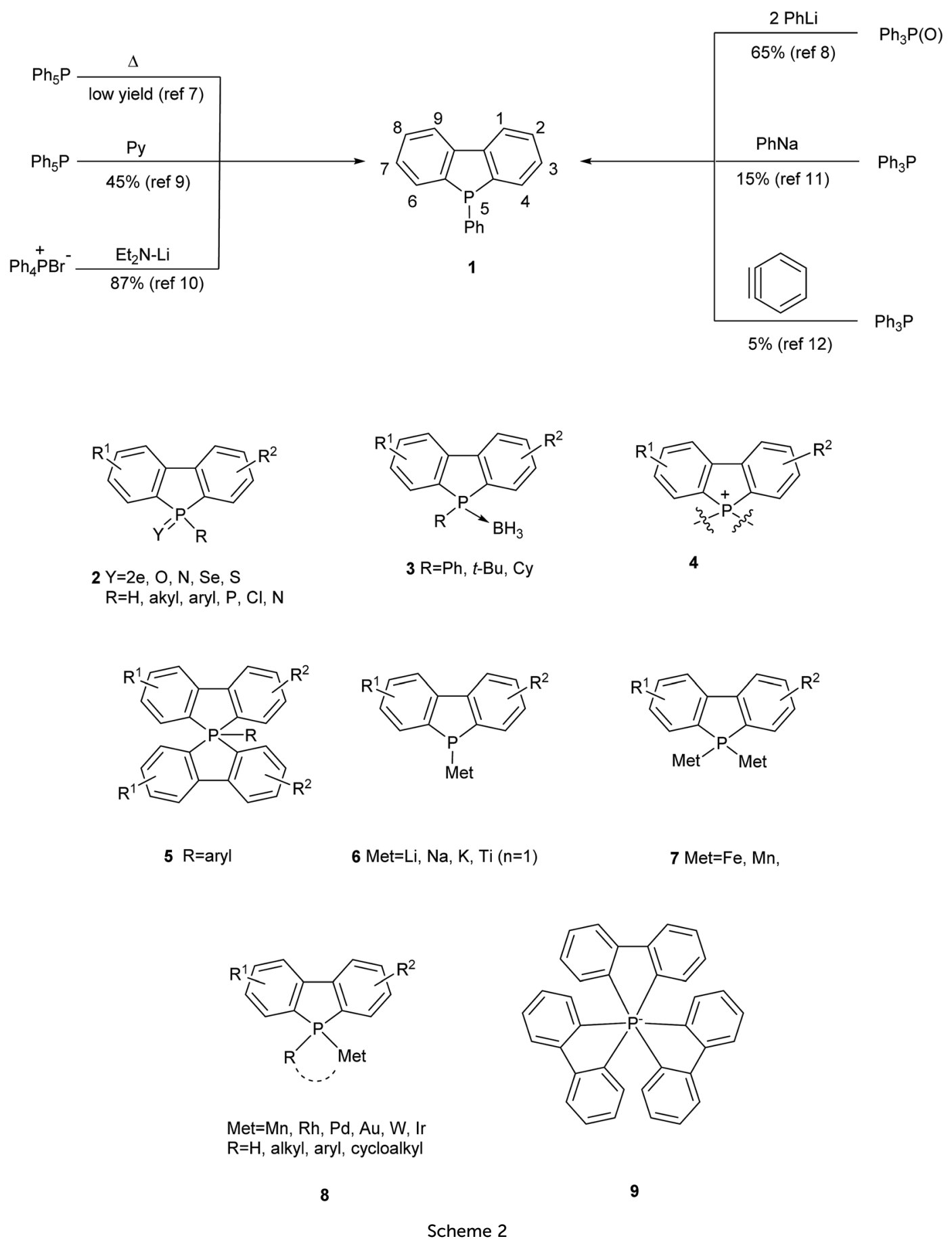

Zhou and Breit et al. obtained 3,7-di-tert-butyl substituted dibenzophospholes functionalized at the phosphorus atom by pyridin-2-(1H)-on-6-yl, 6-pivalamidopyridin-2-yl and isoquinolin-1 $(2 H)$-on-3-yl moieties starting from 2,2'-dibromo-4, $4^{\prime}$ di-tert-butylbiphenyl. ${ }^{28}$

Gaunt, Girolami and Kozimor et al. described the reaction of $\mathrm{PCl}_{3}$ with 2,2'-dibromo-1,1'-biphenyl that unexpectedly gave a mixture of 5-chloro- and 5-bromo-5 $\mathrm{H}$-dibenzophospholes in a $3: 2$ ratio as a result of halogen exchange. Both 5-halodibenzophospholes after separation behaved similarly in the subsequent conversion into a new family of dibenzophospholebased dithiophosphinic acids using elemental sulfur and sodium hydrosulfide hydrate. ${ }^{29}$

\subsection{From $\mathrm{ArPCl}_{2}, \mathrm{Ar}_{2} \mathbf{P C l}$ or $\mathrm{RPCl}_{2}$}

Due to easy access to chlorophosphines, the synthesis of dibenzophospholes involving dilithiobiaryls constitutes a convenient source of these compounds. Using this method, Delft $e$ t al. obtained symmetrical dibenzophospholes 1, 23 and 24 from the corresponding 2,2'-dibromobiphenyl precursors 


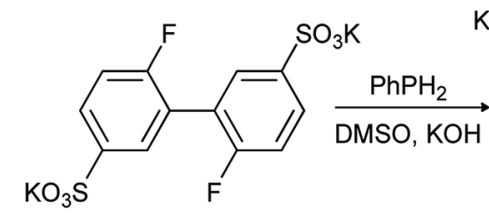

10

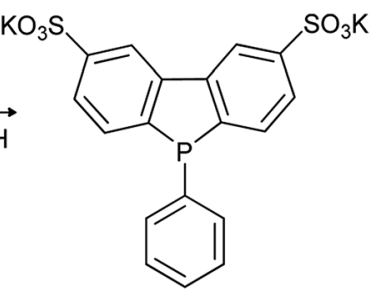

$11(60 \%)$
Scheme 3

bearing $\mathrm{H}$, MeO or $\mathrm{CF}_{3}$ groups by generation of the corresponding dianion with $n$-BuLi in $\mathrm{Et}_{2} \mathrm{O}$ at room temperature followed by quenching the reaction mixture with dichlorophenylphosphine to give 5-phenyldibenzophosphole 1, 2,8-dimethoxy-5-phenyldibenzophosphole 23 and 2,8bis(trifluoromethyl)-5-phenyl-dibenzophosphole 24 in 55\%, $30 \%$ and $57 \%$ yields, respectively (Scheme 6 ). ${ }^{30}$

Gouygou, Leroux et al. obtained symmetrical and unsymmetrical dibenzophospholes 26-37 in 30-96\% yields starting from $2,2^{\prime}$-dihalobiaryls via double halogen/lithium exchange with $n$ BuLi in THF at $-78{ }^{\circ} \mathrm{C}$ followed by trapping the resulting dilithium derivatives with dichlorophenylphosphine (Scheme 7). ${ }^{31}$

The phosphoniafluorene 39 has been obtained according to the above procedure by dilithiation of the $5,5^{\prime}$-disubstituted 2,2'-dibromo-1,1'-biphenyl 38 followed by condensation of the resulting dilithio derivative with dichlorophenylphosphine $\mathrm{PhPCl}_{2}$ and then quaternization of the dibenzophosphole phosphorus atom with MeI in THF. After exchange of the iodide

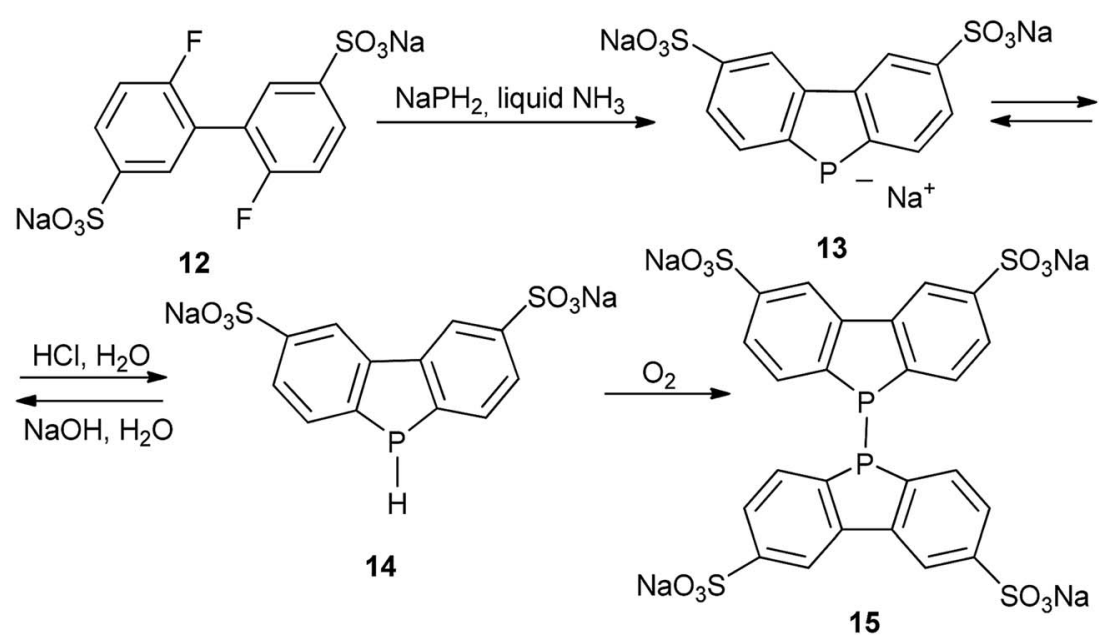

Scheme 4
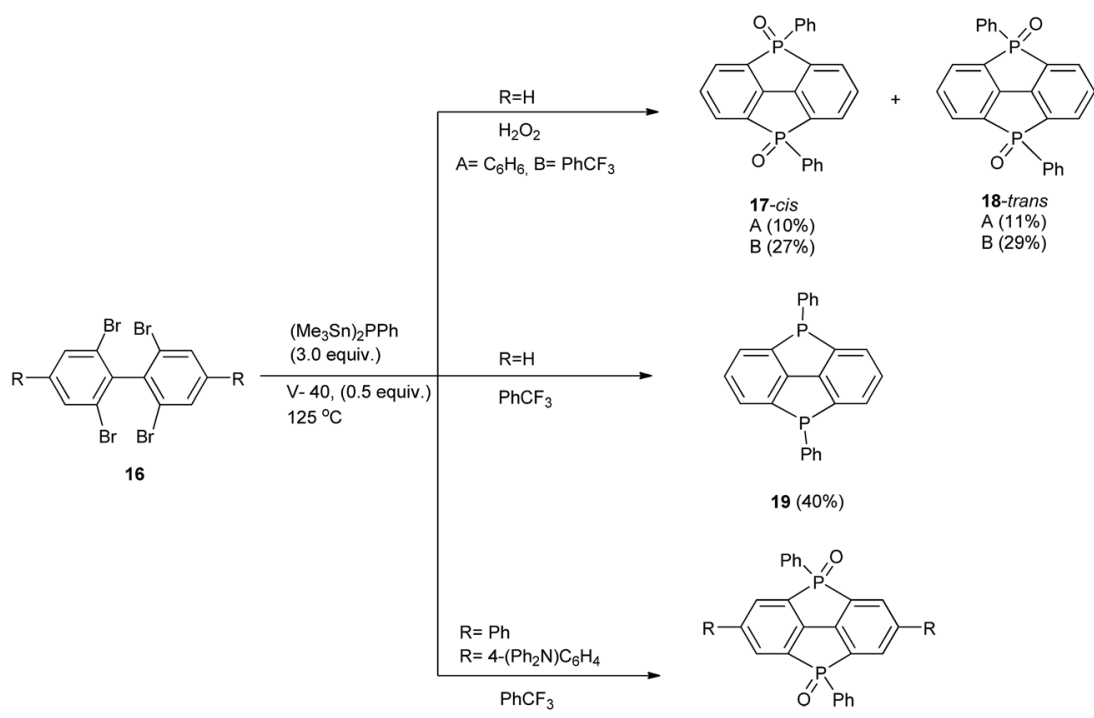

20-trans $\mathrm{R}=\mathrm{Ph}(22 \%)$ 21-trans $\mathrm{R}=4-\left(\mathrm{Ph}_{2} \mathrm{~N}\right) \mathrm{C}_{6} \mathrm{H}_{4}(13 \%)$

Scheme 5 


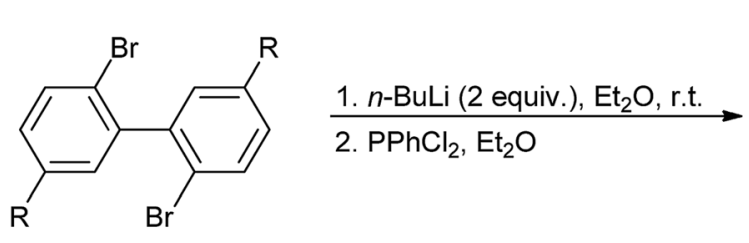

22<smiles>[R]c1ccc2c(c1)c1cc([R])ccc1p2-c1ccccc1</smiles>

$1 \mathrm{R}=\mathrm{H}(55 \%)$

$23 \mathrm{R}=\mathrm{OMe}(30 \%)$

$24 \mathrm{R}=\mathrm{CF}_{3}(57 \%)$

Scheme 6

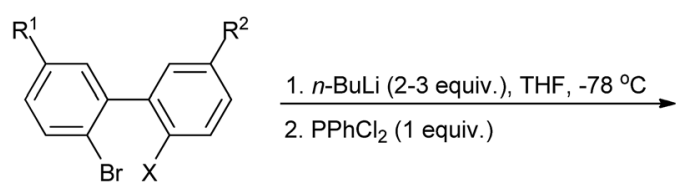

$25 \mathrm{X}=\mathrm{Br}, \mathrm{I}$

$26 \mathrm{R}^{1}=\mathrm{H}, \mathrm{R}^{2}=\mathrm{H}, \mathrm{X}=\mathrm{Br}(82 \%)$

$27 R^{1}=H, R^{2}=F, X=B r(53 \%)$

$28 R^{1}=H, R^{2}=M e, X=B r(40 \%)$

$29 \mathrm{R}^{1}=\mathrm{H}, \mathrm{R}^{2}=\mathrm{OMe}, \mathrm{X}=\mathrm{Br}(49 \%)$

$30 \mathrm{R}^{1}=\mathrm{H}, \mathrm{R}^{2}=\mathrm{Cl}, \mathrm{X}=\mathrm{Br}(56 \%)$

$31 \mathrm{R}^{1}=\mathrm{H}, \mathrm{R}^{2}=\mathrm{Br}, \mathrm{X}=\mathrm{Br}(37 \%)$<smiles>[R]c1ccc2c(c1)c1cc([Z])ccc1p2-c1ccccc1</smiles>

26- 37

$32 \mathrm{R}^{1}=\mathrm{H}, \mathrm{R}^{2}=\mathrm{Ph}, \mathrm{X}=\mathrm{Br}(63 \%)$

$33 \mathrm{R}^{1}=\mathrm{H}, \mathrm{R}^{2}=\mathrm{N}\left(\mathrm{CH}_{3}\right)_{2}, \mathrm{X}=\mathrm{Br}(39 \%)$

$34 \mathrm{R}^{1}=\mathrm{H}, \mathrm{R}^{2}=\mathrm{OCF}_{3}, \mathrm{X}=\mathrm{Br}(61 \%)$

$35 \mathrm{R}^{2}=\mathrm{OCH}_{2} \mathrm{O}, \mathrm{X}=\mathrm{Br}(96 \%)$

$36 \mathrm{R}^{2}=\mathrm{OCF}_{2} \mathrm{O}, \mathrm{X}=\mathrm{I}(30 \%)$

$37 \mathrm{R}^{2}=\mathrm{OCF}_{2} \mathrm{CF}_{2} \mathrm{O}, \mathrm{X}=\mathrm{I}(45 \%)$

Scheme 7

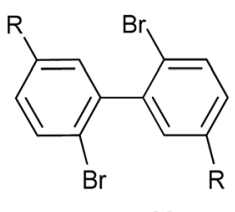

38

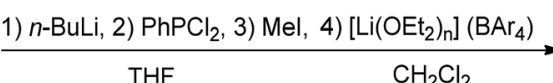

$\mathrm{R}=4-\left(\mathrm{Et}_{2} \mathrm{~N}\right) \mathrm{C}_{6} \mathrm{H}_{4} \mathrm{CH}=\mathrm{CH}, \mathrm{Ar}=\mathrm{C}_{6} \mathrm{~F}_{5}$<smiles>[R]c1ccc2c(c1)-c1cc([R])ccc1P2(C)(c1ccccc1)c1ccccc1</smiles>

39 (57\%)

Scheme 8

ion to the $\mathrm{BAr}_{4}$ anion, compound 39 was obtained as a red solid in $57 \%$ yield (Scheme 8 ). ${ }^{32}$

This method was also used for the preparation of 2-hydroxysubstituted dibenzophosphole oxides 41-44. After bromine/ lithium exchange on the dibromobiphenyl derivative 40, the dilithiated intermediate was treated with either $\mathrm{PhPCl}_{2}$ or $(\mathrm{L}-$ menthyl) $\mathrm{PCl}_{2}$. Then, the dibenzophospholes were oxidized in situ with $\mathrm{H}_{2} \mathrm{O}_{2}$ and the tert-butyldimethylsilyl (TBS) group was removed by reaction with tetra- $n$-butylammonium fluoride (TBAF) to give oxides $\mathbf{4 1}$ and $\mathbf{4 2}$ in 75\% yields. The hydroxy groups<smiles>CC(C)(C)Oc1ccc(Br)c(-c2ccccc2Br)c1</smiles>

1. $t$-BuLi, ether, $-78^{\circ} \mathrm{C}$ to r.t., $\mathrm{RPCl}_{2}$ 2. $\mathrm{H}_{2} \mathrm{O}_{2}, \mathrm{CH}_{2} \mathrm{Cl}_{2}$ 3. TBAF, THF

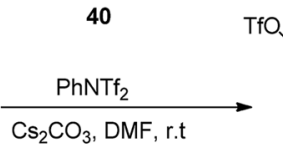

$\mathrm{TfO}$<smiles>[Z7]P1(=O)c2ccccc2-c2cc(C)ccc21</smiles>

$43 \mathrm{R}=\mathrm{Ph}(80 \%)$

$44 \mathrm{R}=\mathrm{L}-\mathrm{menthyl}(70 \%)$<smiles>[R7]P1(=O)c2ccccc2-c2cc(O)ccc21</smiles>

$41 \mathrm{R}=\mathrm{Ph}(75 \%)$

$42 \mathrm{R}=\mathrm{L}$-menthyl $(75 \%)$

Scheme 9 

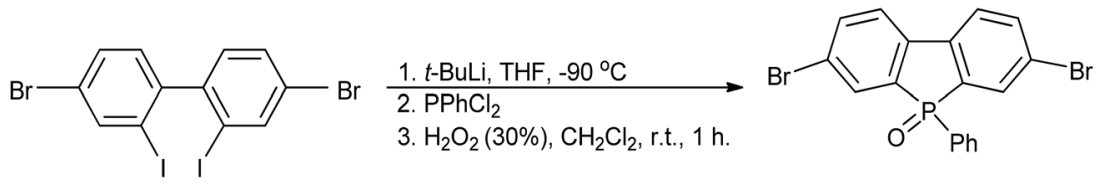

Scheme 10

in the latter were converted into the corresponding triflates $\mathbf{4 3}$ and $\mathbf{4 4}$ by treatment with $\operatorname{PhNTf}_{2}$. For $\mathrm{R}=\mathrm{L}$-menthyl, the dibenzophosphole oxide $\mathbf{4 2}$ was obtained as a mixture of two epimers with opposite configuration at the stereogenic phosphorus center. The mixture was converted into triflates $\mathbf{4 4}$ and the two diastereomers were separated by HPLC (Scheme 9). ${ }^{33}$

$t$-Butyllithium in THF, at $-90{ }^{\circ} \mathrm{C}$ was also used for iodine/ lithium exchange in $\mathbf{4 5}$ followed by reaction with $\mathrm{PhPCl}_{2}$ and oxidation with $\mathrm{H}_{2} \mathrm{O}_{2}$ to give 3,7-dibromo-5-phenyl dibenzophosphole oxide 46 in $47 \%$ yield (Scheme 10). ${ }^{27}$

Another method, described by Ionkin and Marshall in 2003, involved the reaction of the dichloroarylphosphine 47 with potassium in hexanes to give the 5-chlorodibenzophosphole derivative 48 in $64 \%$ yield (Scheme 11). ${ }^{34}$

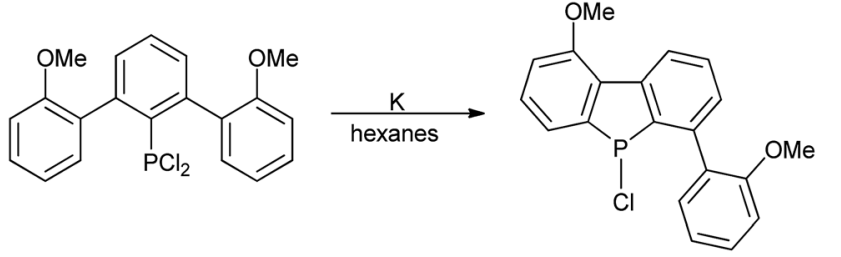

47
In 2006, Wehmschulte et al. described the intramolecular Friedel-Crafts type reaction of the dichlorophosphines $\mathbf{4 9}$ or $\mathbf{5 0}$ initiated by $\mathrm{AlCl}_{3}$ in $\left[d_{6}\right]$-benzene at room temperature. In this reaction dibenzophospholes $\mathbf{5 5}$ and $\mathbf{5 6}$ were formed in $29 \%$ and $43 \%$ yields, respectively, via intermediates $\mathbf{5 1 / 5 2}$ and $\mathbf{5 3 / 5 4}$, as yellow-orange oils, which were decomposed to the final products by addition of pyridine (Py) (Scheme 12). ${ }^{35}$

The same research group synthesised 5-chloro disubstituted dibenzophospholes 58-60 via thermolysis of the aryldichlorophosphine 57 at $200-230{ }^{\circ} \mathrm{C}$ with $\mathrm{HCl}$ evolution (Scheme 13). ${ }^{35}$<smiles>[R]c1cc(-c2cccc(-c3cc([R])c([R])c([R])c3[R])c2P(Cl)Cl)c([R])c([R])c1[R]</smiles>

57

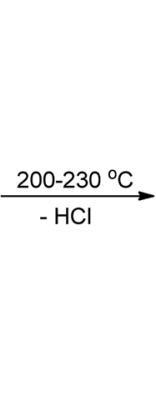

$48(64 \%)$<smiles>[R]c1cc(-c2cccc3c([R])c([R])c([R])c([R])c23)c2c(Cl)c([R])c([R])c([R])c2c1[R]</smiles>

$58 R^{1}=M e, R^{2}, R^{3}=H$ $59 \mathrm{R}^{1}, \mathrm{R}^{3}=\mathrm{H}, \mathrm{R}^{2}=t-\mathrm{Bu}$ $60 R^{1}, R^{2}=H, R^{3}=M e$
Scheme 13

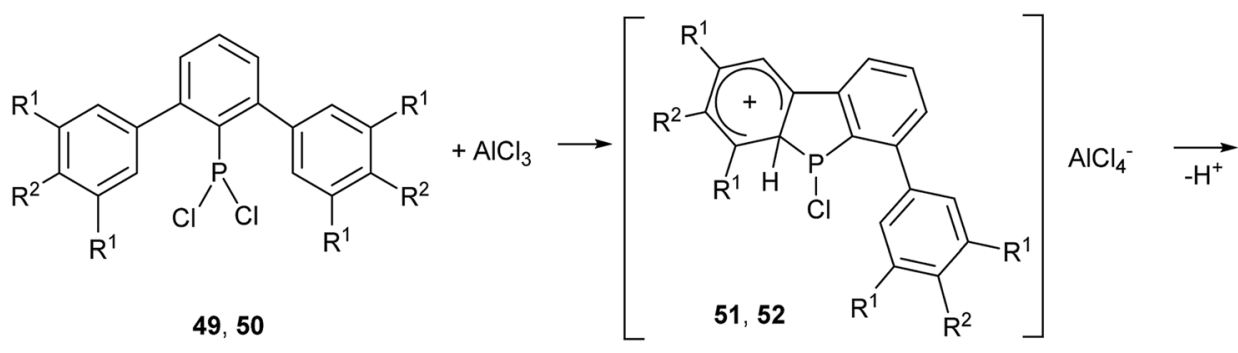<smiles>[R]c1cc(-c2cccc3c2[PH+](Cl)c2c-3cc([R])c([R])c2[R])cc([R])c1[R]</smiles><smiles></smiles>

53,54

55: $R^{1}=M e, R^{2}=H(29 \%)$

56: $\mathrm{R}^{1}=\mathrm{H}, \mathrm{R}^{2}=t-\mathrm{Bu}(43 \%)$ 


\subsection{From $\operatorname{RAr}_{2} \mathbf{P}$ or $\mathrm{Ar}_{3} P$}

5-Phenyldibenzophosphole $\mathbf{1}$ has also been obtained in a two-step reaction involving addition of 1-lithio-2diphenylphosphinylbenzene $\mathbf{6 1}$ to benzyne $\mathbf{6 2}$ followed by cyclisation of the resulting lithio adduct 63. The starting materials 61 and 62 were obtained from 2-bromophenyl-diphenyl phosphine and 1,2-dibromobenzene, respectively (Scheme 14). ${ }^{36}$

The next method, published by Tobisu, Chatani et al. in 2013, involves intramolecular cyclisation of biphenyl derivatives 64 containing $\mathrm{PPh}_{2}$ and $\mathrm{PMePh}$ groups in the presence of catalytic amounts of $\mathrm{Pd}(\mathrm{OAc})_{2}(5 \mathrm{~mol} \%)$ in toluene through the cleavage of the $\mathrm{C}-\mathrm{H}$ bond and exclusive cleavage of the $\mathrm{P}-\mathrm{Ph}$ bond rather than the $\mathrm{P}-\mathrm{Me}$ one. The dibenzophospholes formed first in these reactions were easily oxidized with hydrogen peroxide at room temperature which led to dibenzophosphole oxides 66 and 67 in 92\%, 64\% yields, respectively or reacted with borane dimethylsulfide to give the dibenzophosphole borane 68 in $61 \%$ yield (Scheme 15). ${ }^{37}$

The same reaction, carried out with 1 equivalent of $\mathrm{Pd}(\mathrm{OAc})_{2}$ (in air), gave 66 in 50\% yield, suggesting that the dimeric metallacycle 70 (X-ray analysis) was a plausible intermediate for the catalytic cycle. Dibenzophospholes bearing a range of functional groups ( $\left.\mathrm{Br}, \mathrm{F}, \mathrm{CO}_{2} \mathrm{Me}, \mathrm{Ac}, \mathrm{CN}\right)$ and an array of fused rings (naphthalene, anthracene, furan, pyrrole) could also be synthesised using this method (Scheme 16). ${ }^{37}$

The route was also successfully applied to the synthesis of a diverse array of dibenzophospholes 71-88. The high functional group tolerance allowed access to a range of electronically different dibenzophospholes bearing alkyl 71, 80, 83/84, ether $\mathbf{7 2}$, alkoxyl 82, amine $\mathbf{7 3}$ and $\mathbf{8 1}$, acyl 74, ester 75, nitrile 76, fluoride 77 , chloride $\mathbf{7 8}$, and bromide 79 groups. The $\mathrm{C}-\mathrm{P}$ bond formation also took place with substrates bearing ortho substituents to afford 1-substituted dibenzophospholes $\mathbf{8 0}$ and<smiles>Clc1ccccc1P(c1ccccc1)c1ccc(-c2ccccc2)c(P(c2ccccc2)c2ccccc2)c1</smiles>

Scheme 14

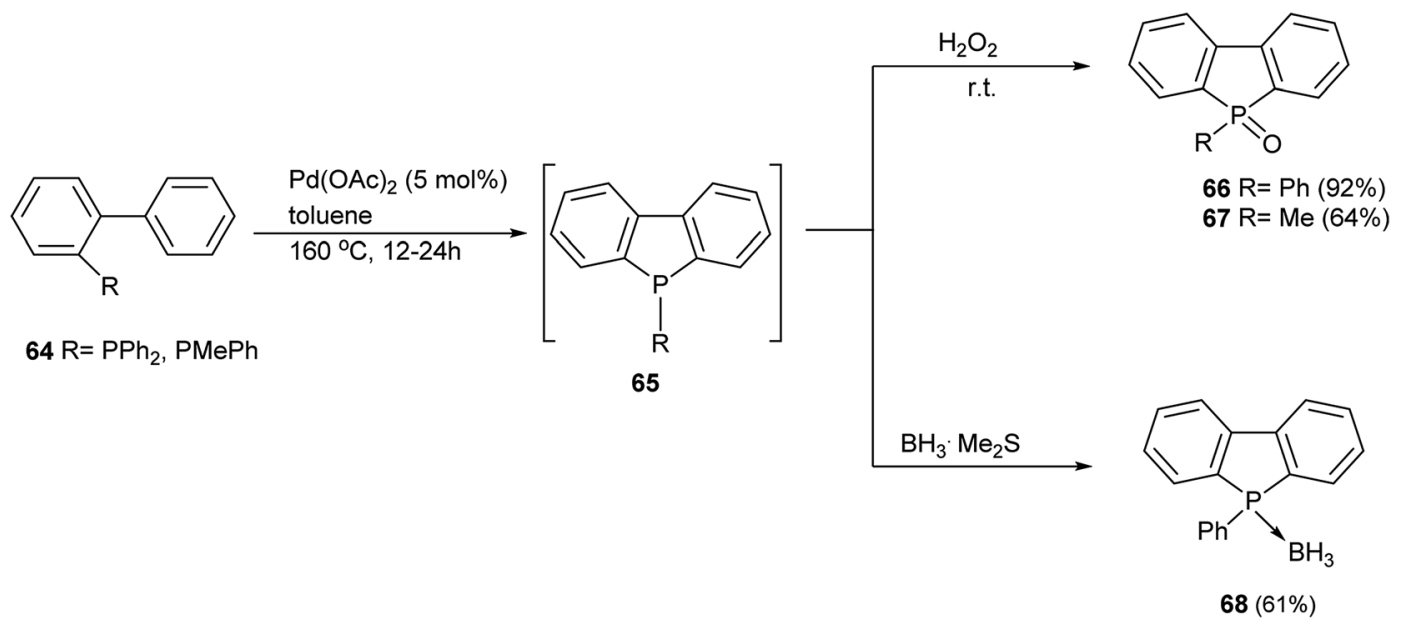

Scheme 15

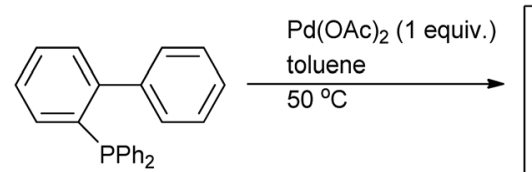

69

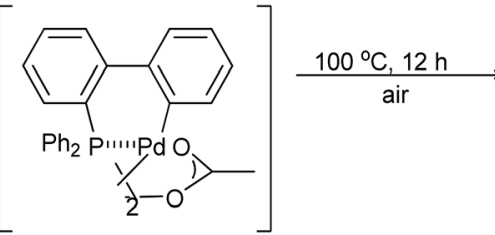

70<smiles>O=P1(c2ccccc2)c2ccccc2-c2ccccc21</smiles>

$66(50 \%)$

Scheme 16 
<smiles>O=P1(c2ccccc2)c2ccccc2-c2ccc(F)cc21</smiles><smiles>[R]c1cccc2c1-c1ccccc1P2(=O)c1ccccc1</smiles>

$71 \mathrm{R}=\mathrm{Bu}(94 \%)$

$72 \mathrm{R}=\mathrm{OMe}(77 \%)$

$73 \mathrm{R}=\mathrm{NMe}_{2}(69 \%)$

$74 \mathrm{R}=\mathrm{Ac}(72 \%)$

$75 \mathrm{R}=\mathrm{CO}_{2} \mathrm{Me}(64 \%)$

$76 \mathrm{R}=\mathrm{CN}(84 \%)$

$77 \mathrm{R}=\mathrm{F}(62 \%)$

$78 \mathrm{R}=\mathrm{Cl}(92 \%)$

$79 \mathrm{R}=\mathrm{Br}(67 \%)$

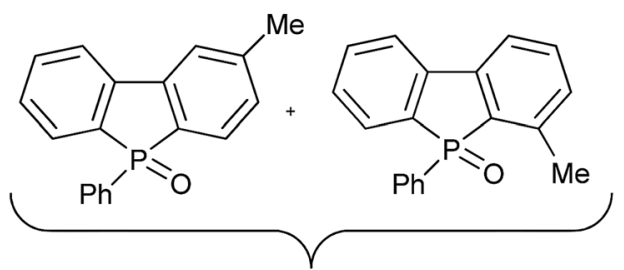

$81 \%(83 / 84=10: 1)$

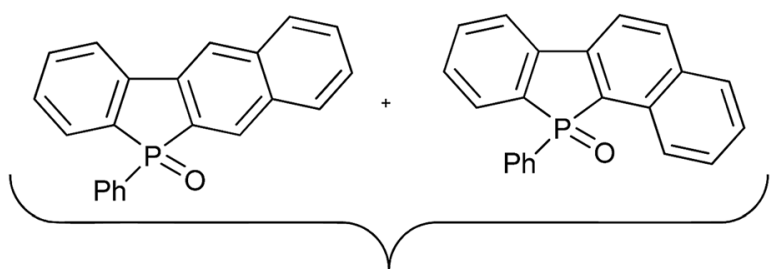

$67 \%(86 / 87=2.8: 1)$
$80 \mathrm{R}=\mathrm{Me}(54 \%)$

$81 \mathrm{R}=\mathrm{Me}_{2} \mathrm{~N}(77 \%)$
$\mathrm{MeO}$<smiles>Cc1ccc2c(c1)-c1ccccc1P2(=O)c1ccccc1</smiles>

$82(74 \%)$<smiles>O=P1(c2ccccc2)c2ccccc2-c2c1c1ccccc1c1ccccc21</smiles>

$85(58 \%)$<smiles>O=P1(c2ccccc2)c2ccccc2-c2c1ccc1ccccc21</smiles>

$88(94 \%)$

Scheme 17

81. Substrates with meta substituents underwent a regioselective cyclisation at the less hindered site to form $\mathbf{8 3}$ as a major product. This synthesis enabled various $\pi$ systems including naphthalene and phenanthrene moieties, to be incorporated into the dibenzophosphole core of the compounds 85-88 (Scheme 17). ${ }^{37}$
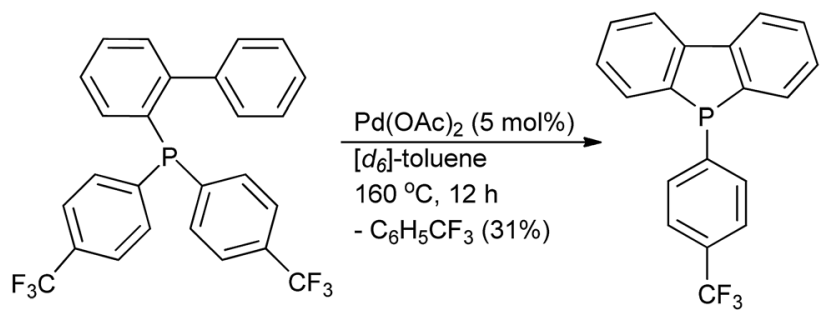

$90(41 \%)$
89

Scheme 18
In a special case, this method could also be applied to the synthesis of 5-P-aryl substituted dibenzophosphole 90 bearing an electron-withdrawing $p$-trifluoromethyl on the aryl group, by cyclisation of bis(trifluoromethylphenyl)-o-(1,1'-biphenyl)phosphine 89 in the presence of $\mathrm{Pd}(\mathrm{OAc})_{2}$, in $\left[d_{6}\right]$-toluene, the final dibenzophosphole 90 being obtained in $41 \%$ yield (Scheme 18). ${ }^{37}$

In the phosphine 91, carrying one $\mathrm{CF}_{3} \mathrm{C}_{6} \mathrm{H}_{4}$ group and one phenyl, a mixture of dibenzophosphole oxides 66 and 92 was obtained upon oxidation with $\mathrm{H}_{2} \mathrm{O}_{2}$, indicating a preference of the $\mathrm{P}-\mathrm{CF}_{3} \mathrm{C}_{6} \mathrm{H}_{4}$ bond cleavage over the unactivated $\mathrm{P}-\mathrm{C}_{6} \mathrm{H}_{5}$ unit (Scheme 19). ${ }^{37}$

Another modification of this approach involved the synthesis of the starting phosphine via the Suzuki-Miyaura crosscoupling of $o$-bromophenyldiphenylphosphine with 2,4-dimethoxyphenylboronic acid, followed by cyclisation in situ, without isolation, to give the final dibenzophosphole oxide. ${ }^{37}$

Satoh and Miura et al. described the transformation of phenylphosphinothioic amides into fused dibenzophosphole 


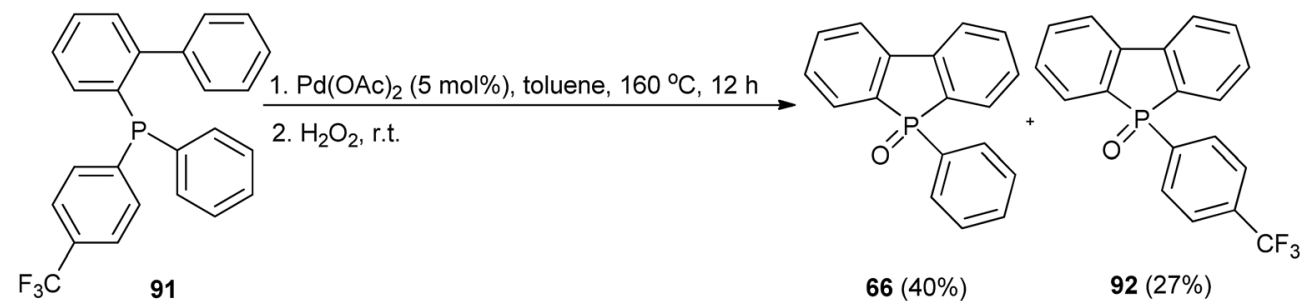

Scheme 19

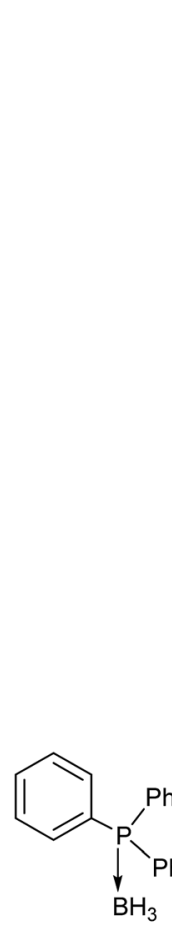

93

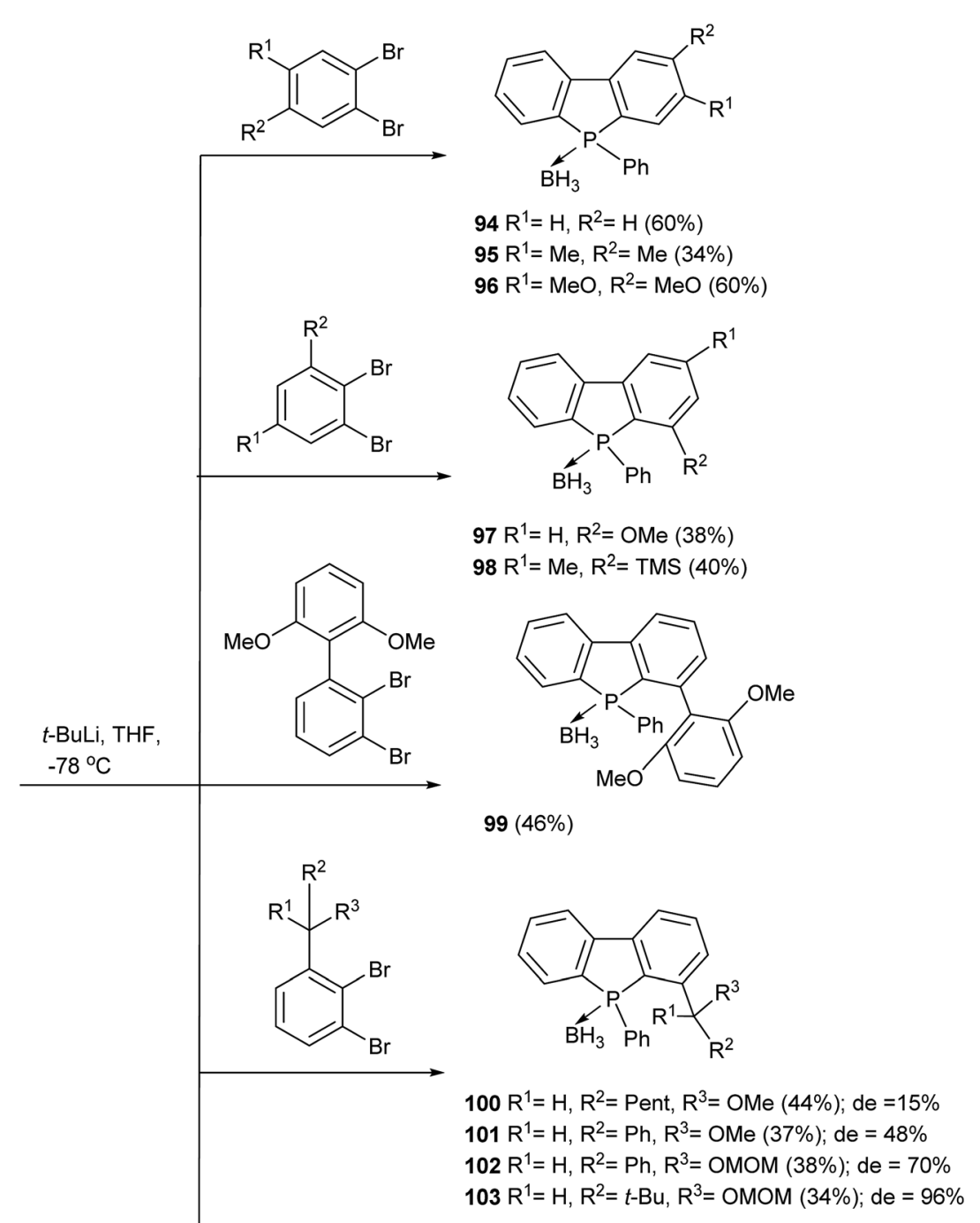

ee $=77 \%$

$M O M=\mathrm{MeOCH}_{2}$

$92(27 \%)$ 
derivatives through rhodium-catalyzed coupling with heterobicyclic alkenes and intramolecular phospha-Friedel-Crafts reactions in a one-pot manner. ${ }^{38}$

\subsection{From $\mathrm{Ar}_{3} \mathrm{P}-\mathrm{BH}_{3}$}

Jugé, Leroux, Colobert et al. reported the first chemo-, regio-, and diastereoselective syntheses of P-chirogenic dibenzophosphole boranes 94-104 based on a transition metal-free, aryne cross-coupling methodology. Most of the reactions started from the tertiary phosphine-borane $\mathbf{9 3}$ and a variety of $\boldsymbol{o}$ dibromobenzenes to simultaneously create an aryl-aryl bond and the five-membered ring of the dibenzophosphole moiety in 15-60\% yields (Scheme 20). ${ }^{36}$

The use of P-modified boranes 105 in which $\mathrm{R}^{3}$ or $\mathrm{R}^{4}=\mathrm{Ph}$ has been replaced by tert-butyl ( $t$-Bu), cyclohexyl (Cy) or orthoanisyl $(o-\mathrm{An})\left(2-\mathrm{MeOC}_{6} \mathrm{H}_{4}\right)$ groups did not improve yields of these reactions (27-44\%). Interestingly, in the case of $105\left(\mathrm{R}^{3}=\right.$ $\mathrm{Ph}, \mathrm{R}^{4}=o$-An), preferential P-o-An cleavage occurred to give 109 $\left(\mathrm{R}^{3}=\mathrm{Ph}\right)$ in $44 \%$ yield (Scheme 21$){ }^{36}$

\subsection{From $\operatorname{Ar}_{2} \mathrm{P}(\mathrm{O}) \mathrm{H}$ or $\operatorname{Ar}(\mathrm{R}) \mathrm{P}(\mathrm{O}) \mathrm{H}$}

Aryl or alkyl biphenyl hydrophosphine oxides have been applied successfully to the synthesis of 5-aryl and 5-alkyl substituted dibenzophosphole oxides. Thus, starting from secondary hydrophosphine oxides 110, Kuninobu et al. obtained 5-aryl substituted dibenzophospholes 111-117 via phosphinehydrogen and carbon-hydrogen bond cleavages in the presence of a catalytic amount of palladium(II) acetate (Scheme 22). This process was also carried out with [2-(2-naphthyl)phenyl]phenylphosphine oxide as a substrate to give the corresponding dibenzophosphole in $92 \%$ yield. ${ }^{39}$

The same methodology was applied to the synthesis of a mixture of 5-i-Pr substituted dibenzophospholes 120 and 121. These compounds were obtained in a ratio of $70: 30$, respectively, starting from a mixture of nondeuterated and deuterated phosphine oxides 118 and 119 in the ratio 1 : 1 . Based on these results, it could be assumed that the $\mathrm{C}-\mathrm{H}$ bond activation of one of the aromatic rings was the rate-determining step (Scheme 23). ${ }^{39}$<smiles>[R]c1cc(Br)c([PH]([R])([R])[B])cc1[R]</smiles>

105<smiles>COc1cc(Br)c(Br)cc1OC</smiles>

$106 R^{1}=C_{3}, R^{2}=C_{3} R^{3}=P h, R^{4}=P h(42 \%)$

$107 R^{1}=H, R^{2}=H, R^{3}=t-B u, R^{4}=P h(27 \%)$

$108 R^{1}=H, R^{2}=H, R^{3}=C y, R^{4}=P h(33 \%)$

$109 R^{1}=H, R^{2}=H, R^{3}=P h, R^{4}=o-A n(44 \%)$

Scheme 21

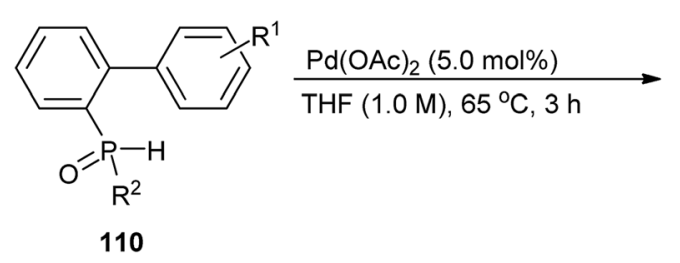<smiles>[R]c1ccc2c(c1)-c1ccccc1P2([R])=O</smiles>

$111 \mathrm{R}^{1}=\mathrm{H}, \mathrm{R}^{2}=\mathrm{Ph}(94 \%)$

$112 \mathrm{R}^{1}=4-\mathrm{MeO}, \mathrm{R}^{2}=\mathrm{Ph}(93 \%)$

$113 \mathrm{R}^{1}=4-\mathrm{CF}_{3}, \mathrm{R}^{2}=\mathrm{Ph}(86 \%)$

$114 \mathrm{R}^{1}=4-\mathrm{Cl}, \mathrm{R}^{2}=\mathrm{Ph}(90 \%)$

115 a,b $R^{1}=3-M e, R^{2}=P h(90 \%)$

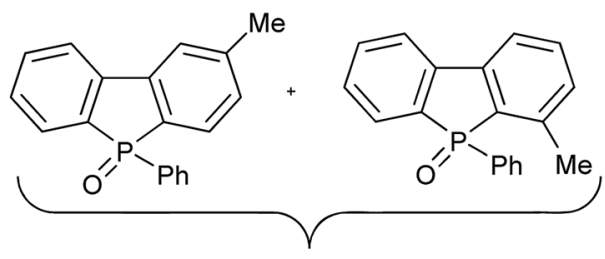

$115 a: 115 b=88: 12(90 \%)$

$116 \mathrm{R}^{1}=2-\mathrm{MeO}, \mathrm{R}^{2}=\mathrm{Ph}(93 \%)$

$117 \mathrm{R}^{1}=4-\mathrm{Ph}, \mathrm{R}^{2}=\mathrm{Ph}(61 \%)$ 
<smiles>CC(C)CP(=O)(c1ccccc1-c1ccccc1)C(C)C</smiles>

118<smiles>CC(C)P1(=O)c2ccccc2-c2ccccc21</smiles>

120

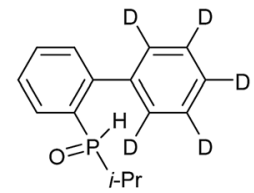

119

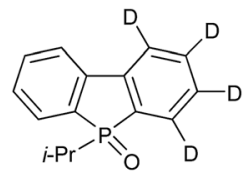

121

$120+121(14 \%)$

Scheme 23

Terphenyl bis(hydrophosphine oxide) 122 was also applied in the same manner by Kuninobu et al. for the synthesis of a polycyclic, conjugated bis(dibenzophosphole oxide) 123 in $87 \%$ yield (Scheme 24$){ }^{39}$

Dibenzophospholes were also obtained by the intramolecular radical cyclisation of 2-biphenylaryl and biphenylalkylphosphine oxides 124-126 in the presence of various initiators: 2,2'-azobis-isobutyronitrile (AIBN), benzoyl peroxide (BPO) or $\mathrm{Et}_{3} \mathrm{~B} / \mathrm{O}_{2}$ under different reaction conditions. In the case of the phosphine oxide $124(\mathrm{R}=\mathrm{Ph})$, the use of typical initiators, such as AIBN and BPO in refluxing benzene, gave the corresponding products 127 in 48\% and 41\%, according to procedures A and B, respectively. Performing the reaction under milder conditions by using triethylborane and oxygen as a radical initiator gave 127 in higher yields of $73 \%$ and $87 \%$, respectively (procedures $\mathrm{C}$ and $\mathrm{D}$ ). These reaction conditions were applicable to other substrates 125 and 126 bearing $p$-anisyl and tert-butyl groups on the phosphorus atom, respectively to give the corresponding products $\mathbf{1 2 8}$ and 129 in good 96\% and 85\% yields, respectively (Scheme 25). ${ }^{40}$

This radical methodology has also been applied to the synthesis of bis(dibenzophosphole oxides) having spatially extended systems of $\pi$-conjugated bonds, by using a double, intramolecular radical cyclisation of the phosphine oxide 130 in the presence of $\mathrm{Et}_{3} \mathrm{~B} / \mathrm{O}_{2}$, in $\mathrm{MeOH}$. The products of this reaction were two diastereoisomeric bis(dibenzophosphole oxides): 131anti and 132-syn obtained in 16\% and 28\% yields, respectively (Scheme 26). ${ }^{40}$

\subsection{From $\mathrm{Ar}_{3} \mathrm{P}(\mathrm{O})$ or $\mathrm{ArR}_{2} \mathrm{P}(\mathrm{O})$}

In this subsection, the syntheses of dibenzophospholes that are described start from phosphine oxides containing at least one aryl group. In 2014, Cui, Jiang et al. developed a new method for the synthesis of dibenzophosphole oxides 134-142

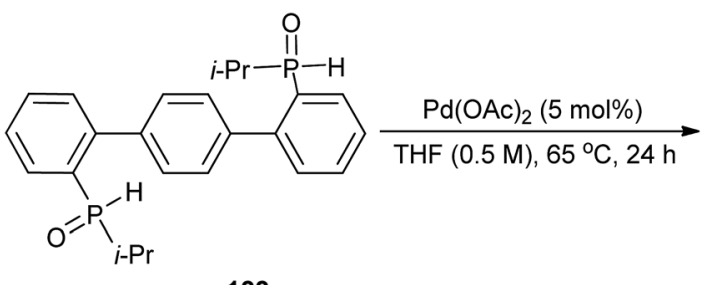

122<smiles>CC(C)[P+]1(=O)c2ccccc2-c2cc3c(cc21)-c1ccccc1[PH]3=O</smiles>

$123(87 \%)$

Scheme 24

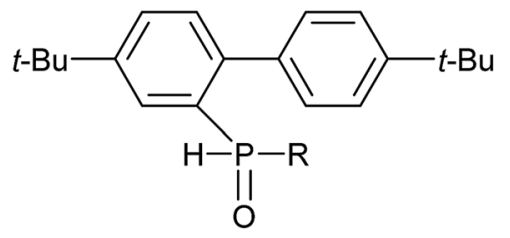
A) AIBN (1.1 equiv.), benzene, $\Delta$
B) BPO (1.1 equiv.), benzene, $\Delta$
C) $\mathrm{Et}_{3} \mathrm{~B} / \mathrm{O}_{2}$ (1.0 equiv.), $\mathrm{CH}_{3} \mathrm{OH}$, r.t.
D) $\mathrm{Et}_{3} \mathrm{~B} / \mathrm{O}_{2}$ (2.1 equiv.), $\mathrm{CH}_{3} \mathrm{OH}$, r.t.

$124 \mathrm{R}=\mathrm{Ph}$

$125 \mathrm{R}=p$-anisyl

$126 \mathrm{R}=t-\mathrm{Bu}$<smiles>[Z19]C(C)(C)c1ccc2c(c1)P([R])(=O)c1cc(C(C)(C)C)ccc1-2</smiles>

$127 \mathrm{R}=\mathrm{Ph}$

A (48\%), B (41\%), C (73\%), D (87\%)

$128 \mathrm{R}=p$-anisyl $(96 \%)$

$129 \mathrm{R}=t-\mathrm{Bu}(85 \%)$ 
<smiles>[R]c1ccc(-c2ccc(CCCC)cc2[PH2](=O)c2ccccc2)cc1</smiles>

130

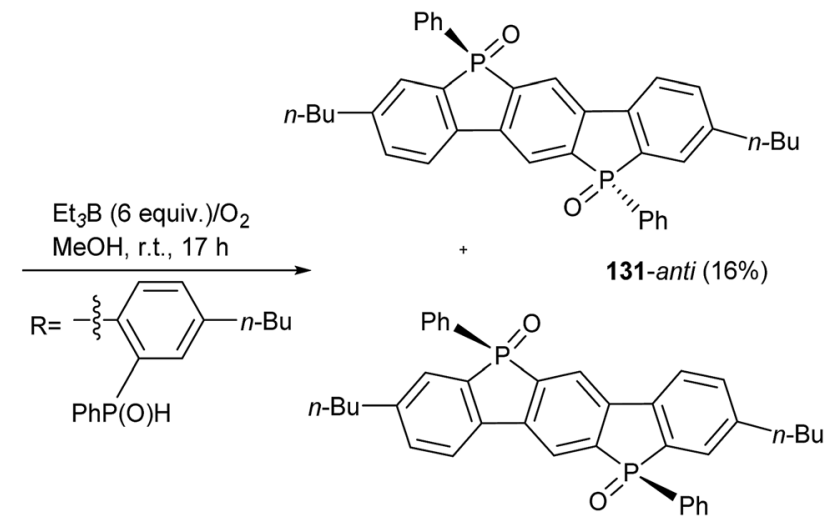

$132-\operatorname{syn}(28 \%)$

Scheme 26

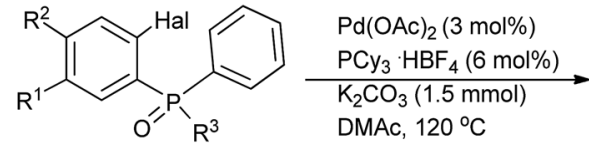

133

$134 \mathrm{R}^{1}=\mathrm{H}, \mathrm{R}^{2}=\mathrm{H}, \mathrm{R}^{3}=\mathrm{Ph}, \mathrm{Hal}=\mathrm{Br}(98 \%)$

$135 \mathrm{R}^{1}=\mathrm{H}, \mathrm{R}^{2}=\mathrm{H}, \mathrm{R}^{3}=\mathrm{Ph}, \mathrm{Hal}=\mathrm{Cl}(97 \%)$

$136 R^{1}=H, R^{2}=M e, R^{3}=P h, \mathrm{Hal}=\mathrm{Br}(85 \%)$

$137 R^{1}=\mathrm{MeO}, R^{2}=H, R^{3}=\mathrm{Ph}, \mathrm{Hal}=\mathrm{Br}(96 \%)$

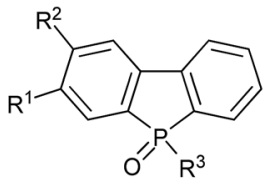

134-142

$138 \mathrm{R}^{1}=\mathrm{H}, \mathrm{R}^{2}=\mathrm{Cl}, \mathrm{R}^{3}=\mathrm{Ph}, \mathrm{Hal}=\mathrm{Br}(94 \%)$

$139 R^{1}=H, R^{2}=F, R^{3}=P h, ~ H a l=B r(97 \%)$

$140 \mathrm{R}^{1}=\mathrm{H}, \mathrm{R}^{2}=\mathrm{EtO}_{2} \mathrm{C}, \mathrm{R}^{3}=\mathrm{Ph}, \mathrm{Hal}=\mathrm{Br}(90 \%)$

$141 R^{1}=H, R^{2}=N C, R^{3}=\mathrm{Ph}, \mathrm{Hal}=\mathrm{Br}(83 \%)$

$142 \mathrm{R}^{1}=\mathrm{H}, \mathrm{R}^{2}=\mathrm{H}, \mathrm{R}^{3}=i-\mathrm{Pr}, \mathrm{Hal}=\mathrm{Br}(94 \%)$

Scheme 27<smiles>O=P(c1ccccc1)(c1ccccc1)c1cc(OCc2ccccc2Br)ccc1Br</smiles>

143
$\mathrm{Pd}(\mathrm{OAc})_{2}(3 \mathrm{~mol} \%)$

$\mathrm{PCy}_{3} \cdot \mathrm{HBF}_{4}(6 \mathrm{~mol} \%)$

$\mathrm{K}_{2} \mathrm{CO}_{3}$, (2.5 equiv.)

DMAc, $120^{\circ} \mathrm{C}$<smiles>O=P1(c2ccccc2)c2ccccc2-c2cc3c(cc21)OCc1ccccc1-3</smiles>

$144(82 \%)$

Scheme 28

from the readily available ortho-halodiarylphosphine oxides 133 by use of $\mathrm{Pd}(\mathrm{OAc})_{2}$ as a catalyst complexed with $\mathrm{PCy}_{3}$ leading to intramolecular palladium-catalysed arylation (Scheme 27). ${ }^{\mathbf{4 1}}$

An intramolecular double arylation catalysed by $\mathrm{Pd}(\mathrm{OAc})_{2}$ was applied to the synthesis of polycyclic dibenzophosphole oxide 144 starting from the dibromo derivative 143 in $82 \%$ yield (Scheme 28). ${ }^{41}$

Another intramolecular version of the double arylation was realised by the same research group starting from diaryl-2,5dibromophosphine oxide 145 and arylboronic acids or heteroarenes. Here, the phosphine complexed $\mathrm{Pd}(\mathrm{OAc})_{2}$ as a catalyst brought about the intramolecular arylation and, in the same pot, afforded further functionalised dibenzophosphole oxides 146-152 in 75-87\% yields by a Suzuki-Miyaura cross-coupling (146-148) or direct cross-coupling with a heteroarene (149152) (Scheme 29). ${ }^{41}$

Ishikawa and Manabe obtained the dibenzophosphole 154 in $35 \%$ yield by an intramolecular heteroaromatic electrophilic substitution reaction of the phosphine oxide $\mathbf{1 5 3}$ in the presence of triflic anhydride $\mathrm{Tf}_{2} \mathrm{O}$ in pyridine. In this reaction, the oxygen atom of the phosphoryl group first reacted with triflic anhydride $\mathrm{Tf}_{2} \mathrm{O}$ to generate an electrophilic intermediate and this was followed by electrophilic aromatic ring closure enhanced by the electron-releasing hydroxyl group; final OH/OTf conversion afforded 154 in $35 \%$ yield (Scheme 30). ${ }^{42}$ 


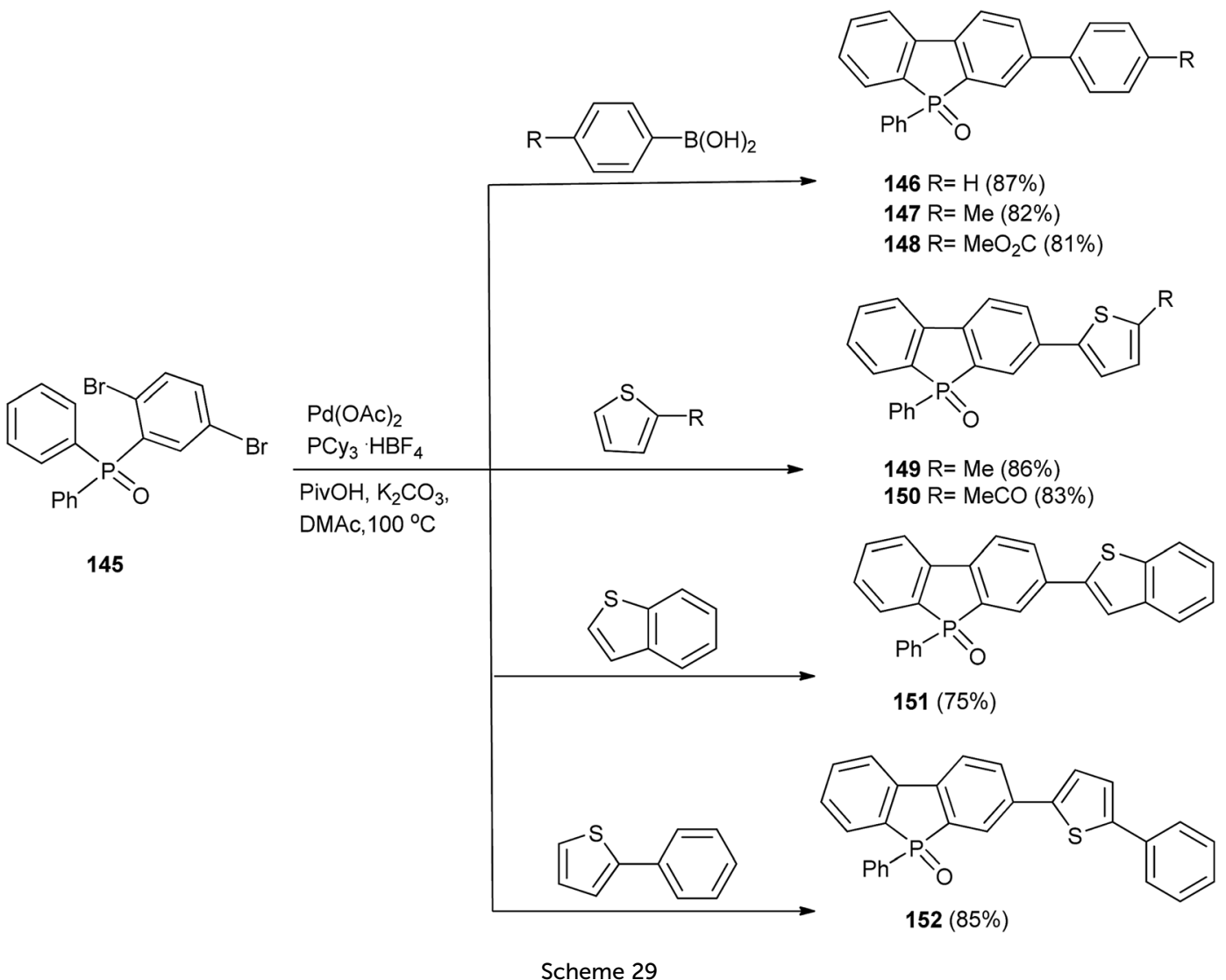

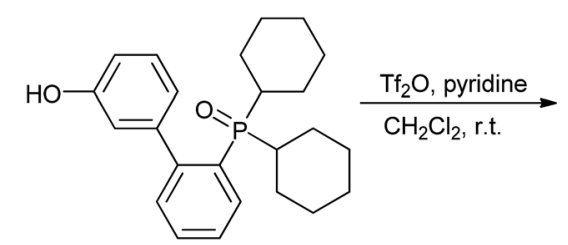

153

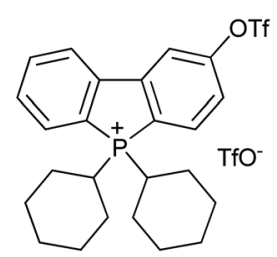

$154(35 \%)$
Scheme 30

Stankevič et al. synthesised a new group of bulky 5-tertbutyldibenzophosphole 5-oxides from acyclic diaryl-tert-butylphosphine oxides and organolithiums. ${ }^{43}$

Other syntheses of dibenzophospholes starting from phosphine oxides of type $\operatorname{ArR}_{2} \mathrm{P}(\mathrm{O})$ and $\mathrm{R}_{3} \mathrm{P}(\mathrm{O})$ are described in the subsection 2.7.

\subsection{From $\mathrm{R}_{2} \mathrm{P}(\mathrm{O}) \mathrm{CH}_{3}$ or $\mathrm{R}_{2} \mathrm{P}(\mathrm{O}) \mathrm{OCH}_{3}$}

Tanaka et al. synthesized enantioenriched benzopyrano- or naphthopyrano-fused helical dibenzophosphole oxides 156, $157,160,161,165$ by the rhodium-catalyzed, enantioselective, double $[2+2+2]$ cycloaddition of methyl dialkynylphophinates $155\left(\mathrm{R}^{2}=\mathrm{OMe}\right)$ with phenol or naphthol-linked tetraynes in 16$40 \%$ yields. In a similar way, dialkynyl methyl and phenyl phosphine oxides $155\left(\mathrm{R}^{2}=\mathrm{Me}, \mathrm{Ph}\right)$ were employed to afford 158, 159, 162, 163, 164 and 165 in 30-59\% yields (Scheme 31). ${ }^{44}$
Synthesis of dibenzophospholes from aryl substituted phosphine oxides $\operatorname{Ar}_{3} \mathrm{P}(\mathrm{O})$ and $\operatorname{ArR}_{2} \mathrm{P}(\mathrm{O})$ has been described in the previous subsection 2.6.

\subsection{From $(\mathrm{RO})_{3} \mathrm{P}(\mathrm{O})$}

Only one synthesis of dibenzophospholes has been reported starting from organic phosphates. The spirobiphosphoniafluorene 167 was obtained by the reaction of the dilithio derivative, obtained from the 2,2'-dibromo-1,1'-biphenyl 38, with triphenyl phosphate followed by $\mathrm{I} / \mathrm{BAr}_{4}$ counterion exchange, in $32 \%$ yield (Scheme 32). ${ }^{32}$

\subsection{From $\mathrm{Ar}_{3} \mathrm{P}=\mathrm{N}-\mathrm{R}$}

Synthesis of dibenzophospholes utilizing organophosphorus reagents containing a $\mathrm{P}=\mathrm{Y}$ bond, where $\mathrm{Y}$ is a heteroatom $(\mathrm{Y}=$ $\mathrm{N}, \mathrm{P}$ ) other than oxygen, sulfur or selenium are also rare transformations. Nief et al. obtained dibenzophospholes by transmetalation of the intramolecularly stabilized lithium derivative 171 to give the potassium salt 172, followed by intramolecular nucleophilic attack of the latter on the phenyl ring to form the intermediate 173. Further aromatization by deprotonation with PhK produced the potassium salt of the 5amino-dibenzophosphole $174(\mathrm{R}=n$-Bu) as a white, insoluble solid. The starting lithium derivative $\mathbf{1 7 1}$ was obtained via $\mathrm{NH}$ and $\mathrm{CH}$ deprotonation of the phosphonium bromide $\mathbf{1 7 0}$ followed by ortho-lithiation of one of the phenyl rings with $n$ butyllithium in toluene/hexane. The phosphonium bromides 


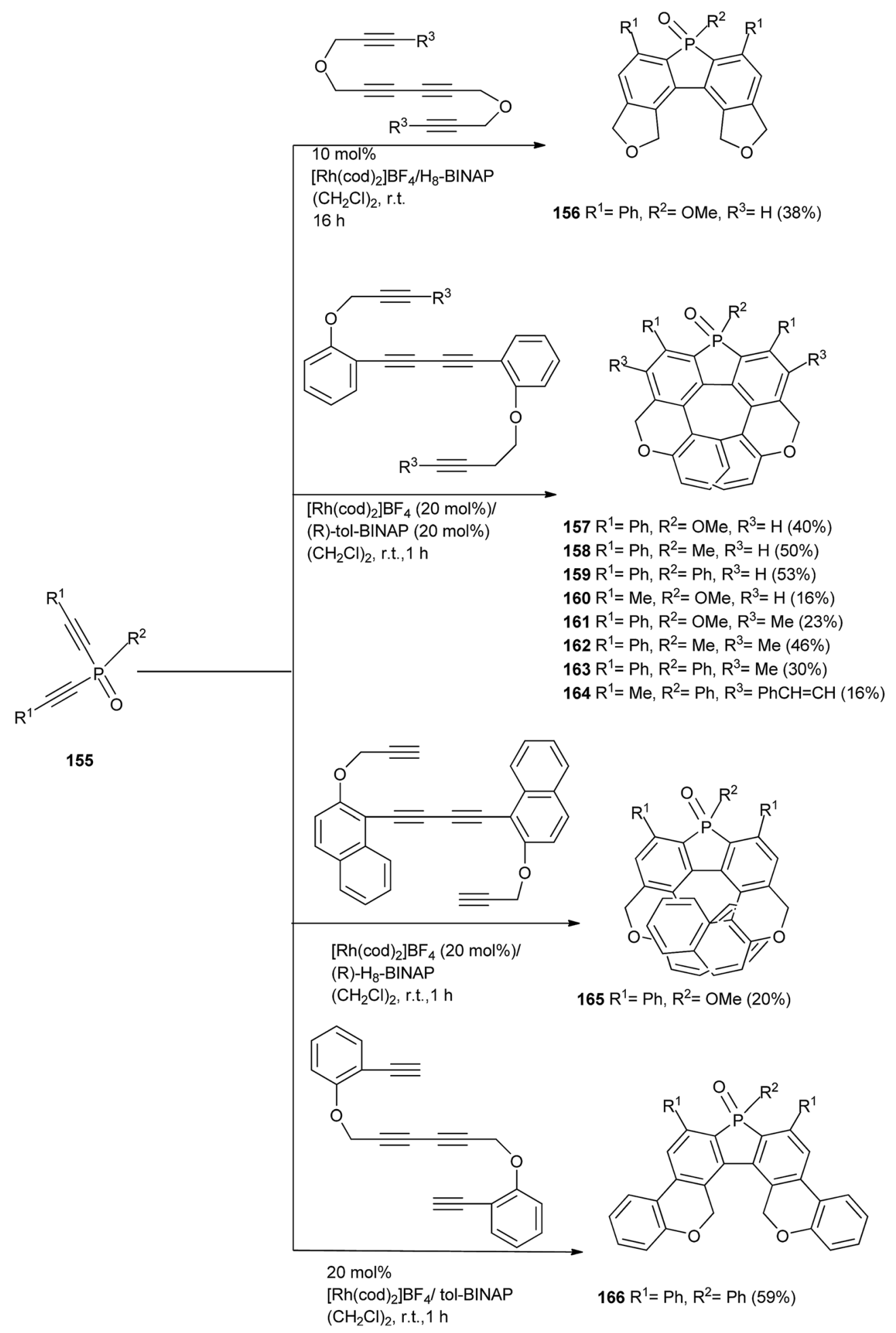

Scheme 31

170 were synthesized from triphenylphosphine $\mathbf{1 6 8}$ and primary alkyl amines (R $=t$-Bu, i-Pr, $n$-Bu) (Scheme 33). ${ }^{45}$

\subsection{From $\mathrm{ArP}=\mathrm{PMe}_{3}$}

Simpson, Protasiewicz et al. obtained a sterically hindered dibenzophosphole $\mathbf{1 7 6}$ by photolysis of the phosphorane derivative 175 in $90 \%$ yield (Scheme 34$).{ }^{46}$

\subsection{From phospholes and benzophospholes}

An interesting synthesis of dibenzophospholes and their heteroaromatic analogs, in which one benzene moiety was replaced by thiophene, furan, pyrrole or indole, was presented by Mathey et al. using a classical 7-phosphanonorbornadiene route developed by this group. First, 3,4-dimethyl-1cyanophosphole 177 was converted into the phospha- 


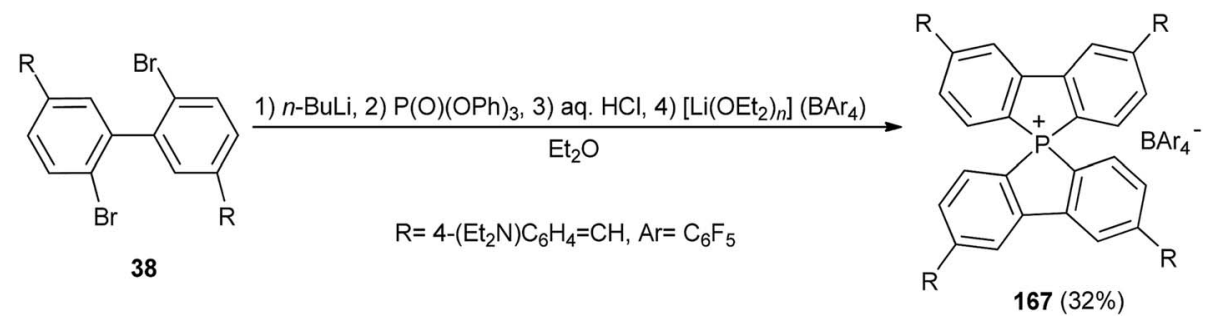

Scheme 32

$$
\begin{array}{cccc}
\mathrm{Ph}_{3} \mathrm{P}+\mathrm{R}-\mathrm{NH}_{2} & \underset{\mathrm{Br}_{2}, \mathrm{Et}_{3} \mathrm{~N}}{\mathrm{CH}_{2} \mathrm{Cl}_{2}} & \stackrel{\mathrm{Ph}_{3} \mathrm{P}-\mathrm{NH}-\mathrm{R}}{+\mathrm{Br}^{-}} & \frac{2 n-\mathrm{BuLi}}{\text { hexane }} \\
168 & & 170 & \text { toluene } \\
& & &
\end{array}
$$

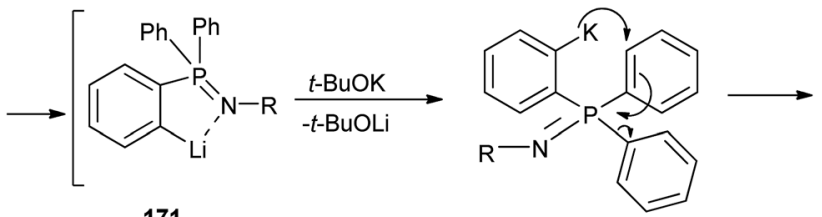

171

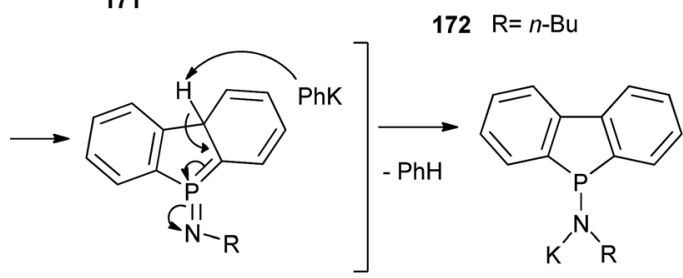

$173 \mathrm{R}=n-\mathrm{Bu}$

$174 \mathrm{R}=n-\mathrm{Bu}(72 \%)$

Scheme 33

norbornadiene $\mathbf{1 7 8}$ in a three-step sequence involving a replacement of the $\mathrm{CN}$ groups by the corresponding $\mathrm{Ar}^{1}-\mathrm{Ar}^{2}-$ Li derivative followed by metalation with $\mathrm{W}(\mathrm{CO})_{5}-(\mathrm{MeCN})$ and cycloaddition of the resulting phosphole with acetylenedicarboxylate. Next, thermolysis of $\mathbf{1 7 8}$ gave tungsten complexes of the dibenzophospholes 180-184 in 60-72\% yields, as a result of insertion of the electrophilic phosphinidene intermediate $\mathbf{1 7 9}$ into a $\mathrm{C}-\mathrm{H}$ bond using carbene-like chemistry (Scheme 35). ${ }^{47}$

Nyulászi, Hissler, Réau et al. obtained the air-stable dibenzophosphole sulfide 186 and the dibenzophosphole oxide 187 under aerobic irradiation (320-400 $\mathrm{nm}$ ) of dilute toluene solutions of 1-phenyl-2,3,4,5-tetra(3-thienyl)thiooxophosphole $185(\mathrm{Y}=\mathrm{S})$ and 1-phenyl-2,3,4,5-tetra(3-thienyl)-oxophosphole $185(\mathrm{Y}=\mathrm{O})$ containing a catalytic amount of iodine, in 10\% and $26 \%$ yields, respectively (Scheme 36$).{ }^{48}$

The photocyclisation of 188, using the Katz-modified approach, gave a mixture of the monocyclised derivative 189 and the fully cyclised target dibenzophosphapentaphene 190, in $50 \%$ and $20 \%$ yields, respectively after separation. Then, treatment of 190 with methyl triflate afforded the phospholium salt 191 in $60 \%$ yield. The final phosphapentaphene 192 was obtained by desulfurisation of the latter with $\mathrm{P}\left(\mathrm{NMe}_{2}\right)_{3}$, in $50 \%$ yield (Scheme 37). ${ }^{49}$

Another method, reported by Matano et al. is the cycloaddition of alkynes to biaryls containing a benzophosphole unit, catalysed by palladium(II) acetate, in the presence of pivalic acid $(\mathrm{PivOH})$ and $\mathrm{Bu}_{4} \mathrm{NBr}$. The examples of this method are with compounds 193 ( $\mathrm{Y}=\mathrm{S}, \mathrm{NMe}$ ) and 4-octyne, in which the authors obtained polycyclic aromatic compounds 195 and 196 containing dibenzophosphole oxide and dibenzothiophene or carbazole units in $14 \%$ and $53 \%$ yields, respectively (Scheme 38). ${ }^{44}$

\section{Functionalisation of dibenzophospholes}

Dibenzophospholes can be functionalised at the phosphorus atom and on the two peripheral benzene rings. The functionalisation can be achieved during synthesis of the dibenzophosphole rings or as a result of post-ring-synthesis modifications.

\subsection{Functionalisation at phosphorus atom}

One of the most important features of the phosphole ring is a low degree of aromaticity and easy availability of a free electron pair on the phosphorus atom, which enables chemical<smiles>CC(C)=Pc1c(-c2c(C(C)C)cc(C(C)C)cc2C(C)C)cccc1-c1c(C(C)C)cc(C(C)C)cc1C(C)C</smiles>

175

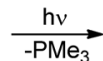<smiles>CC(C)c1cc(C(C)C)c(-c2ccc3c4c(C(C)C)cc(C(C)C)cc4p(C(C)C)c3c2)c(C(C)C)c1</smiles>

$176(90 \%)$

Scheme 34 


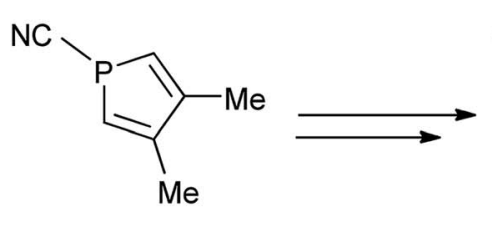

177<smiles>COC(=O)C1=C(C)C2C(C)=C(C)C1P2([Al])(O[Na])[Al][Al]</smiles>

$178(41 \%-69 \%)$

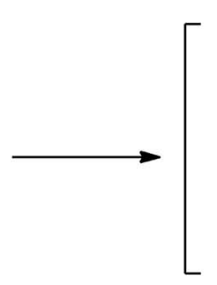<smiles>[R]c1cc([R])c2c(c1)[PH2]([N+]([O-])([O-])C([R])(C)C)c1ccccc1-2</smiles>

$180 \mathrm{R}^{1}=\mathrm{H}, \mathrm{R}^{2}=\mathrm{H}(72 \%)$

$181 \mathrm{R}^{1}=\mathrm{Br}, \mathrm{R}^{2}=\mathrm{H}(68 \%)$

$182 \mathrm{R}^{1}=\mathrm{H}, \mathrm{R}^{2}=$ OMe $(60 \%)$

$183 \mathrm{R}^{1}=\mathrm{H}, \mathrm{R}^{2}=\mathrm{CF}_{3}(65 \%)$

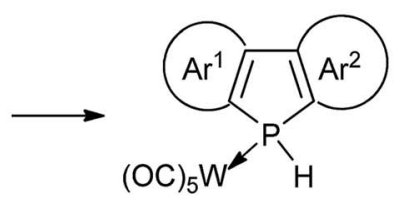

180-184

Scheme 35<smiles>c1cc(-[Y]2c(-c3ccsc3)c(-c3ccsc3)c(-c3ccsc3)c2-c2ccsc2)cs1</smiles>

$185 Y=S, O$
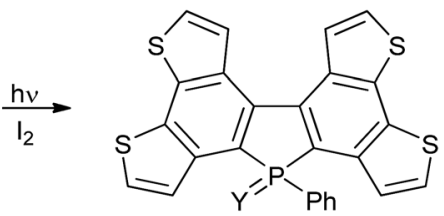

$186 Y=S(10 \%)$ $187 Y=O(26 \%)$
Scheme 36

modifications of phospholes by oxidation, sulfurization (addition of elemental sulfur), metalation or quaternization. This is due to the fact that tricoordinate phosphorus atom assumes a pyramidal geometry and the lone electron pair at the phosphorus atom has a high degree of s orbital character. These two properties limit the effective interaction between the lone electron pair and the conjugated $\pi$-electron system of the phosphole ring.

3.1.1. Oxidation. Oxidation of trivalent phosphorus in dibenzophospholes to the corresponding oxides includes direct methods with oxidizing reagents and indirect ones via phosphonium salts or iminophosphoranes.
Stelzer, Sheldrick et al. obtained 5-phenyl-2-2'-bis(sulfonato)$5 \mathrm{H}$-dibenzophosphole-5-oxide dipotassium salt 197 directly in $92 \%$ yield by treating an aqueous solution of the salt $\mathbf{1 1}$ with hydrogen peroxide (Scheme 39). ${ }^{\mathbf{2 6}}$

The dibenzophosphole tripotassium salt 199 was obtained by reaction of $5,5^{\prime}$-bis(sulfonato)-2,2'-difluoro-1,1'-biphenyl dipotassium salt 10 with $\mathrm{PH}_{3}$ using $\mathrm{DMSO} / \mathrm{KO} t \mathrm{Bu}$ as a basic medium. In this reaction, the tripotassium salt 198 was formed first and next reacted with hydrogen peroxide to give 199 in $41 \%$ yield (Scheme 40). ${ }^{26}$

Other examples of the direct oxidation are reactions of substituted 5-phenyldibenzophospholes 200 with hydrogen peroxide in diethyl ether which gave the corresponding oxides 1, 23 and 24 in $85 \%, 83 \%$ and $86 \%$ yields, respectively (Scheme 41). ${ }^{51}$

The same reagent was employed in the synthesis of fully perfluorinated dibenzophosphole oxide 202 starting from the dibenzophosphole $\mathbf{2 0 1}$ in dichloromethane. Symmetrical diphenyl-, dithienyl- and diphenylethynyl-substituted hexafluorodibenzophosphole oxides 203-205, could also be obtained in 25\%, 60\% and 50\% yields, respectively (Scheme 42 ). ${ }^{52}$

The conversion of P-phenyl into P-alkyl using 5-phenyldibenzophosphole $\mathbf{1}$ followed by P-oxidation to give the 

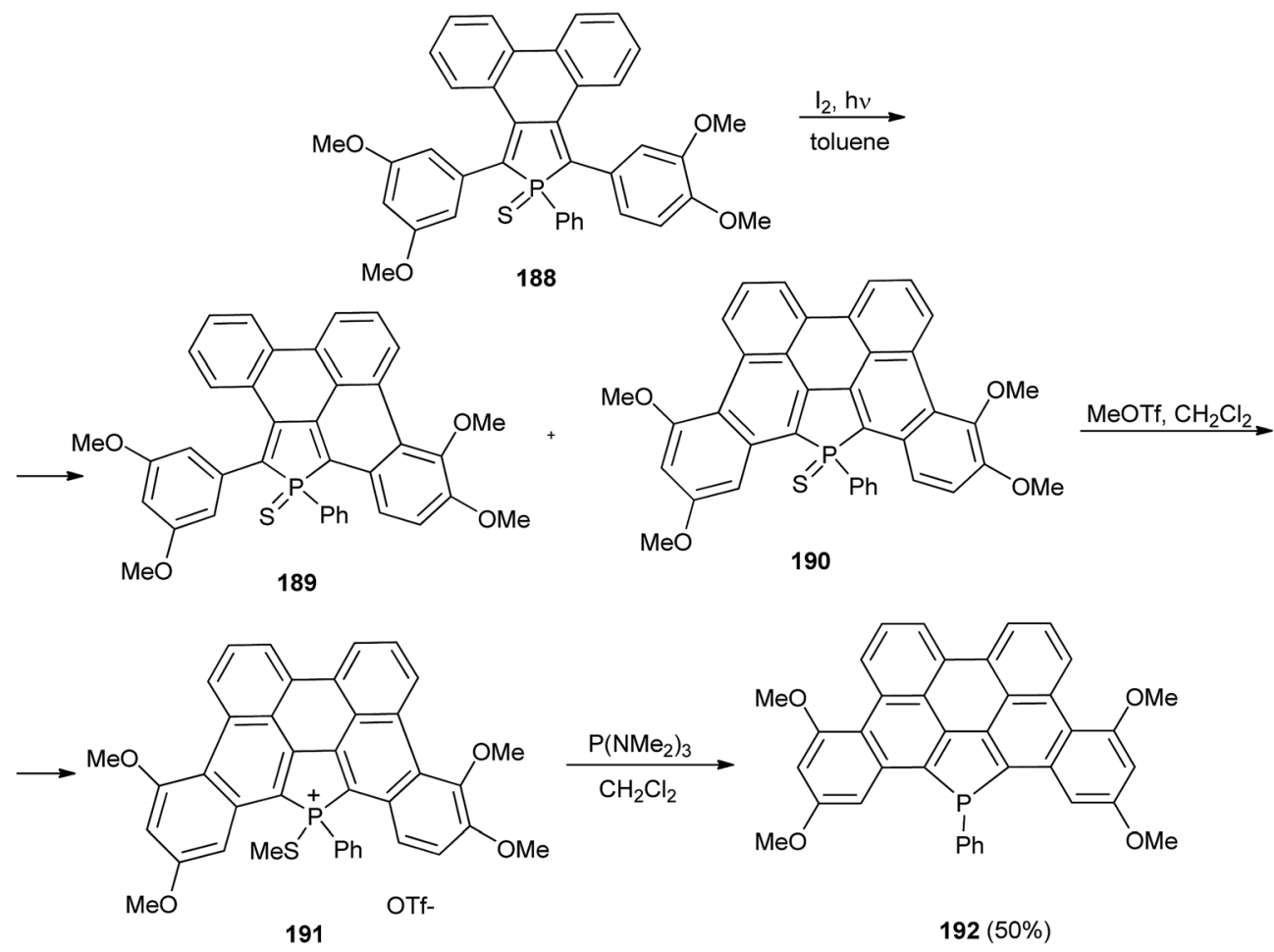

Scheme 37

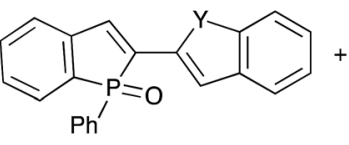

$193 \mathrm{Y}=\mathrm{S}, \mathrm{NMe}$

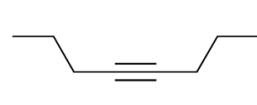

194<smiles>CCCc1c2c(c3c(c1CCC)c1ccccc1p3-c1ccccc1)P(=O)(c1ccccc1)c1ccccc1-2</smiles>

$195 \mathrm{Y}=\mathrm{S}(14 \%)$

$196 \mathrm{Y}=\mathrm{NMe}(53 \%)$

Scheme 38

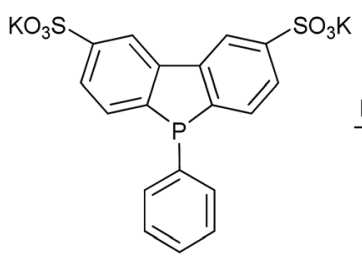

11

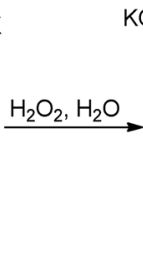

$\mathrm{KO}_{3} \mathrm{~S}$

$197(92 \%)$
Scheme 39

corresponding oxides has been realized by Durán et al. Thus, the reaction of $\mathbf{1}$ with lithium in tetrahydrofuran delivered a Plithium derivative, which was first reacted with methyl iodide or ethyl bromide and then was oxidised with hydrogen peroxide. The final oxides 206 and 207 were obtained in 96\% yields (Scheme 43)..53

In contrast, treatment of $\mathbf{1}$ with lithium and direct oxidation of the resulting P-lithium salt with peracetic acid $\left(\mathrm{H}_{2} \mathrm{O}_{2} / \mathrm{AcOH}\right)$ at $45{ }^{\circ} \mathrm{C}$ led to the corresponding phosphinic acid 208 in $63 \%$ yield (Scheme 44). ${ }^{54}$

Hissler, Réau et al. oxidized the phosphorus atom in the dibenzophosphapentaphene 192, containing a fused dibenzophosphole moiety, with sodium metaperiodate $\left(\mathrm{NaIO}_{4}\right)$ in dichloromethane giving the corresponding oxide 209 in $70 \%$ yield (Scheme 45). ${ }^{49}$

Chi, Chou and Chang et al. modified $5 H$-dibenzophosphole 211, which was synthesised in situ from 5-phenyl dibenzophosphole, by the cross-coupling reaction of the $\mathrm{P}-\mathrm{H}$ bond with aryl bromide $\mathbf{2 1 0}$ in the presence of $\mathrm{CuI}$ as a catalyst, was followed by oxidation of the resulting intermediate with $\mathrm{H}_{2} \mathrm{O}_{2}$ to give 5-[4-(carbazo-9-yl)phenyl]dibenzophosphole 5-oxide 212 in $34 \%$ yield (Scheme 46$){ }^{55}$

3.1.2. Reduction of $\mathbf{P}=\mathbf{O}$ and $\mathbf{P}=\mathbf{N}$ bonds. Diphenylsilane was used by Delft et al. in reduction of the $\mathrm{P}=\mathrm{O}$ bond in dibenzophosphole oxides 213 in $\left[d_{8}\right]-1,4$-dioxane, at $100{ }^{\circ} \mathrm{C}$ to give 5-phenyldibenzophosphole 1, 2,8-dimethoxy-5-phenyldiben- 

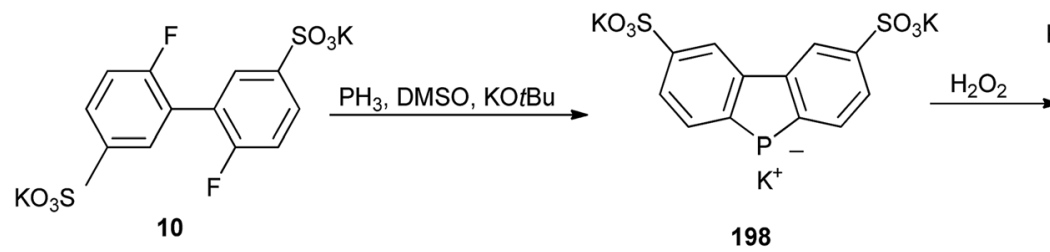<smiles>O=P1(O)c2ccc(S(=O)(=O)[O-])cc2-c2cc(S(=O)(=O)O[Na])ccc21</smiles>

$199(41 \%)$

Scheme 40

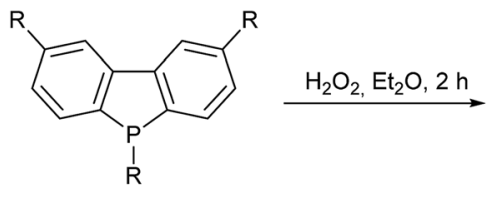

200<smiles>[R]c1ccc2c(c1)-c1cc([R])ccc1P2([R])=O</smiles>

$1 \mathrm{R}=\mathrm{H}(85 \%)$

$23 \mathrm{R}=\mathrm{OMe}(83 \%)$

$24 \mathrm{R}=\mathrm{CF} 3(86 \%)$

Scheme 41

zophosphole 23 and 5-phenyl-2,8-bis(trifluoromethyl)-dibenzophosphole 24 in $19-55 \%$ yields (Scheme 47 ). ${ }^{51}$

Delft et al. also reduced dibenzophosphole iminophosphoranes 214 , by means of diphenylsilane in $\left[d_{8}\right]$-1,4-dioxane at $101{ }^{\circ} \mathrm{C}$ producing the corresponding dibenzophospholes 1 or 23. For the compound $23(\mathrm{R}=\mathrm{MeO})$, the reduction of the $\mathrm{P}=\mathrm{N}$ bond was faster, than for the unsubstituted compound $1(\mathrm{R}=$ H) (Scheme 48). ${ }^{56}$

The same research group used diphenylsilane $\mathrm{Ph}_{2} \mathrm{SiH}_{2}$ for reduction of the water-sensitive $\mathrm{P}=\mathrm{N}$ bond in the dibenzophosphole iminophosphorane $\mathbf{2 1 5}$ which was obtained in the Staudinger reaction of $\mathbf{1}$ with benzyl azide. Much faster reduction was observed with $\mathrm{PhSiH}_{3}$. Other alkyl, cycloalkyl, allyl and aryl azides were also employed in the Staudinger reaction with a catalytic amount $(10 \% \mathrm{~mol})$ of the dibenzophosphole 1 . This methodology was utilised practically in the synthesis of primary

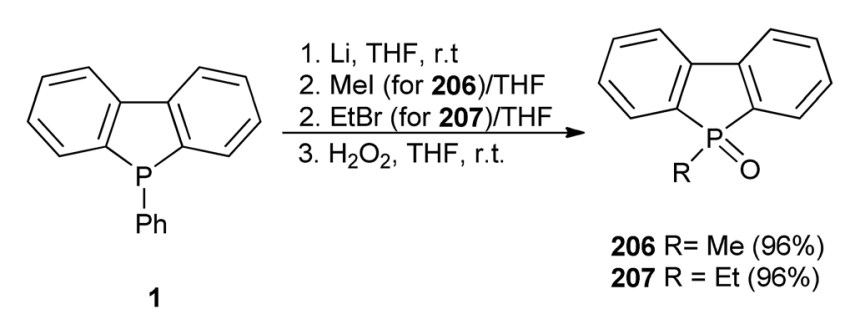

Scheme 43<smiles>c1ccc(-c2ccccc2P(c2ccccc2)c2ccccc2)cc1</smiles>

1

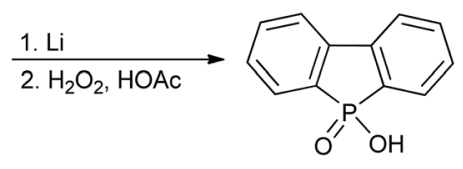

$208(63 \%)$
Scheme 44

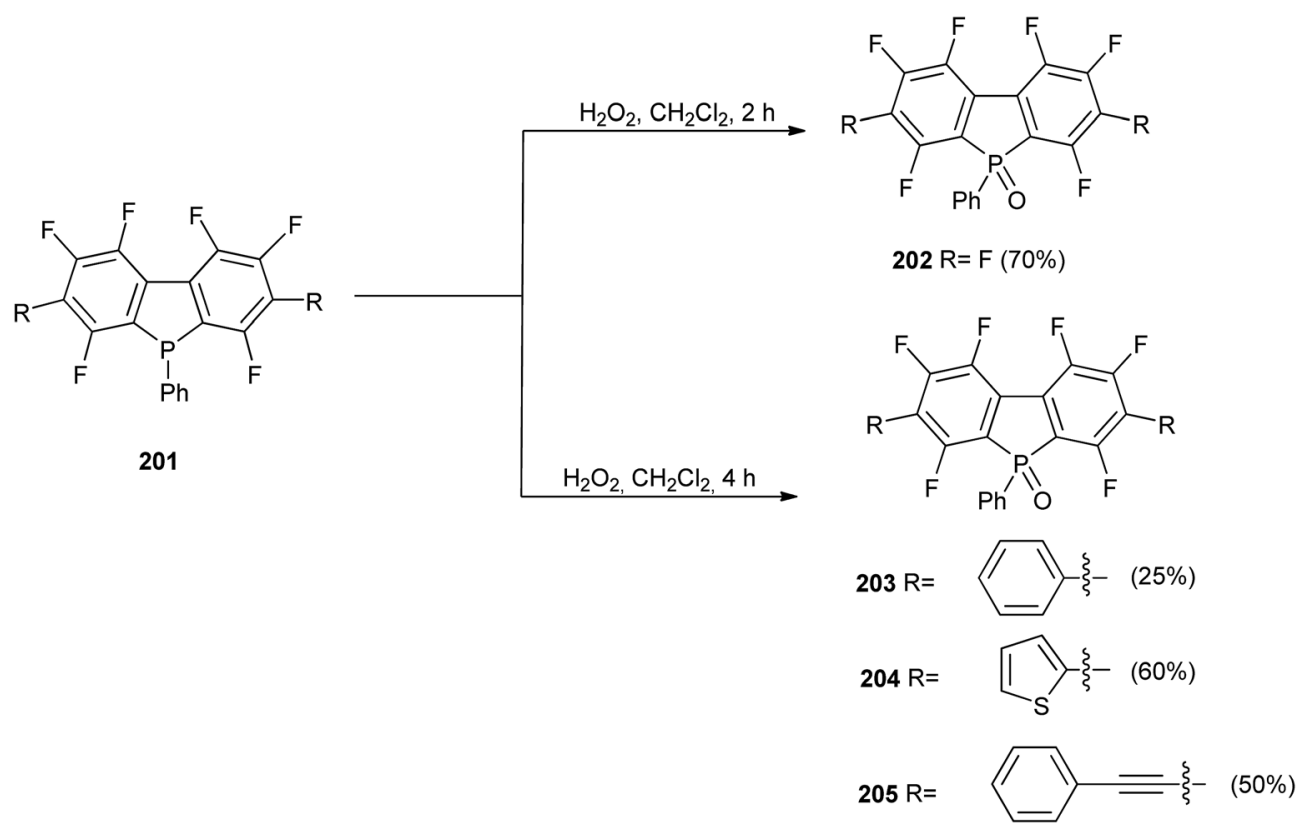

Scheme 42 


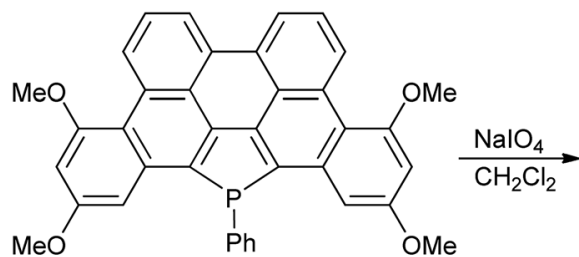

192

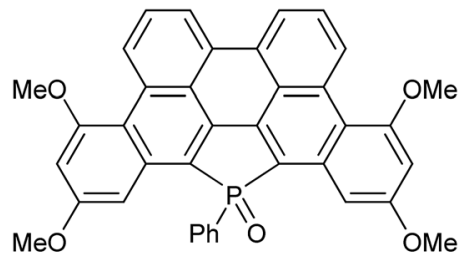

$209(70 \%)$

Scheme 45

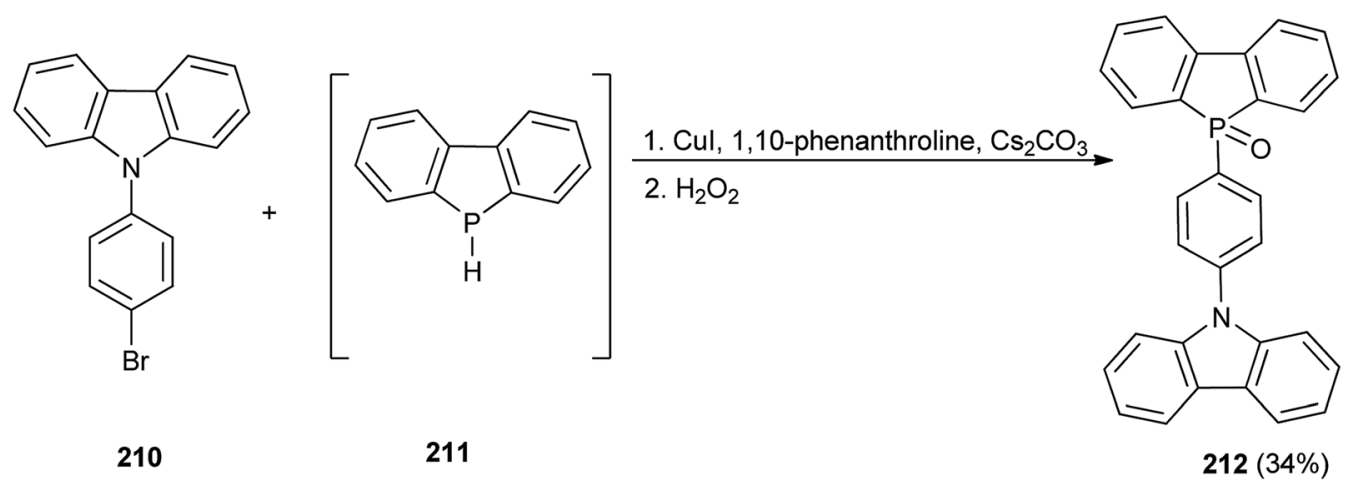

Scheme 46<smiles>[R]c1ccc2c(c1)-c1cc([R])ccc1P2(=O)c1ccccc1</smiles>

$213 \mathrm{R}=\mathrm{H}, \mathrm{OMe}, \mathrm{CF}_{3}$

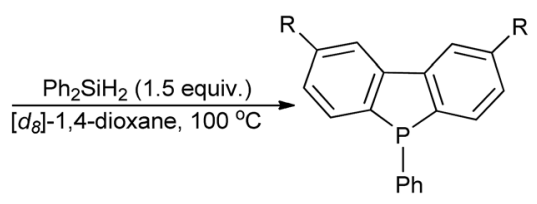

$1 \mathrm{R}=\mathrm{H}(55 \%)$

$23 \mathrm{R}=\mathrm{OMe}(19 \%)$

$24 \mathrm{R}=\mathrm{CF}_{3}(55 \%)$

Scheme 47

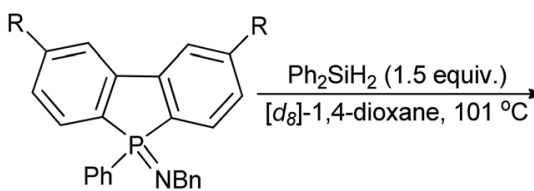

214

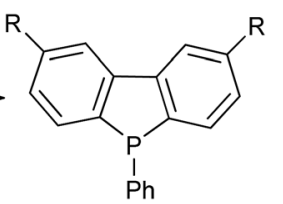

$1 \mathrm{R}=\mathrm{H}(74 \%)$

$23 \mathrm{R}=\mathrm{OMe}$

Scheme 48

amines via intermediate iminophosphoranes 215 which could be easily hydrolysed with $\mathrm{H}_{2} \mathrm{O}$ to the dibenzophosphole oxide $\mathbf{6 6}$ (Scheme 49).57

López-Calahorra et al. used trichlorosilane in toluene to reduce dibenzophosphole oxides $\mathbf{2 1 6}$ to dibenzophospholes 217-219. The dibenzophosphole 217 was isolated as a colorless oil in 93\% yield while $\mathbf{2 1 8}$ and $\mathbf{2 1 9}$ were directly converted into the corresponding cyclopalladates due to a rapid oxidation in air (Scheme 50). ${ }^{58}$
Further examples of reduction of dibenzophosphole oxides are described in subsection 3.1.5 (Schemes 57 and 59).

3.1.3. Sulfurization. In 2012, Hissler, Réau et al. obtained the dibenzophosphapentaphene sulfide 190 by the reaction of $\sigma^{3}, \lambda^{3}$-dibenzophosphapentaphene 192 containing in its fused structure a dibenzophosphole unit, with $\mathrm{S}_{8}$ in triethylamine, in $20 \%$ yield (Scheme 51 ). ${ }^{49}$

The dibenzophosphole sulfides 220-anti and 221-syn were prepared by conversion of the corresponding oxides 131-anti and 132-syn with Lawesson's reagent in toluene. X-ray studies confirmed two, almost flat P-terphenyl units of the ladder-type. These compounds were obtained in $67 \%$ and $54 \%$ yields, respectively (Scheme 52$){ }^{40}$

Voituriez and Marinetti et al. obtained the phosphine sulfide 223 from the corresponding oxide $222\left(\mathrm{R}_{\mathrm{p}}\right)$ by using Lawesson's reagent, in $79 \%$ yield. Photolysis of compound 223 afforded the helicene 224, with $\mathrm{M}$ helical configuration, as the major product in $50 \%$ yield (Scheme 53 ). ${ }^{33}$

A ferrocene-containing dibenzophosphole sulfide 226 was obtained in the reaction of 5-cyanophosphole 225 with $t$-butyllithium followed by treatment of the resulting 5-P lithium derivative with a ferrocene (FER) derivative and addition of elemental sulfur. The final product was further converted into the corresponding aldehyde which was then reduced to a primary alcohol (Scheme 54 )..$^{59}$

3.1.4. Selenylation. A series of substituted dibenzophosphole selenides 228-232 was obtained by addition of elemental selenium to the corresponding dibenzophosphole derivatives 227. Since the reaction was carried out in deuterated 

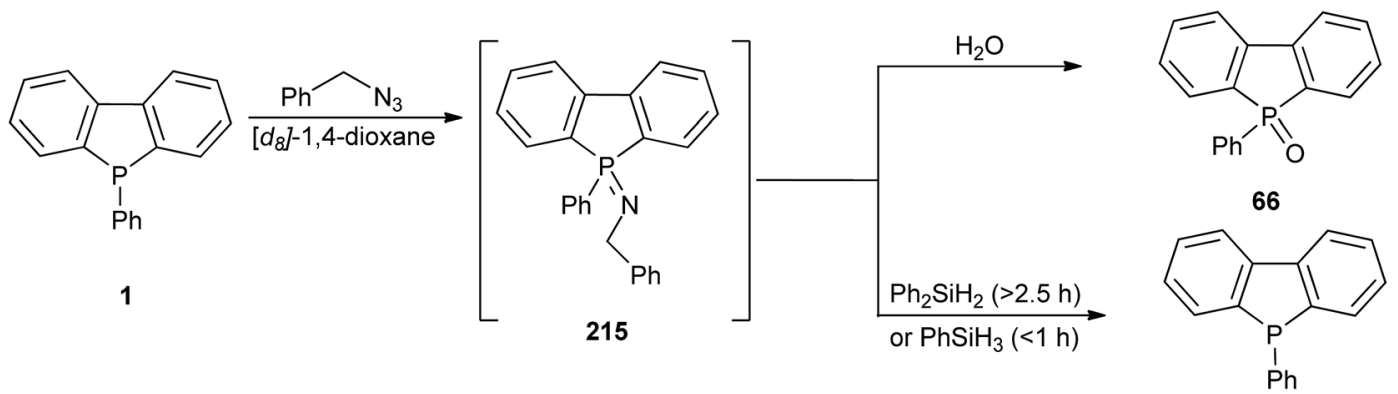

Scheme 49<smiles>[R]c1ccc2c(c1)P([R])(=O)c1cc([R])ccc1-2</smiles><smiles>[R]c1ccc2c3ccc([R])cc3p([R1])c2c1</smiles>

216

$217 R^{1}=H, R^{2}=H, R^{3}=M e,(93 \%)$

$218 R^{1}=C N, R^{2}=H, R^{3}=M e$

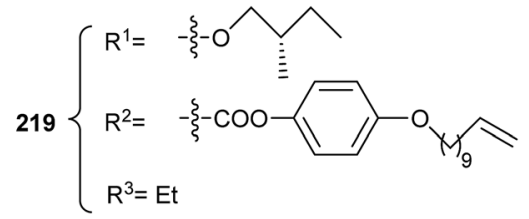

Scheme 50

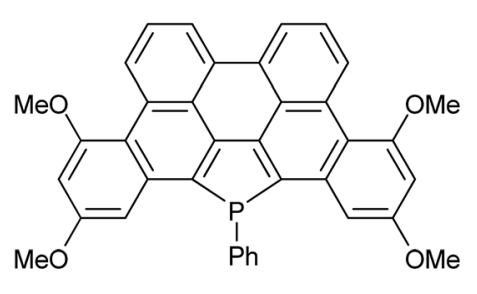

192

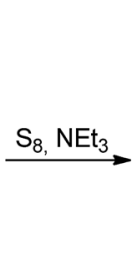

$\mathrm{NEt}_{3}$

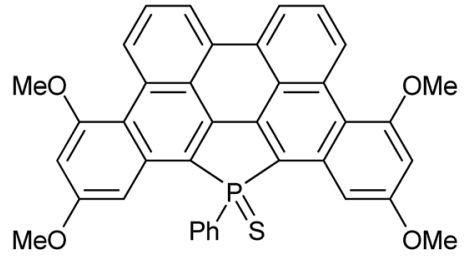

$190(20 \%)$

Scheme 51<smiles>CCCCCc1ccc2c(c1)P(=O)(c1ccccc1)c1cc3c(cc1-2)P(=O)(c1ccccc1)c1cc(CCCC)ccc1-3</smiles>

131-anti<smiles>CCCCc1ccc2c(c1)P(=O)(c1ccccc1)c1cc3c(cc1-2)P(=O)(c1ccccc1)c1cc(CCCC)ccc1-3</smiles>

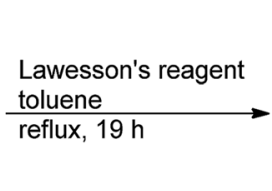

-Bu-

220-anti (67\%) toluene reflux, $19 \mathrm{~h}$

Lawesson's reagent<smiles>CCCCc1ccc2c(c1)P(=S)(c1ccccc1)C(=S)c1cc3c(cc1-2)P(=S)(c1ccccc1)c1cc(CCCC)ccc1-3</smiles>

Scheme 52 


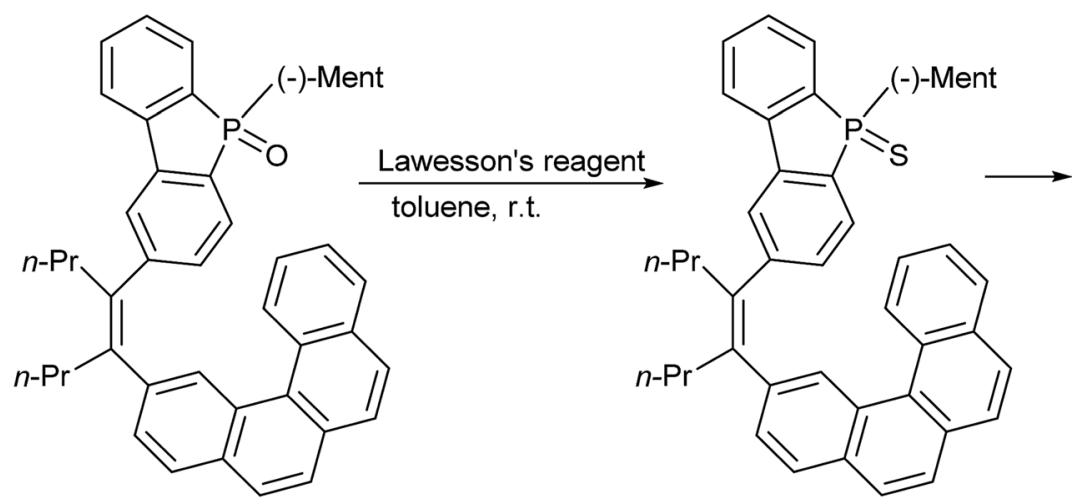

(Rp)-222

(Rp)-223 (79\%)<smiles>CCCCC(C)[C@H]1C[C@H](C)CC[C@H]1C(C)C</smiles>

(Rp, M)-224 (50\%)

Scheme 53

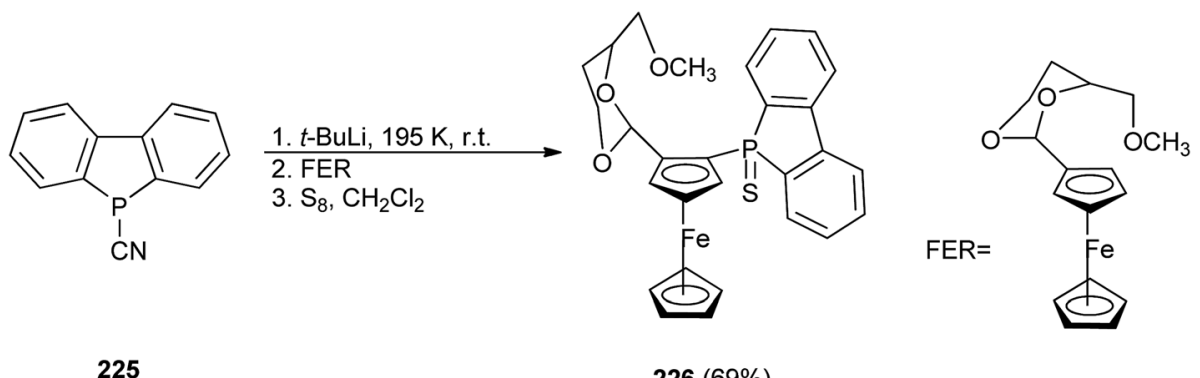

Scheme 54

chloroform, at room temperature, in an NMR tube, the yields of this reaction were not determined (Scheme 55). ${ }^{31}$

3.1.5. Metalation. The dibenzophosphole binding with metals via the phosphorus atom requires either a direct availability of a dibenzophosphole $\mathrm{P}^{\mathrm{III}}$ atom or reduction of $\mathrm{P}^{\mathrm{IV}}$ to $\mathrm{P}^{\mathrm{III}}$ atom prior to the binding so that the P-electron pair is available to interact with a metal. Thus, the reduction of the P-phenyl substituted helicene dibenzophosphole oxide $\left(R_{p}, M\right) 233$ with $\mathrm{HSiCl}_{3} / \mathrm{Et}_{3} \mathrm{~N}$ followed by reaction with a mixture of $\mathrm{NaAuCl}_{4}$ $\cdot 2 \mathrm{H}_{2} \mathrm{O}$ and 2,2'-thiodiethanol as a reducing agent, afforded the gold chloride complex $\left(\mathrm{R}_{\mathrm{p}}, \mathrm{M}\right) 234$ in $46 \%$ yield (Scheme 56$){ }^{33}$

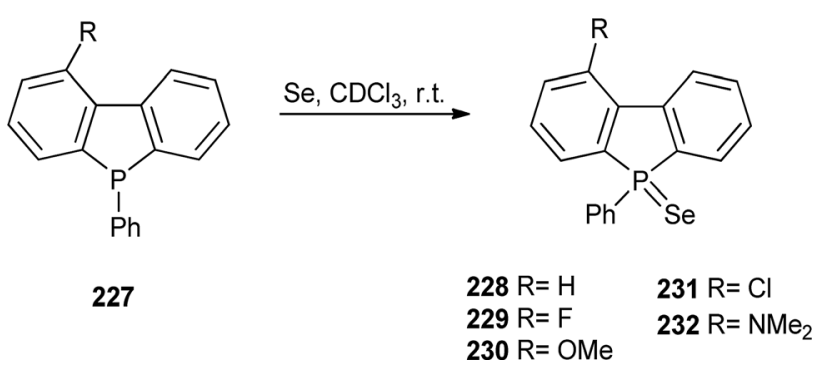

Scheme 55 


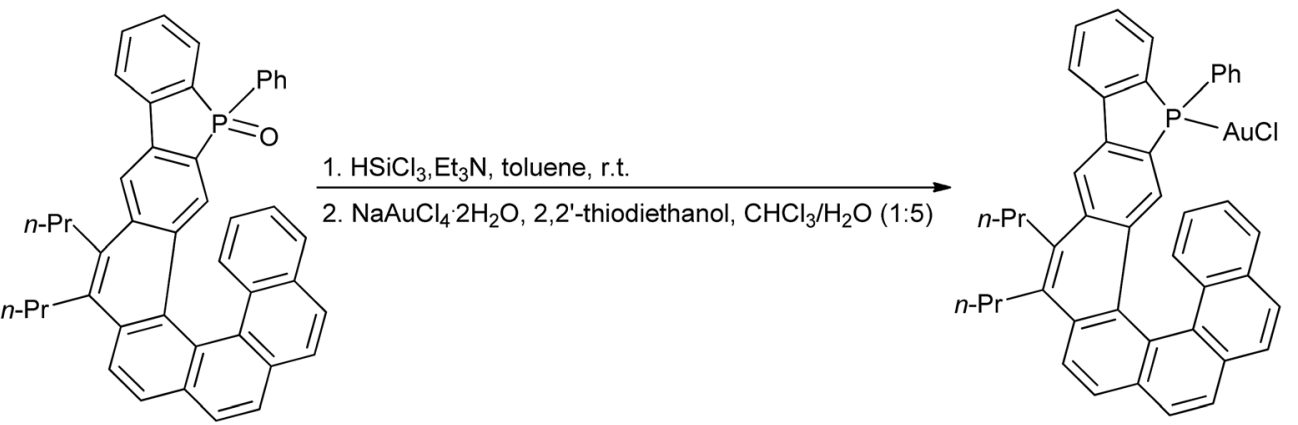

$(\mathrm{Rp}, \mathrm{M})-\mathbf{2 3 3}$

(Rp, M)-234 (46\%)

Scheme 56

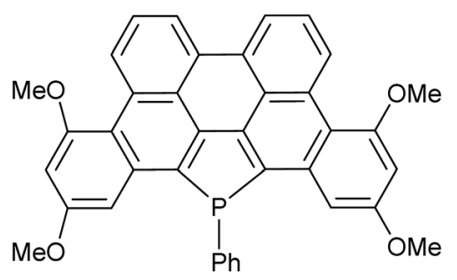

192

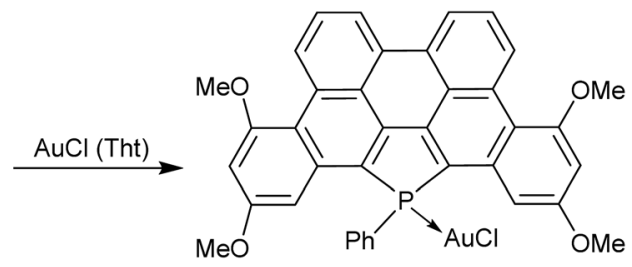

$235(75 \%)$

Scheme 57

Another gold chloride complex 235 was obtained in the reaction of the dibenzophosphapentaphene 192 with chloro(tetrahydrothiophene) (Tht) gold(I) in 75\% yield (Scheme 57). ${ }^{49}$

The P-menthyl substituted [6] helicene $\left(\mathrm{R}_{\mathrm{p}}, \mathrm{P}\right) \mathbf{2 3 6}$ was reduced under analogous conditions and reacted with [ $[\operatorname{Ir}(\operatorname{cod})$ $\left.\operatorname{IrCl}\}_{2}\right]$ (cod $=1,5$-cyclooctadiene) to give the helicene 237 in $37 \%$ yield (Scheme 58 ). ${ }^{33}$

The dibenzophosphole Fe-complex $\mathbf{2 3 9}$ was obtained in the reaction of 6-substituted dibenzophosphole 238 with $\mathrm{Fe}_{2}(\mathrm{CO})_{9}$ after crystallisation from benzene, in $76 \%$ yield. Analogously, the Ru-complex 240 was obtained in $68 \%$ yield after crystallization from chloroform (Scheme 59). ${ }^{35}$

In 2002, Decken et al. obtained Fe-complexes 242 and 243 from dibenzophospholyl-Li 241 and $\mathrm{CpFe}(\mathrm{CO})_{2} \mathrm{X}(\mathrm{X}=\mathrm{Br}$, I) in THF, at room temperature, in $93 \%$ and $87 \%$ yields, respectively. Heating 242 or 243 in refluxing xylenes resulted in the formation of trace amounts of $\mathbf{2 4 4}$ as well as large amounts of intractable green solids, however, in the reaction of bis $\left(1,1^{\prime}\right.$ dibenzophospholyl) 245 and $\mathrm{Cp}_{2} \mathrm{Fe}_{2}(\mathrm{CO})_{4}$ in refluxing xylenes a mixture of cis- and trans-isomers 244 was obtained in a $1: 15$ ratio, in $75 \%$ yield (Scheme 60). ${ }^{60}$

The same research group obtained ( $\mu_{2}$-dibenzophospholyl)-( $\mu_{2}-$ bromo)-dimanganese-octacarbonyl 246 from dibenzophospholyl$\mathrm{Li}$ and $\mathrm{Mn}(\mathrm{CO})_{5} \mathrm{Br}$ in THF in $69 \%$ yield (Scheme 61). ${ }^{61}$

The $\operatorname{bis}\left(\mu_{2}\right.$-dibenzophospholyl)-dimanganese-octacarbonyl 247 was obtained by heating of bis(1,1'-dibenzophospholyl) 245 and $\mathrm{Mn}_{2}(\mathrm{CO})_{10}$ in refluxing xylenes in $78 \%$ yield. The same compound was formed by refluxing ( $\mu_{2}$-dibenzophospholyl)- $\left(\mu_{2}-\right.$ bromo)-dimanganese-octacarbonyl 246 in the same solvent (Scheme 62). ${ }^{61}$

A mixture of (1-phenyldibenzophosphole)-dimanganesenonacarbonyl 248 and di(1-phenyldibenzophosphole)-

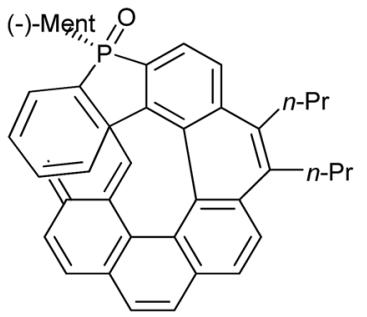

(Rp,P)-236

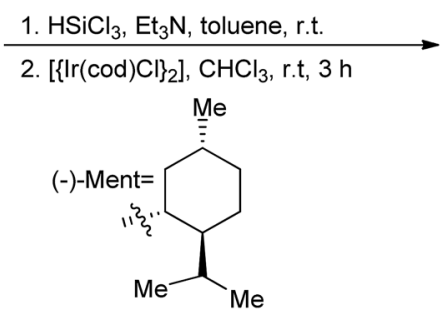

Scheme 58

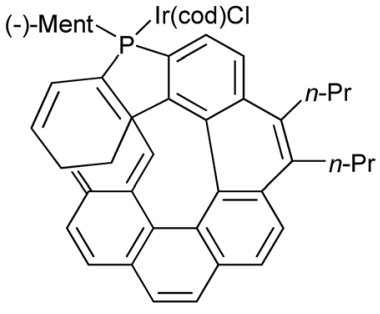

(P)-237 (37\%) 


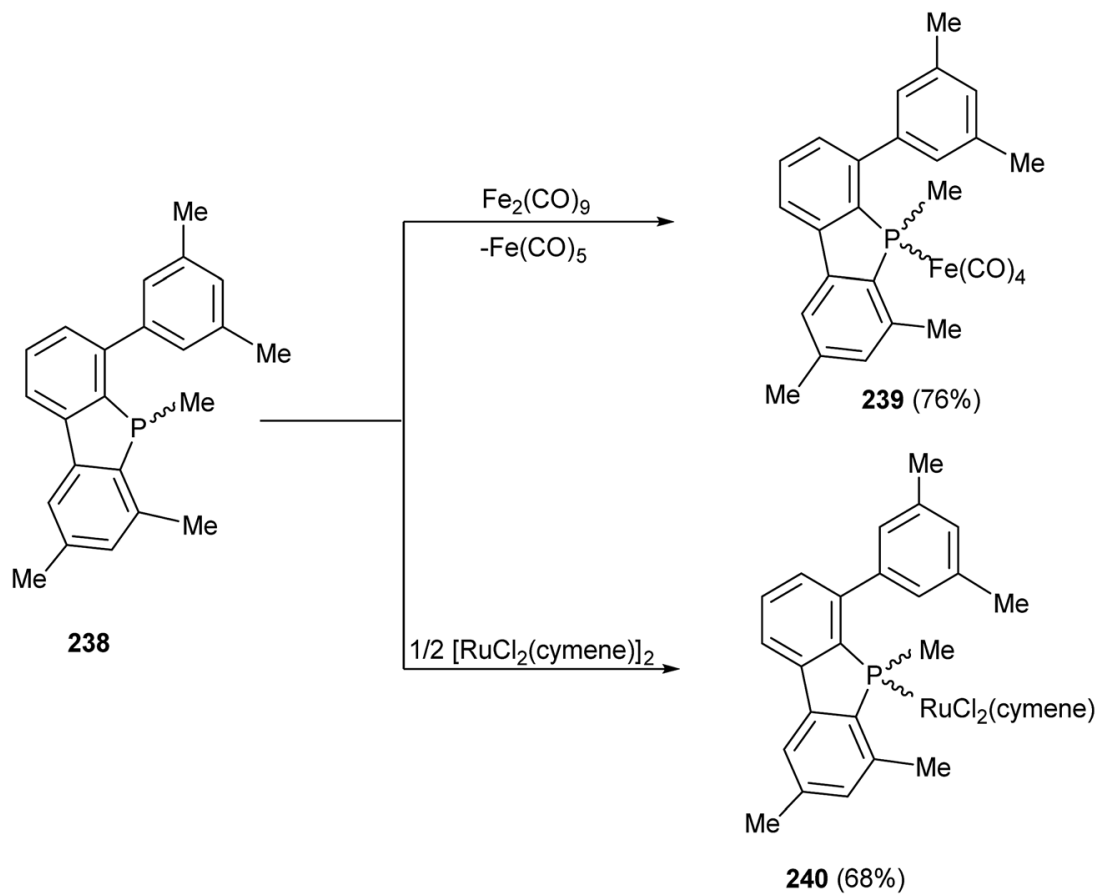

Scheme 59

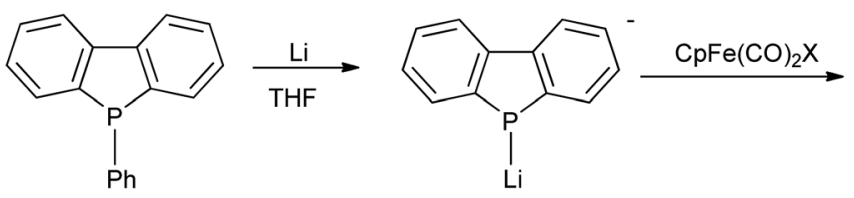

1

241
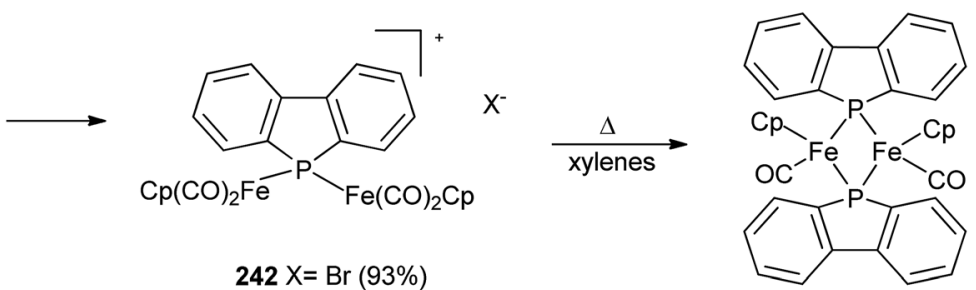

$242 \mathrm{X}=\mathrm{Br}(93 \%)$

$243 X=\mid(87 \%)$<smiles>c1ccc2c(c1)c1ccccc1p1c3ccccc3p21</smiles>

245

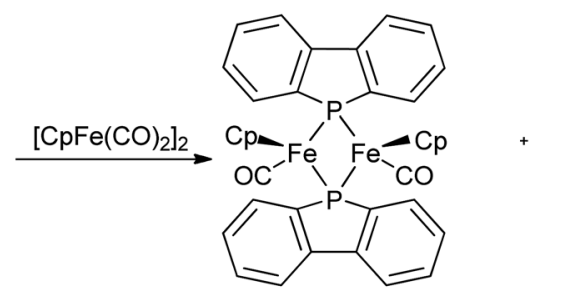

244-cis

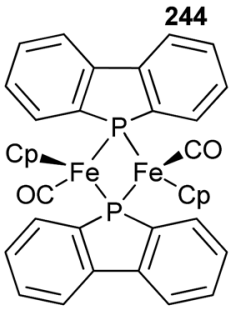

244-trans

Scheme 60

dimanganese-octacarbonyl 249 was obtained by reaction of 5phenyldibenzophosphole $\mathbf{1}$ with dimanganese decacarbonyl in xylenes, in $17 \%$ and $13 \%$ yields, respectively. $\left(\eta^{1}\right.$ -
Dibenzophospholyl)tris(dimethylamido)titanium $\quad 250$ was formed by a reductive cleavage of the $\mathrm{P}-\mathrm{Ph}$ bond in the 5phenyldibenzophosphole $\mathbf{1}$ using potassium followed by 
<smiles>c1ccc(P(c2ccccc2)c2ccccc2)cc1</smiles>

1<smiles></smiles>

241

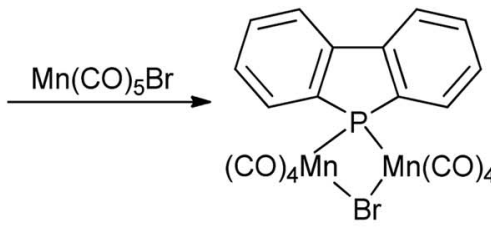

$246(69 \%)$

Scheme 61

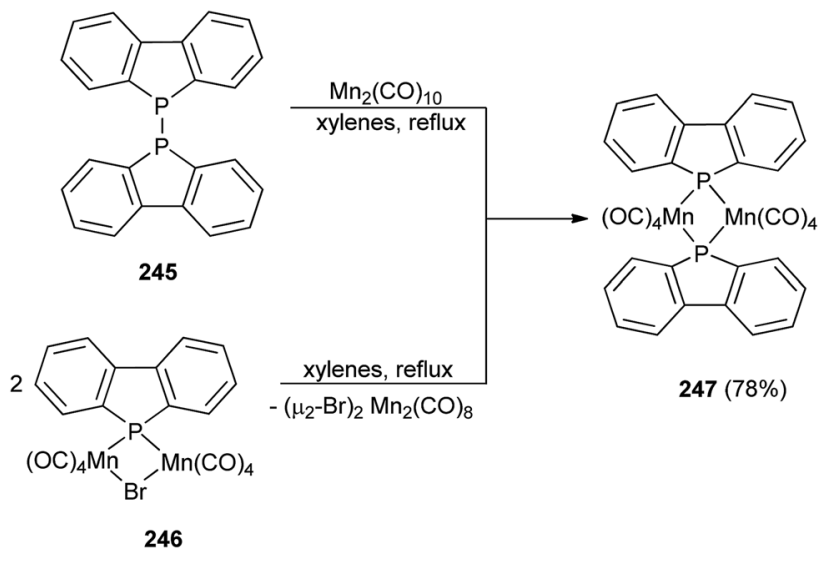

Scheme 62

a subsequent acidification with acetic acid and reaction with tetrakis(dimethylamido)titanium $\left(\mathrm{Ti}\left(\mathrm{NMe}_{2}\right)_{4}\right)$ in $41 \%$ yield (Scheme 63). ${ }^{53,61}$

Jugé and Gouygou et al. obtained the dibenzophosphole Rhcomplex 252 by reaction of chloro-(1,5-cyclooctadiene)rho$\operatorname{dium}(\mathrm{I})$ with the dibenzophosphole 251 in dichloromethane, in the presence of silver tetrafluoroborate, in $86 \%$ yield (Scheme 64). ${ }^{62}$

The dibenzophosphole Pd-complex 254 was formed in the reaction of the dibenzophosphole 253, obtained from 211 and chlorodibenzotropilydene (toluene, reflux), with dichloro-(1,5cyclooctadiene)palladium(II) $\left(\mathrm{Pd}(\operatorname{cod}) \mathrm{Cl}_{2}\right)$ in dichloromethane, at room temperature, in 95\% yield (Scheme 65). ${ }^{63}$

López-Calahorra et al. synthesized the Pd-complexes 255257 from dibenzophospholes 217-219 and an optically active dimeric cyclopalladium compound. The reaction of the dimer with the dibenzophosphole 217 gave the complex 255. In the cases of 256 and 257, a mixture of diastereomers was separated by column chromatography followed by decoordination of the dibenzophospholes by the reaction of the pure diastereomers with 1,2-bis(diphenylphosphino)ethane and oxidation of the enantiomerically pure dibenzophospholes to their oxides using $\mathrm{H}_{2} \mathrm{O}_{2}$ (Scheme 66). ${ }^{58}$

3.1.6. P-Alkylation. The dibenzophosphole sodium salt $\mathbf{1 3}$ obtained from 2,2'-difluoro-5, $5^{\prime}$-disulfonato-1,1'-biphenyl 12 by treatment with $\mathrm{NaPH}_{2}$ in liquid ammonia, was utilised as a reactive intermediate in reactions with electrophiles, such as benzyl chlorides and tosylates. Thus, coupling of the sodium salt 13 with 2,2'-bis(chloromethyl)-1,1'-biphenyl in DMF afforded the bidentate ligand 258 containing sulfonated dibenzophospholes moieties in $94 \%$ yield. Bis-[2,2'-bis(sulfonato)-5Hdibenzophospholyl]-2,3-O-isopropylidene-D-threitoltetrasodium salt 259 was obtained by reaction of the sodium salt 13 with 1,4di-O- $p$-toluenesulfonyl-2,3-O-isopropylidene-D-threitol in 1,4dioxane or THF in $20 \%$ yield (Scheme 67$){ }^{26}$

The reaction of the lithium derivative 261 with (chloromethyl)phosphine borane $\mathbf{2 6 0}$, in the presence of $5 \%$

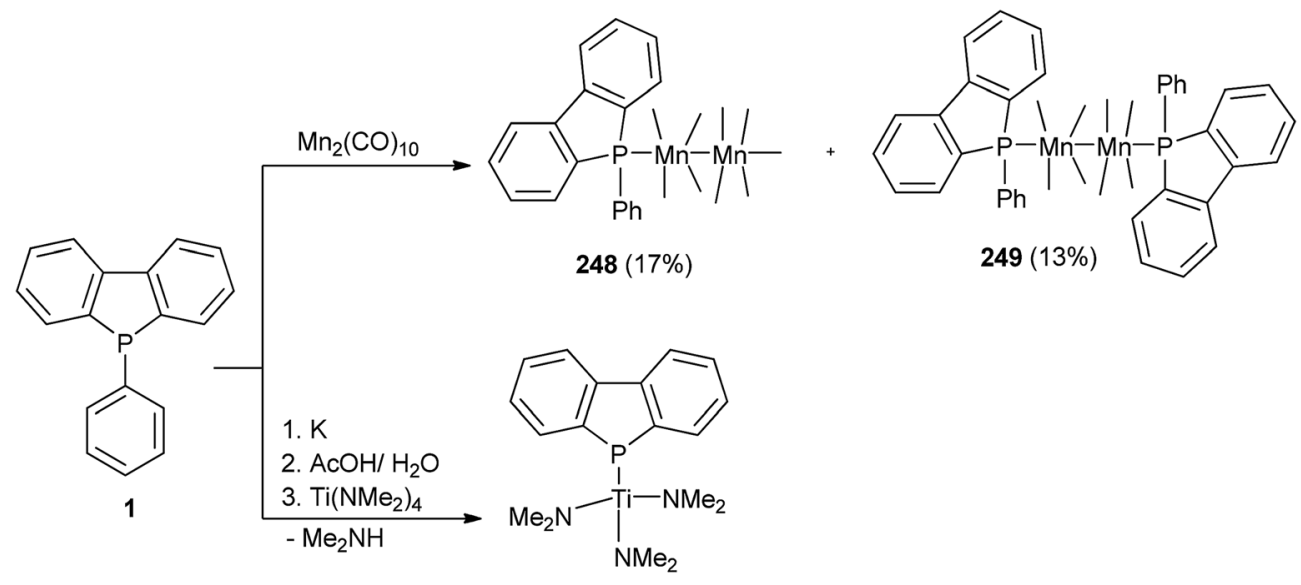




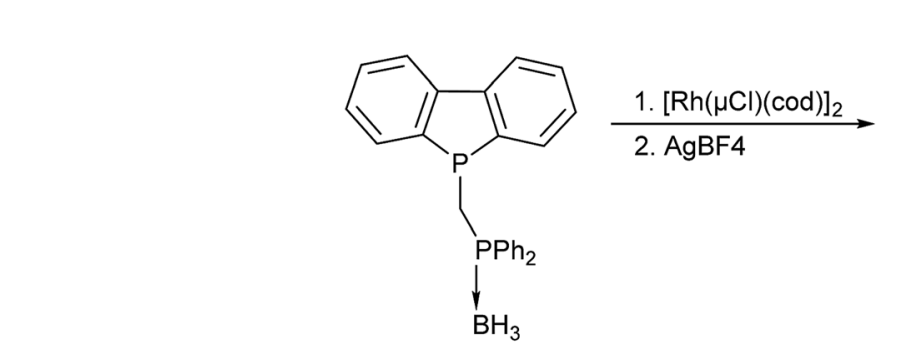

251

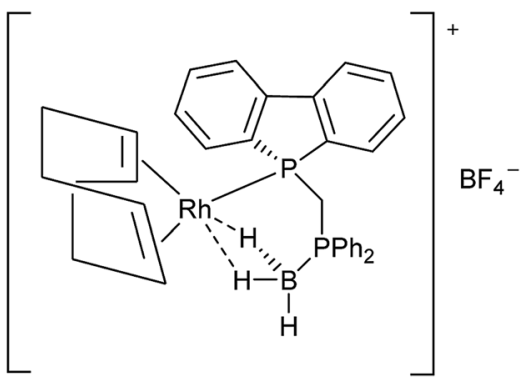

$252(86 \%)$

Scheme 64

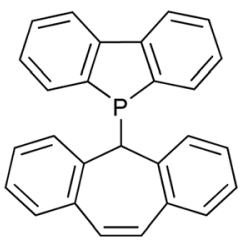

253

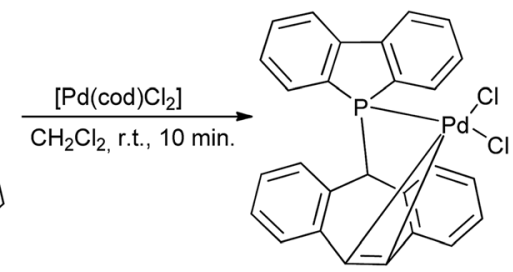

$254(95 \%)$
Scheme 65

$\mathrm{Pd}(\mathrm{OAc})_{2} / \mathrm{dppf}$ gave 5-diphenylphosphinylmethylene dibenzophosphole borane $\mathbf{2 5 1}$ in $\mathbf{5 2 \%}$ isolated yield. Direct alkylation of 261 without the presence of the Pd catalyst gave 251 in $<10 \%$ yield (Scheme 68). ${ }^{62}$

3.1.7. P-Arylation. P-Arylation of unsubstituted dibenzophospholes was realised by a two-step reaction starting with $\mathrm{P}-\mathrm{H}$ deprotonation of the tungsten complex $\mathbf{1 8 0}$ followed by reaction with $\mathrm{BrCN}$ and then with $\mathrm{PhLi}$ afforded the tungsten $\mathrm{P}$ arylated dibenzophosphole 262 in $26 \%$ yield. The final step involved removal of the $\mathrm{W}(\mathrm{CO})_{5}$ tungsten moiety by heating with 1,1'-(1,2-ethanediyl)bis(1,1-diphenyl)phosphine in refluxing xylene to give 5-phenyldibenzophosphole 1 in $25 \%$ yield (Scheme 69). ${ }^{47}$
3.1.8. P-Quaternisation. The phosphorus atom in the dibenzophosphapentaphene 192 could be quaternised via the corresponding dibenzophosphapentaphene sulfide by reaction with methyl triflate to give 191, or directly with MeOTf to give 263 in $45 \%$ yield (Scheme 70$){ }^{49}$

\subsection{Functionalisation of benzene units}

The second method of functionalization of dibenzophospholes is introduction of substituents onto one or two benzene rings including functional group interconversions. An example of such a process is shown in Scheme 71. Electrophilic bromination of 5-ethyl-5 $\mathrm{H}$-dibenzophosphole 5-oxide 264 with bromine in acetic acid at $45{ }^{\circ} \mathrm{C}$ gave the 5-ethyl-3-bromo-5 $\mathrm{H}$-dibenzophosphole 5-oxide 265 in $53 \%$ yield followed by electrophilic nitration of the second benzene ring and reduction of the $\mathrm{NO}_{2}$ to $\mathrm{NH}_{2}$ group with iron under acidic conditions. Further diazotization with sodium nitrite in a cooled mixture of sulfuric acid and water led to the corresponding diazonium salt which was decomposed by addition of copper(I) oxide in the presence of copper(II) nitrate. Subsequent reaction of the phenolic $\mathrm{OH}$ group so formed with $(S)$-2-methyl tosylate in the presence of potassium carbonate gave the chiral product 267 in $95 \%$ yield. Conversion of the bromine atom to a carboxylic group was

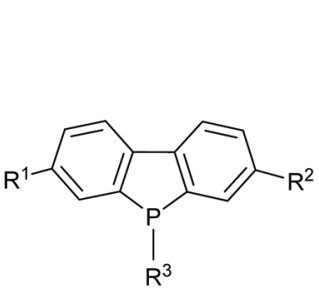

217-219

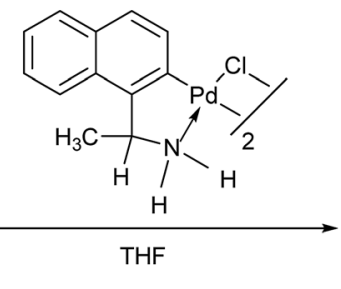

$255 R^{1}=H, R^{2}=H, R^{3}=\operatorname{Me}(83 \%)$ $256 \mathrm{R}^{1}=\mathrm{CN}, \mathrm{R}^{2}=\mathrm{H}, \mathrm{R}^{3}=\mathrm{Me}(85 \%)$

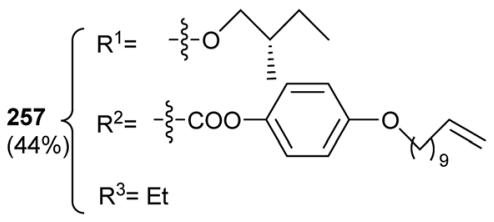




.

RSC Advances<smiles></smiles><smiles>[GeH2]=[TeH4]</smiles><smiles>CS(=O)(=O)c1ccc2c(c1)c1cc(S(C)(=O)=O)ccc1p2Cc1ccccc1-c1ccccc1Cp1c2ccc(S(C)(=O)=O)cc2c2cc(S(C)(=O)=O)ccc21</smiles>

$258(94 \%)$

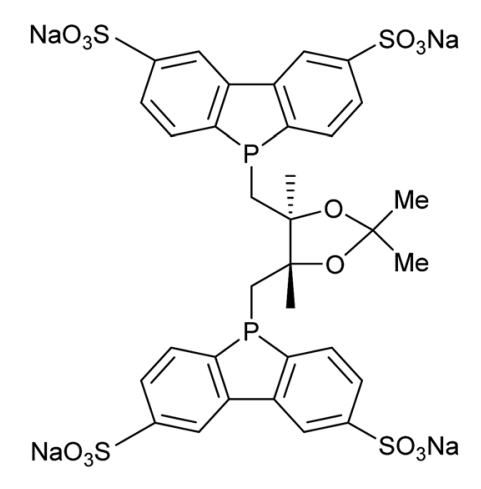

$259(20 \%)$

Scheme 67

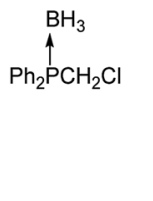

260

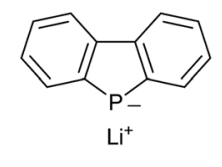

$\stackrel{5 \% \operatorname{Pd}(\mathrm{OAc})_{2} / \mathrm{dppf}}{\longrightarrow}$

261

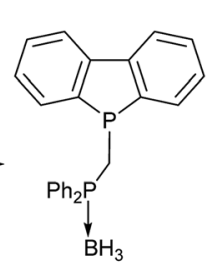

$251(52 \%)$
Scheme 68

realised by a cross-coupling reaction with potassium cyanide in the presence of palladium(II) acetate followed by alkaline hydrolysis with $\mathrm{Ca}(\mathrm{OH})_{2}$ to give the acid 268 in $80 \%$ yield. Finally, the latter was esterified with 4-(undec-10-enoxy)phenol to give 269 also in $80 \%$ yield (Scheme 71 ). ${ }^{64}$

Dibenzophosphole ring elongation was realised via the cross-coupling reaction of the 3-bromo dibenzophosphole $\mathbf{2 7 0}$ with (2-benzylaminophenyl)pinacolatoboron to give the biaryl derivative $\mathbf{2 7 1}$, followed by cyclisation of the latter to afford a fused polyaromatic compound 272 in $71 \%$ yield (Scheme 72 ). ${ }^{37}$

3,7-Bis(4-diphenylamino)phenyl substituted dibenzophosphole 273 was obtained via the double Suzuki-Miyaura crosscoupling reaction of $\mathbf{4 6}$ with 4-(diphenylamino)phenylboronic acid in the presence of $\mathrm{Pd}\left(\mathrm{PPh}_{3}\right)_{4}$ in $80 \%$ yield (Scheme 73$) .{ }^{27}$

Voituriez and Marinetti et al. functionalised dibenzophosphole oxides by incorporating them into larger [6]- and [8]helicenes. The triflates of the dibenzophosphole oxides $\mathbf{4 3}$, $\left(S_{p}\right) 274$ and $\left(R_{p}\right) 275$ were submitted to Suzuki cross-coupling reactions with a benzophenanthrene-substituted olefinic boronate. The coupling reactions were performed in the presence of $\left[\mathrm{PdCl}_{2}\left(\mathrm{SPhos}_{2}\right]\right.$ (SPhos = 2-dicyclohexyl-phosphino-2',6'-dimethoxybiphenyl) as the catalyst under standard conditions. The corresponding olefinic derivatives $276,\left(S_{p}\right) 277$ and $\left(R_{p}\right) 278$ were obtained in high yields $(78-87 \%)$. The photochemical cyclisation of compound $276(\mathrm{R}=\mathrm{Ph})$ in cyclohexane/THF led to

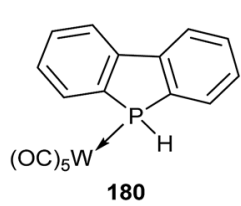

180

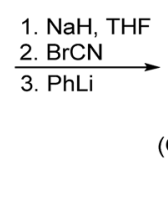<smiles>NC(=O)c1ccccc1[PH]1([N+](=O)[O-])c2ccccc2-c2ccccc21</smiles>

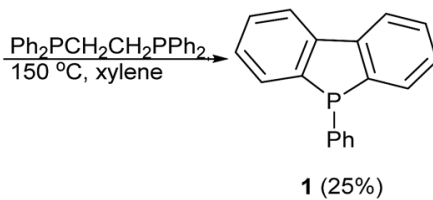

Scheme 69 


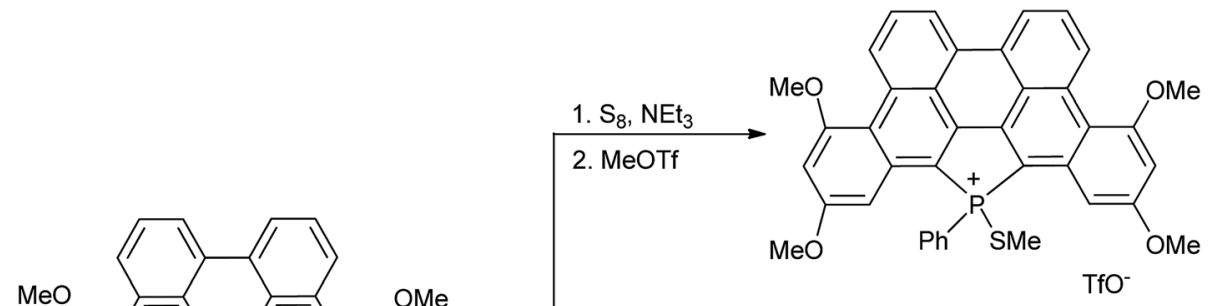

191

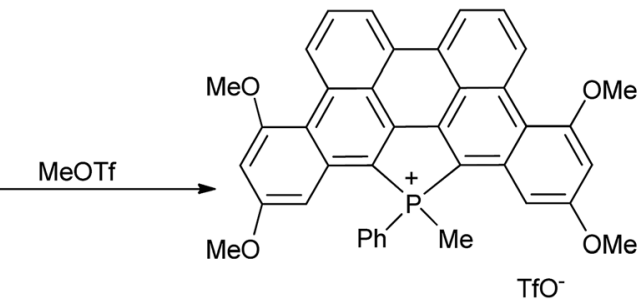

$263(45 \%)$

Scheme 70

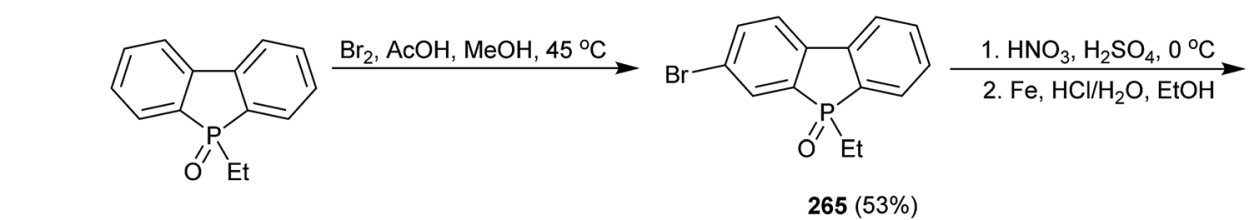

264

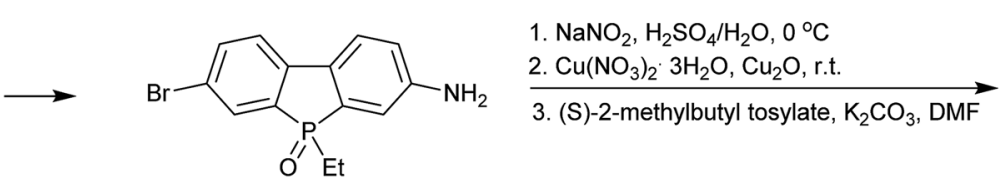

$266(82 \%)$

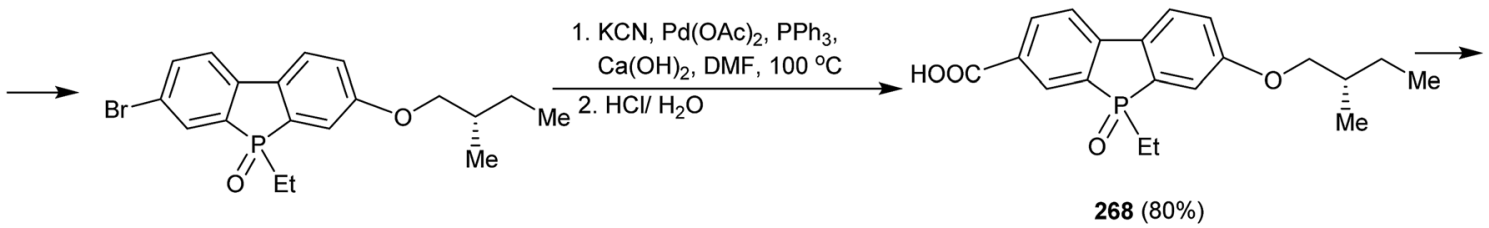

$267(95 \%)$

1. $N, N^{\prime}$-Dicyclohexylcarbodiimide 4-dimethylaminopyridine $\mathrm{CH}_{2} \mathrm{Cl}_{2}$, r.t 2. 4-(undec-10-en-1-oxy)phenol], r.t<smiles>C=C[14CH2]Oc1ccc(OC(=O)c2ccc3c(c2)P(=O)(CC)c2cc(OC[C@H](C)CC)ccc2-3)cc1</smiles>

Scheme 71

the formation of a mixture of [6]- and [8]-helicenes 279 and 282, in a $7: 3$ ratio, in $31 \%$ and $20 \%$ yields after purification, respectively. The cyclisation of 277 afforded a mixture of isomeric 280 from which $\left(\mathrm{S}_{\mathrm{p}}, \mathrm{P}\right) \mathbf{2 8 0}$ was isolated in $40 \%$ yield. The oxidative photocyclisation of 278 led to a mixture of $\left(R_{p}, M\right)$ 281 and $\left(\mathrm{R}_{\mathrm{p}}, \mathrm{P}\right) \mathbf{2 8 3}$, in a $50: 42$ ratio. Each isomer was isolated in $30 \%$ yield (Scheme 74$).{ }^{33}$

\section{Optoelectronic properties of dibenzophosphole derivatives}

Dibenzophospholes and their derivatives belong to a group of polycyclic fused heteroaromatic compounds with spatially developed systems of $\pi$-type bonds, which play an important role in modern, lightweight and low-cost electronic elements 
<smiles>O=P1(c2ccccc2)c2ccccc2-c2ccc(Br)cc21</smiles>

270

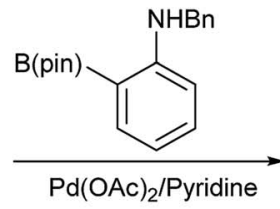

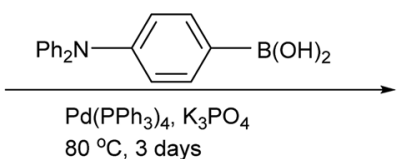

46<smiles>CCCCC1(c2ccccc2)c2ccc(-c3ccc(N(c4ccccc4)c4ccccc4)cc3)cc2P1(=O)c1ccccc1</smiles>

$273(80 \%)$

Scheme 73

such as photovoltaic cells (PV), organic light emitting diodes (OLEDs) and field effect transistors (FETs). The functionalisation of one or both benzene rings and/or derivatization of the
$\mathrm{P}^{\mathrm{III}}$ atom (as $\mathrm{P}^{+}$or $\mathrm{P}=\mathrm{X}$, where $\mathrm{X}=\mathrm{N}, \mathrm{O}, \mathrm{P}, \mathrm{S}, \mathrm{Se}$ ) necessarily results in modification of physicochemical properties of the dibenzophospholes such as: solubility, HOMO/LUMO energy levels, ionization potentials, energy gap, wavelength as well as intensity of absorption and emission. By careful selection of such modifications, new optoelectronic materials with improved properties can be produced.

\subsection{Non-fused dibenzophospholes}

4.1.1. Simple dibenzophospholes. Several promising compounds for optoelectronics have been reported and include dibenzophospholes 1, 66, 228, 284-291 containing various substituents on the phosphorus atom. These have potential applications in sundry optoelectronic elements including photovoltaic cells, organic light-emitting diodes (OLEDs), bioand chemical sensors and nonlinear optical devices NLOs (Scheme 75). ${ }^{12,65}$<smiles>[R]P1(=O)C2=CC=C(Oc3ccccc32)c2ccccc21</smiles>

$43 \mathrm{R}=\mathrm{Ph}$

$274 \mathrm{R}=(-)-$ Ment, $\left(\mathrm{S}_{\mathrm{p}}\right)$ $275 R=(-)-$ Ment, $\left(R_{p}\right)$
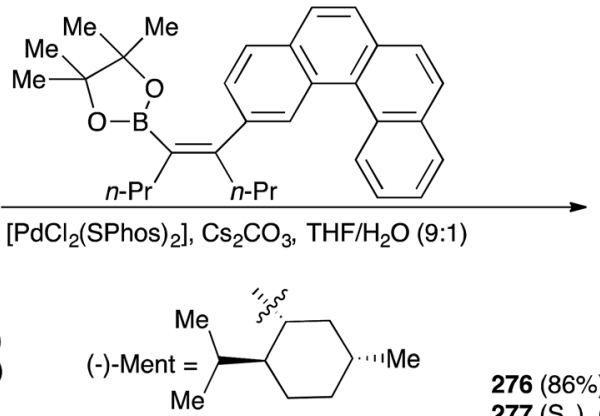<smiles>CCCC(=C(CC)c1ccc2ccc3ccc4ccccc4c3c2c1)c1ccc2c(c1)-c1ccccc1P2(=O)P</smiles>

$276(86 \%) \rightarrow\left(R_{p}, M\right) 279+\left(R_{p}, P\right) 282$

$277\left(S_{p}\right),(78 \%) \rightarrow\left(S_{p}, P\right) 280$

$278\left(R_{p}\right),(87 \%) \rightarrow\left(R_{p}, M\right) 281+\left(R_{p}, P\right) 283$

$\frac{\mathrm{h} v}{\mathrm{I}_{2} \text {, propylene oxide, cyclohexane/THF }}$<smiles></smiles><smiles>[R]P1(=O)c2ccccc2-c2c1ccc1c(C(C)C)c(CCC)c3ccc4ccc5ccccc5c4c3c21</smiles>

$279\left(R_{p}, M\right),(31 \%)$

$280\left(S_{p}, P\right),(40 \%)$

$281\left(R_{p}, M\right),(30 \%)$

$282\left(R_{p}, P\right),(20 \%)$

$283\left(R_{p}, P\right),(30 \%)$ 
<smiles>c1ccc(-p2c3ccccc3c3ccccc32)cc1</smiles>

1<smiles>S=P1(c2ccccc2)c2ccccc2-c2ccccc21</smiles>

285<smiles>C[PH]1(C)c2ccccc2-c2ccccc21</smiles>

289<smiles>O=P1(c2ccccc2)c2ccccc2-c2ccccc21</smiles>

66<smiles>CP1(=[Se])c2ccccc2-c2ccccc21</smiles>

286<smiles>C[P+]1(c2ccccc2)c2ccccc2-c2ccccc21</smiles>

290<smiles>[S-]=P1(c2ccccc2)c2ccccc2-c2ccccc21</smiles>

228<smiles>CP1(=O)c2ccccc2-c2ccccc21</smiles>

287<smiles>Cl[Ge](Cl)(c1ccccc1)p1c2ccccc2c2ccccc21</smiles>

291<smiles></smiles>

284

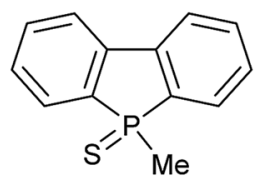

288

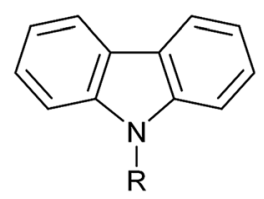

$\mathrm{R}=\mathrm{Me}, \mathrm{C}_{6} \mathrm{H}_{5}$

292

Scheme 75

Chen and Huang et al. presented a theoretical study on the optical and electronic properties of dibenzophospholes 1, 66, 228, 284-290, involving calculations of the highest occupied molecular orbitals (HOMO), the lowest unoccupied molecular orbitals (LUMO), triplet energies $\left({ }^{3} E_{\mathrm{g}}\right)$, energy gaps $\left(E_{\mathrm{g}}\right)$ as well as other calculations leading to: ionization potentials (IPs), electron affinities (EAs), including calculations of the reorganization energies $(\lambda)$ and singlet exciton generation fractions $\left(\chi_{\mathrm{s}}\right)$, together with radiative lifetimes and emission spectra. Optoelectronic properties of these compounds were compared with carbazoles 292, which are currently one of the most commonly used chemical units in optoelectronic devices. The dibenzophospholes 1, 66, 228, 284-290 had lower levels of the HOMO and LUMO than the carbazoles 292. However, the compounds 1 and $\mathbf{2 8 4}$ had a wider range of energy gaps, relative to carbazole analogues due to the nonplanar molecular structures and stronger electron-donating ability of the phosphorus atom. Chemical modifications of the $\mathrm{P}^{\mathrm{III}}$ atom through oxidation, sulfurization and selenylation led to a gradual increase of the HOMO levels in the following order: $-6.26 \mathrm{eV}(287)<$ $-5.83 \mathrm{eV}(\mathbf{2 8 8})<-5.43 \mathrm{eV}(\mathbf{2 8 6}),-6.23 \mathrm{eV}(\mathbf{6 6})<-5.86 \mathrm{eV}(\mathbf{2 8 5})<$ $-5.51 \mathrm{eV}$ (228), while the LUMO decreased to around $-1.55 \mathrm{eV}$, which was far below the LUMO levels of 1 and 284. This correlation showed that introduction of electron-withdrawing substituents (O, S, Se atoms) enhanced the injection and electron-transport abilities of the dibenzophospholes 66, 228, 285-286 and 288. For the ionized compounds 289 and 290
$\left(\mathrm{P}^{+} \mathrm{Me}\right.$ and $\left.\mathrm{P}^{+} \mathrm{Ph}\right)$, the positively charged phosphorus atom reduced the hole injection, but enhanced the electron-accepting ability of these compounds. The energy gap decreased in the following order: $4.95(284)>4.94(1)>4.80(287)>4.75(66)>$ $4.52(290)>4.51(289)>4.33(285)>4.28(288)>3.97(228)>$ $3.88 \mathrm{eV}$ (286). The triplet energies $\left({ }^{3} E_{g}\right)$ of the dibenzophospholes 1, 66, 228, 284-288 showed their potential applications as host materials, as well as revealed that dibenzophospholes 1 and 284 could be promising building blocks for the host materials. For the dibenzophospholes 1, 66, 284 and 287, the calculated singlet and triplet exciton-formation cross section $\sigma_{\mathrm{s}} /$ $\sigma_{\mathrm{t}}$ and corresponding singlet exciton generation fractions $\left(\chi_{\mathrm{s}}\right)$ suggested their potential as highly efficient fluorescent-lightemitting materials. The chemical modification of the $\mathrm{P}^{\mathrm{III}}$ atom with $\mathrm{S}$ and Se atoms, in the dibenzophospholes 228, 285, 286 and 288 caused a slight decrease of the $\chi_{\mathrm{s}}$ values in the range of 15-20\%. The calculated values of the ionization potentials (IPs) and electronic affinities (EAs) showed that dibenzophospholes could be used simultaneously as electron-transport and holetransport materials according to different substitutions on the $\mathrm{P}$ atom. The abilities to create holes and to accept electrons were improved by the introduction of strong electron-withdrawing substituents or replacement of P-methyl for P-phenyl. For the dibenzophospholes 66 and 287, smaller hole transport reorganization energies $\left(\lambda_{\text {hole }}\right)$ were calculated than their electron transport reorganization energies $\left(\lambda_{\text {electron}}\right)$, which means faster hole transport than electron transport in these compounds. The 
opposite correlation occurred in the dibenzophospholes $\mathbf{2 2 8}$ and 286 for which values of $\lambda_{\text {hole }}$ were bigger than their values of $\lambda_{\text {electron }}$ and indicated a slower hole transfer, than the electron transfer. The time-dependent density functional theory (TDDFT) calculations showed electron transitions for dibenzophospholes 1, 66, 284-285, 287-288 as well as their effect on the emission spectra in both vacuum and solvent (THF) as shown in Fig. ${ }^{65}$

Based on the theoretical emission spectra, the dibenzophospholes 1, 66, 284-285, 287-288 may constitute deep blue light emitting materials in the range of $\lambda_{\mathrm{em}}=327-419 \mathrm{~nm}$. The Stokes shifts of 1 and 284 were calculated to about $45 \mathrm{~nm}$, and the shifts of their derivatives 66, 285, 287 and 288 were all around $65 \mathrm{~nm}$ relative to carbazoles 292, the Stokes shifts of which were within $10 \mathrm{~nm}$. The calculated emission spectra of dibenzophospholes 66, 285, 287 and 288 in vacuum, were red shifted and thio-modified dibenzophospholes 285 and 288 showed a small intramolecular charge-transfer emission at $\lambda=$ $415 \mathrm{~nm}$. The solvent effects led to larger Stokes shifts of dibenzophospholes 284, 287 and 288 in comparison to the carbazole analogues 292. For the compounds 284 and 287, THF stabilized their excited states, causing small red shifts (4-10 $\mathrm{nm}$ ) of the emission spectra in comparison with those in vacuum. The opposite correlation was observed in the dibenzophosphole 288, where the solvent effects stabilized the ground state and induced the blue shift of the emission spectra.
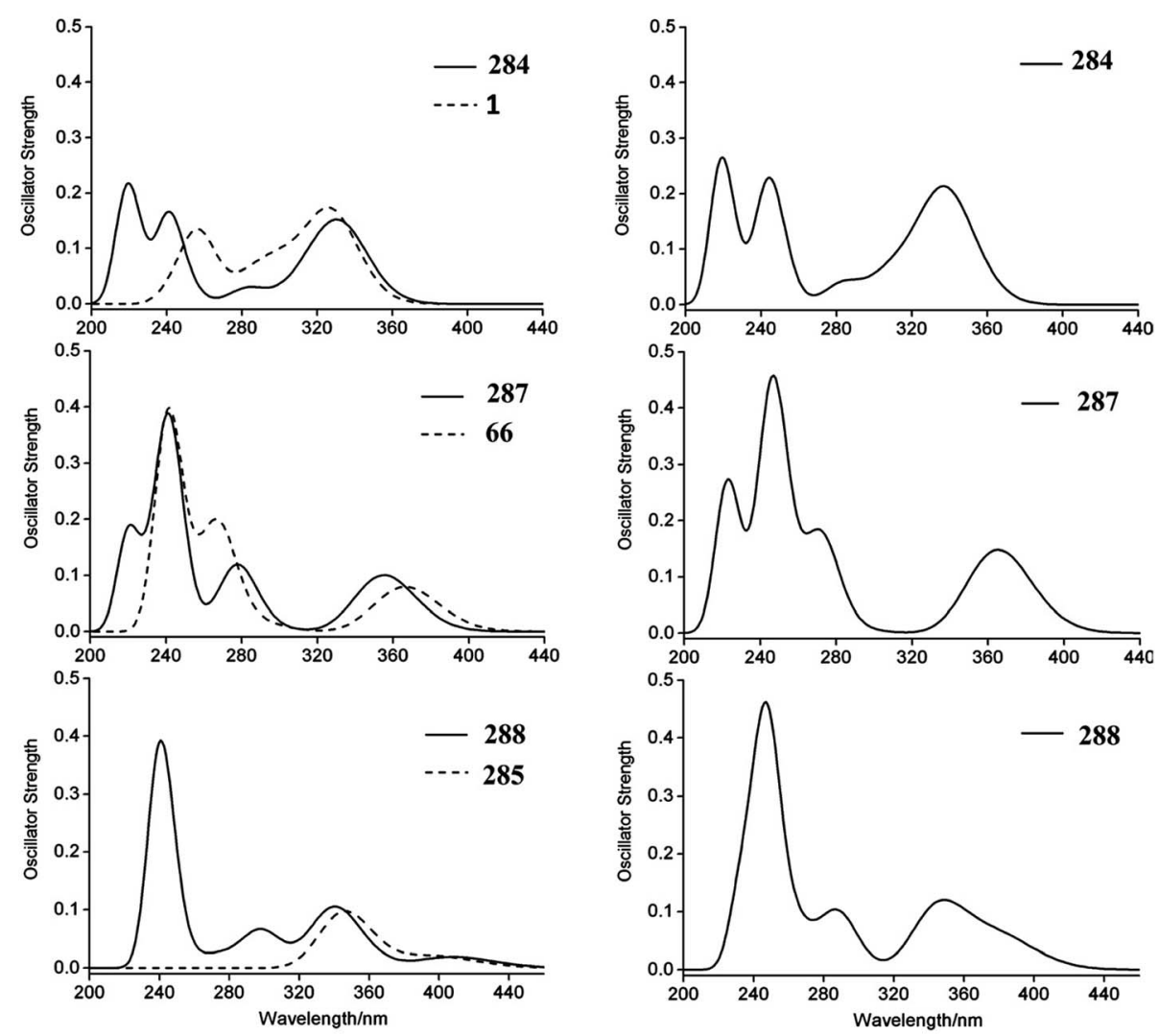

Fig. 2 The simulated emission spectra of dibenzophospholes 1, 66, 284-285, 287-288, in vacuum (left) and in solution (THF, right) ${ }^{65}$ (reprinted with permission from the American Chemical Society).

Table 1 Wavelengths of maximum absorption $\left(\lambda_{\text {abs }}\right)$, half-wave potential $\left(E_{\mathrm{p} 1 / 2}\right)$, wavelengths of maximum emission $\left(\lambda_{\text {em }}\right)$, quantum yields of photoluminescence $\left(\phi_{\mathrm{PL}}\right)$, decomposition temperature $\left(T_{\mathrm{d}}\right)$ and molar absorption coefficient $(\varepsilon)$ of the compounds 66,285 and 291 , in $\mathrm{CH}_{2} \mathrm{Cl}_{2}$

\begin{tabular}{|c|c|c|c|c|c|c|}
\hline \multirow[b]{2}{*}{ Compound } & \multicolumn{2}{|c|}{ UV-Vis absorption } & \multicolumn{2}{|c|}{ Photoluminescence (PL) } & \multirow{2}{*}{$\begin{array}{l}\begin{array}{l}\text { Electrochemical } \\
\text { properties }\end{array} \\
E_{\mathrm{p} 1 / 2}[\mathrm{eV}]\end{array}$} & \multirow{2}{*}{$\frac{\text { Thermal properties }}{T_{\mathrm{d}}{ }^{a}\left[{ }^{\circ} \mathrm{C}\right]}$} \\
\hline & $\lambda_{\mathrm{abs}}[\mathrm{nm}]$ & $\log \varepsilon$ & $\lambda_{\mathrm{em}}[\mathrm{nm}]$ & $\phi_{\mathrm{PL}}$ & & \\
\hline 66 & 332 & 2.9 & 366 & 0.042 & -1.93 & 213 \\
\hline 285 & 330 & 2.9 & 366 & 0.002 & -1.92 & 220 \\
\hline 291 & 330 & 3.0 & 366 & 0.134 & -1.80 & 220 \\
\hline
\end{tabular}

${ }^{a}$ TGA, $10 \%$ weight loss. 
The radiative lifetimes were calculated by using Einstein transition probabilities for the compounds 1, 66, 284-285, 287 and 288. The dibenzophospholes 285 and 288 showed longer lifetimes than commonly used carbazoles 292, whereas the dibenzophospholes 1, 66, 284 and 287 had similar radiative lifetimes in comparison to the commonly used carbazoles 292 .

In addition to this theoretical study, further investigations with thermogravimetric analysis (TGA) showed that the derivatives 66, 285 and 291 possess good thermal stabilities. This is important for the fabrication of OLEDs, because low-molecular weight species are often deposited as thin films by vacuum evaporation. The derivatives 66, 285 and 291 emitted in the UV region and were photoluminescent. The Stokes shifts of these compounds were relatively small (about 32-36 nm), which suggested a minimal rearrangement of molecules during photoexcitation. The quantum yields were dependent on the nature of the groups attached to the phosphorus atom. Selected photophysical, electrochemical and thermal data for these compounds are presented in Table $1 .^{12}$

In 2011 the group of Anzenbacher $\mathrm{Jr}$ et al. ${ }^{66}$ investigated solid-state interactions, fluorescence and phosphorescence properties of dibenzophospholes 66, 228 and 285 as single crystals and the mixed crystals of 228 and 285 acquired in $\mathrm{CH}_{2} \mathrm{Cl}_{2} / \mathrm{MeOH}$ glass at $77 \mathrm{~K}$. Moreover, an X-ray diffraction analysis was carried out, which indicated that the mixed crystal of 228 and 285 showed a larger number of intermolecular interactions such as $\pi-\pi$ and $\mathrm{Se}-\mathrm{H}$, than each of them in the single crystals. The fluorescence maxima of the dibenzophospholes 66, 228, 285 in a glass corresponded to the wavelength at $\lambda=363-364 \mathrm{~nm}$. However, in the compounds 228 and 285 the fluorescence was strongly suppressed due to the higher spin-orbit coupling of selenium 228 and sulfur 285 .

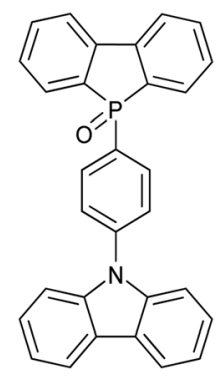

212<smiles>[R]c1ccc2c(c1)-c1cc([R])ccc1P2(C)(C)c1ccccc1</smiles>

39<smiles>[R]c1ccc(P23(c4ccc([R])cc4-c4cc([R])ccc42)c2ccc([R])cc2-c2ccc([R])cc23)cc1</smiles>

167
$\mathrm{R}=4-\left(\mathrm{Et}_{2} \mathrm{~N}\right) \mathrm{C}_{6} \mathrm{H}_{4} \mathrm{CH}=\mathrm{CH}, \mathrm{Ar}=\mathrm{C}_{6} \mathrm{~F}_{5}$<smiles>[R]c1ccc2c(c1)-c1cc([R])ccc1[Si]2(C)C</smiles>

293<smiles>[R]c1ccc2c(c1)-c1cc([R])ccc1[Si]21c2ccc([R])cc2-c2cc([R])ccc21</smiles>

294

Scheme 76

Scheme 77

Table 2 Selected properties of the compound $212^{a}$

\begin{tabular}{|c|c|c|c|c|c|c|c|c|}
\hline$\lambda_{\mathrm{abs}}[\mathrm{nm}]$ & $\lambda_{\mathrm{Ph}}[\mathrm{nm}]$ & $\lambda_{\mathrm{PL}}[\mathrm{nm}]$ & $E_{1 / 2}^{\mathrm{ox}}[\mathrm{V}]$ & $E_{1 / 2}^{\mathrm{red}}[\mathrm{V}]$ & HOMO $[\mathrm{eV}]$ & LUMO $[\mathrm{eV}]$ & $E_{\mathrm{s}}[\mathrm{eV}]$ & $\begin{array}{l}\text { Thermal properties } \\
T_{\mathrm{d}}\left[{ }^{\circ} \mathrm{C}\right]\end{array}$ \\
\hline
\end{tabular}

${ }^{a}$ The oxidation and reduction experiments were conducted in $\mathrm{CH}_{2} \mathrm{Cl}_{2}$ and THF solution, $E_{1 / 2}(\mathrm{~V})$ refers to $\left[\left(E_{\mathrm{pa}}+E_{\mathrm{pc}}\right) / 2\right]$, where $E_{\mathrm{pa}}$ and $E_{\mathrm{pc}}$ were the anodic and cathodic peak potentials referenced to the $\mathrm{Fc}^{+} / \mathrm{Fc}$ couple, $E_{\mathrm{s}}=|\mathrm{HOMO}-\mathrm{LUMO}|$ from the redox data. 
electron injection and transport without lowering of the triplet energy gap (Scheme 76). ${ }^{55}$

The selected electrochemical, thermal and photophysical characterisation of the dibenzophosphole 212 is presented in Table 2.

Additionally, thermogravimetric analysis (TGA) of the dibenzophosphole 212, which decomposed at $365{ }^{\circ} \mathrm{C}$, showed that this compound is capable of forming stable films upon thermal evaporation.

Other potential optoelectronic materials are dibenzophospholes 39 and 167. These compounds exhibited strong acceptor

Table 3 Selected optical properties of the dibenzophospholes 39 and 167 and their silicon analogues, in $\mathrm{CH}_{2} \mathrm{Cl}_{2}$ (ref. 32) ${ }^{a}$

\begin{tabular}{|c|c|c|c|c|c|}
\hline \multirow[b]{2}{*}{ Compound } & \multicolumn{2}{|c|}{$\begin{array}{l}\text { UV-Vis } \\
\text { absorption }\end{array}$} & \multicolumn{2}{|c|}{ Fluorescence } & \multirow{2}{*}{$\begin{array}{l}\begin{array}{l}\text { Two photon } \\
\text { absorption (TPA) }\end{array} \\
\lambda_{\max }^{2}[\mathrm{~nm}]\end{array}$} \\
\hline & $\begin{array}{l}\lambda_{\max } \\
{[\mathrm{nm}]}\end{array}$ & $\begin{array}{l}\varepsilon / 10^{5} \mathrm{M}^{-1} \\
{\left[\mathrm{~cm}^{-1}\right]}\end{array}$ & $\lambda_{\mathrm{em}}[\mathrm{nm}]$ & $\phi_{\mathrm{F}}$ & \\
\hline 39 & 464 & 0.57 & 647 & 0.52 & 932 \\
\hline 167 & 496 & 1.03 & 715 & 0.04 & 932 \\
\hline 293 & 376 & 0.76 & 464 & 0.16 & 752 \\
\hline 294 & 395 & 2.37 & 492 & 0.28 & 775 \\
\hline
\end{tabular}

${ }^{a} \sigma^{(2)}$ divided by the molar mass (MW). properties and showed enhanced two-photon absorptions at $\lambda=$ $932 \mathrm{~nm}$, therefore these compounds should be useful as longwavelength emissive materials (Scheme 77). ${ }^{32}$

The absorption and emission maxima of the dibenzophospholes 39 and 167 showed bathochromic shifts compared with their silicon analogues 293 and 294, due to the strong acceptor properties of the phosphonium cores. The effect of solvents on optical properties in toluene, acetone and dichloromethane was also investigated for these compounds. The longest absorption wavelengths of the dibenzophospholes 39 and 167 were at $\lambda=460$ and $495 \mathrm{~nm}$, respectively in toluene and were almost the same as those in $\mathrm{CH}_{2} \mathrm{Cl}_{2}$. However, in acetone, the dibenzophospholes 39 and 167 exhibited blueshifted absorption maxima at $\lambda=430$ and $467 \mathrm{~nm}$, respectively. The dibenzophosphole 39 exhibited higher fluorescence quantum yield, than its spirocyclic analog 167, which emitted much weaker fluorescence. The opposite trend was observed for the silicon compounds, in which spirocyclic framework of 293 improved the quantum yield. Another important difference was reported for fluorescence properties of dibenzophospholes and their silicon analogues. The emission bands of silicon derivatives 293 and 294 exhibited maxima at $\lambda=464$ and $492 \mathrm{~nm}$, while dibenzophospholes 39 and 167 were bathochromically shifted to $\lambda=647$ and $715 \mathrm{~nm}$, respectively, in $\mathrm{CH}_{2} \mathrm{Cl}_{2}$. The twophoton absorption (TPA) showed maxima for the silicon<smiles>COP1(=O)c2cc3c4c(-c5ccccc5)c2-c2c(c(cc(-c5ccccc5)c21)COC4)COC3</smiles>

156<smiles>O=P1(c2ccccc2)c2ccc3c4c2-c2c(c(cc(-c5ccccc5)c21)OCc1cccc(-c2ccccc2)c1-4)OC3</smiles>

159<smiles>Cc1c(/C=C/c2ccccc2)c2c(c3c1P(=O)(c1ccccc1)c1c(C)c(/C=C/c4ccccc4)c4c(c1-3)-c1ccccc1OC4)-c1ccccc1OC2</smiles>

164<smiles>COP1(=O)c2cc(-c3ccccc3)cc3c2-c2c(-c4ccccc4OCO)c(cc(-c4ccccc4)c21)OC3</smiles>

157<smiles>COc1ccc2c3c1-c1c(c(C)cc4c1P(=O)(OC)c1c(cccc1-c1ccccc1-3)OC4)CO2</smiles>

160<smiles>COP1(=O)c2ccccc2-c2c3c(cc(-c4ccccc4)c21)COc1cc(COCc2ccccc2)cc(c1)C3</smiles>

165<smiles>CP1(=O)c2cc3c(-c4ccccc4)c(c2-c2c4c(cc(-c5ccccc5)c21)OCc1ccccc1-4)C=CC=C3</smiles>

158<smiles>COc1cccc2c1-c1c(c(C)c(C)c3c1-c1c4c(C)c(-c5ccccc5)c(c1-c1ccccc1-4)P3(=O)OC)OC2</smiles>

161<smiles>O=P1(c2ccccc2)c2cc3c4c(-c5ccccc5)c2-c2c(c(cc(-c5ccccc5)c21)-c1ccccc1OC4)COc1ccccc1-3</smiles>

166

Scheme 78 
analogues 293 and 294 at $\lambda=752$ and $775 \mathrm{~nm}$, respectively. However, for the dibenzophospholes 39 and 167, the TPA maxima were in accordance with the bathochromic shifts and were red-shifted. Photophysical characterisation of the investigated compounds is summarized in Table 3.

4.1.2. Helicene type dibenzophospholes. Structurally unique benzopyrano- and naphthopyrano-fused helical dibenzophospholes 156-161 and 164-166 are also interesting candidates for organic semiconducting materials (Scheme 78). ${ }^{\mathbf{4 4}}$

Optical data for the dibenzophospholes 157-161 and 164166 compared with the dibenzophosphole 156, which does not

Table 4 Photophysical properties of the fused helical dibenzophospholes $156-161$ and $164-166$ in $\mathrm{CHCl}_{3}\left(10^{-5} \mathrm{M}\right)$

\begin{tabular}{|c|c|c|}
\hline & UV absorption & Emission $^{a}$ \\
\hline Compound & $\lambda_{\max }[\mathrm{nm}]$ & $\lambda_{\max }[\mathrm{nm}]$ \\
\hline 156 & 259,341 & 375 \\
\hline 157-(-) & 288,341 & 477 \\
\hline 158-(-) & 288,344 & 471 \\
\hline 159-(-) & 289,337 & 474 \\
\hline $160-(-)$ & 281,338 & 469 \\
\hline 161-(-) & 285,343 & 464 \\
\hline $164-(+)$ & $281,348^{b}$ & $482^{b}$ \\
\hline $165-(+)$ & 308,386 & 490 \\
\hline 166 & 275 & 406 \\
\hline
\end{tabular}

${ }^{a}$ Excited at $280 \mathrm{~nm} .{ }^{b}$ Measured for a $E / Z$ mixture.
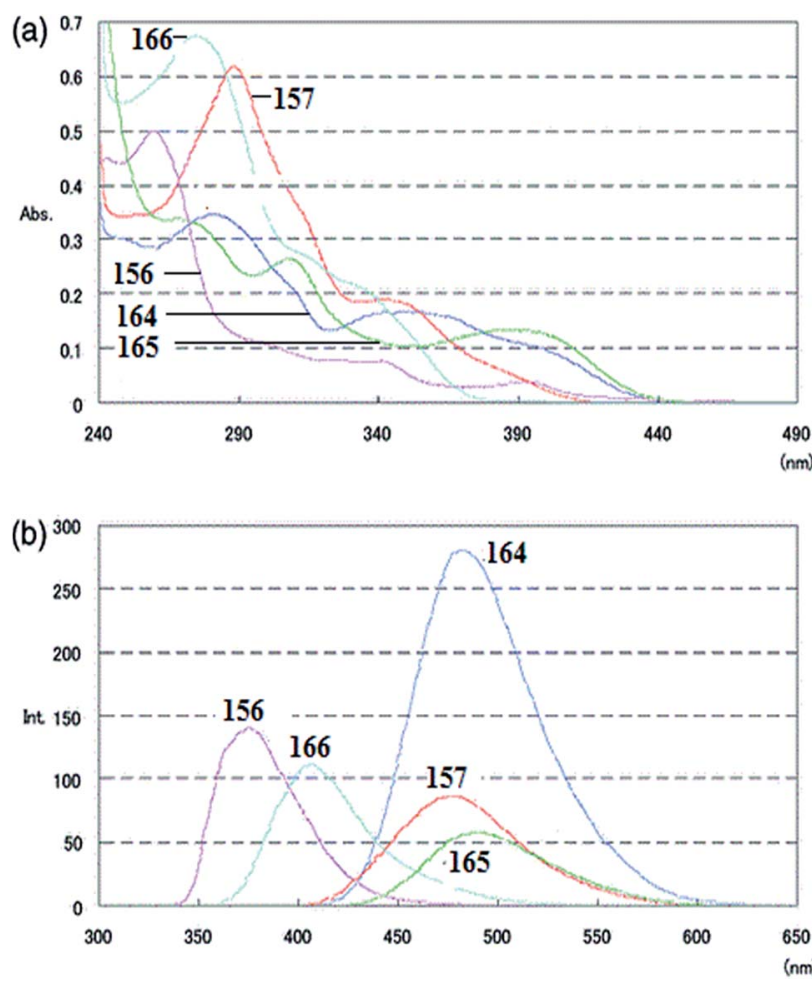

Fig. 3 UV-Vis absorption and emission spectra of compounds 156157 and $164-166$, in $\mathrm{CHCl}_{3}\left(10^{-5} \mathrm{M}\right)^{44}$ (reprinted with permission from the American Chemical Society). contain the 2-alkoxyphenyl group, showed large red-shifts of absorption and emission maxima. The substituents on the phosphorus atom showed a small impact on the absorption and emission maxima in dibenzophospholes 157-159, which oscillated around at $\lambda=288 \mathrm{~nm}$ and $475 \mathrm{~nm}$, for the absorption and emission maxima, respectively. The same effect was observed for substitutions at the 2- and 7-positions in dibenzophospholes 161 and 164. Compound 160 exhibited absorption maximum at a similar wavelength as $\mathbf{1 6 4}$, but the emission was less shifted. The farthest red-shifts for the absorption and emission maxima were observed for the dibenzophosphole 165 (Table 4 and Fig. 3). ${ }^{44}$

4.1.3. Perfluorinated dibenzophospholes. Interesting examples of benzene ring functionalisation are perfluorinated derivatives 202-205. The fluorine atoms in the aromatic systems stabilised LUMO energy levels and improved electron transport and cofacial packing. The dibenzophospholes 202-205 have a potential application as n-type electronic components with useful electron transport properties what makes them interesting candidates for devices based on electro- and photoluminescence (Scheme 79). ${ }^{52}$

The absorption and emission spectra of the derivatives 203-205 were slightly red-shifted in comparison to the dibenzophosphole 202. The photoluminescence spectra of all

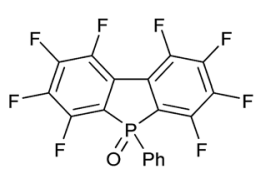

202

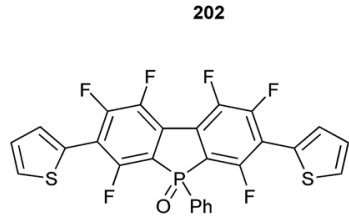

204

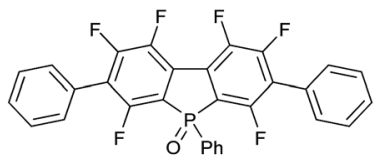

203

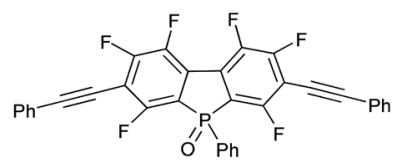

205
Scheme 79

Table 5 Wavelengths of absorption $\left(\lambda_{\text {abs }}\right)$, emission maxima of photoluminescence $\left(\lambda_{\mathrm{em}}\right)$, quantum yields $\left(\phi_{\mathrm{PL}}\right)$ of the compounds $202-$ 205, in solution and solid state

\begin{tabular}{|c|c|c|c|c|c|}
\hline \multirow[b]{2}{*}{ Compound } & \multicolumn{2}{|c|}{$\begin{array}{l}\text { UV-Vis } \\
\text { absorption }\end{array}$} & \multicolumn{3}{|c|}{ Photoluminescence } \\
\hline & $\begin{array}{l}\lambda_{\mathrm{abs}} \\
{[\mathrm{nm}]}\end{array}$ & $\log \varepsilon$ & $\begin{array}{l}\lambda_{\mathrm{em}} \\
{[\mathrm{nm}] \text { solution }}\end{array}$ & $\begin{array}{l}\phi_{\mathrm{PL}} \\
\text { solution }\end{array}$ & $\begin{array}{l}\lambda_{\mathrm{em}} \\
{[\mathrm{nm}] \text { solid }}\end{array}$ \\
\hline 202 & 325 & 3.6 & 365 & $0.18^{a}$ & 378 \\
\hline 203 & 338 & 3.8 & 395 & $0.60^{a}$ & 428 \\
\hline 204 & $\begin{array}{l}385 \\
369\end{array}$ & - & $\begin{array}{l}424 \\
443\end{array}$ & $0.54^{b}$ & - \\
\hline 205 & 380 & 3.7 & $\begin{array}{l}414 \\
432\end{array}$ & $0.98^{b}$ & 472 \\
\hline
\end{tabular}

${ }^{a}$ Referenced to 1,4-bis-(5-phenyl-2-oxazolyl)benzene (POPOP) in THF $\left(\phi_{\mathrm{F}}=0.97\right) .{ }^{b}$ Referenced to 9,10 -diphenylanthracene in $\operatorname{THF}\left(\phi_{\mathrm{F}}=0.9\right)$. 

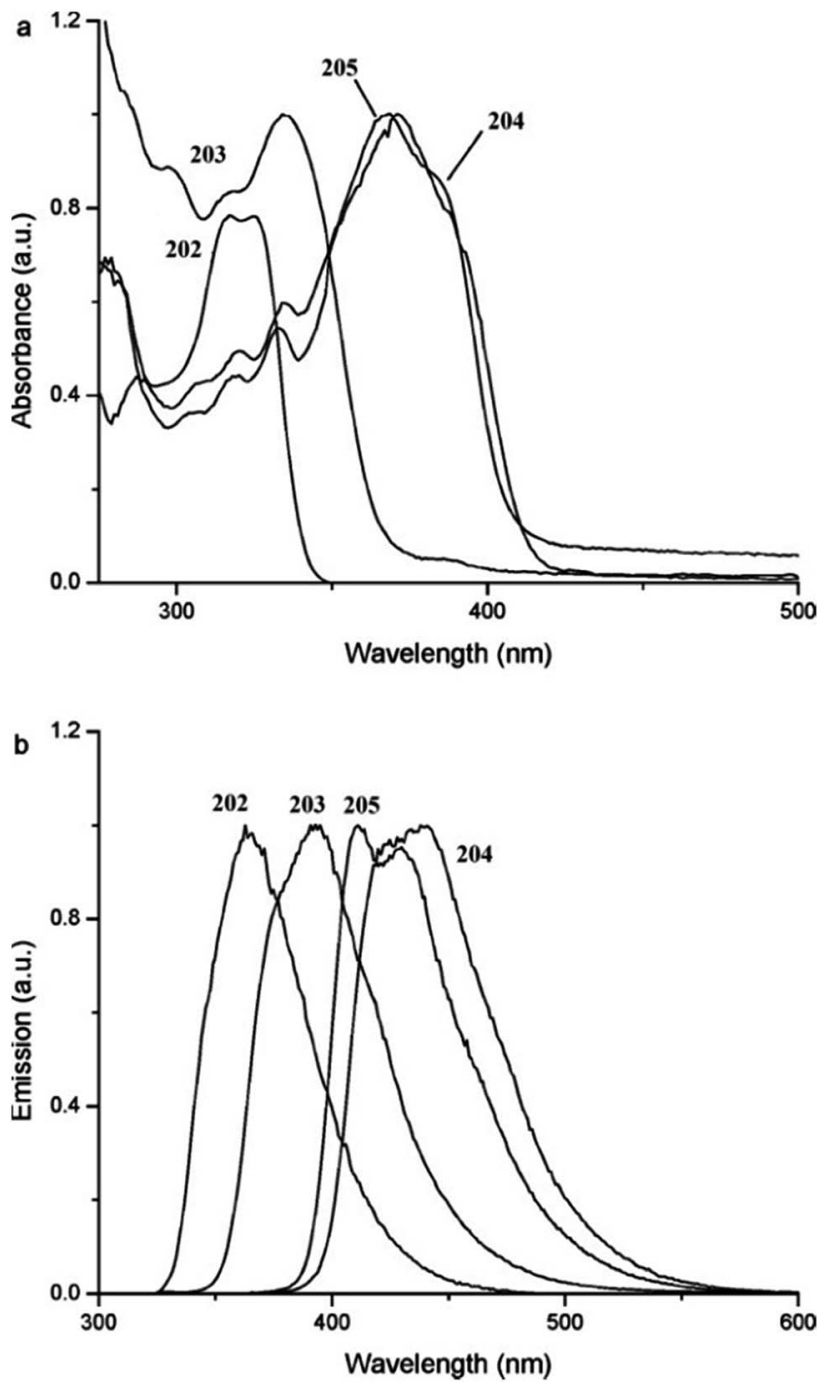

Fig. 4 UV-Vis absorption (a) and emission (b) spectra of the compounds 202-205 in THF ${ }^{52}$ (reprinted with permission from the American Chemical Society).

investigated compounds 202-205 showed maxima between $\lambda_{\mathrm{em}}=365$ to $432 \mathrm{~nm}$. These values were in the ultraviolet to violet range and corresponded to blue light emission, for the solution and solid states. The quantum yields of dilute solutions varied significantly with the nature of the 3,7-substituents. The highest value was observed for the derivative 205 . The optical properties of these compounds are presented in Table 5 and Fig. $4 .^{52}$

Tilley et al. investigated electrochemical properties of dibenzophospholes 202-205. Selected results are summarized in Table 6.

The 3,7-thienyl and alkynyl disubstituted derivatives 204 and 205 exhibited a decrease of LUMO values by $0.1-0.3 \mathrm{eV}$ compared to the dibenzophosphole 202, due to their slightly longer conjugation length. Additionally, the thienyl dibenzophosphole 204 exhibited higher HOMO energy level, than the alkynyl derivative 205. The derivative 203 had the widest range of the energy gap. The low values of LUMO levels in
Table 6 Values of HOMO, LUMO energy levels and energy gap $\left(E_{g}\right)$ of the compounds 202-205 in acetonitrile $\left(0.1 \mathrm{Mn}^{-} \mathrm{Bn}_{4} \mathrm{~N}^{+} \mathrm{PF}_{6}{ }^{-}\right.$in $\mathrm{CH}_{3} \mathrm{CN}$ )

\begin{tabular}{llll}
\hline Compound & HOMO $^{a}[\mathrm{eV}]$ & LUMO $^{a}[\mathrm{eV}]$ & $E_{\mathrm{g}}[\mathrm{eV}]$ solution \\
\hline $\mathbf{2 0 2}$ & - & $-3.0^{b}$ & - \\
$\mathbf{2 0 3}$ & -6.7 & $-3.0^{b}$ & 3.7 \\
$\mathbf{2 0 4}$ & -6.2 & $-3.1^{b}$ & 3.1 \\
$\mathbf{2 0 5}$ & -6.5 & $-3.3^{b, c}$ & 3.2
\end{tabular}

${ }^{a}$ Referenced to Fe/Fe ${ }^{+} .{ }^{b}$ Reversible reduction. ${ }^{c}$ Three drops of toluene was added to improve solubility in $\mathrm{CH}_{3} \mathrm{CN}$.

dibenzophospholes 202-205, suggested that these compounds could be useful as n-type conducting materials. ${ }^{52}$

\subsection{Fused dibenzophospholes}

4.2.1. Linearly fused dibenzophospholes. Several dibenzophospholes have been reported that are attractive prospects for optoelectronic uses, including 129, 131-anti, 133-syn, 220-anti, 221-syn. These compounds attract increasing attention due to relatively small HOMO-LUMO energy gaps and the possibility to tune their properties through diverse functionalisations at the phosphorus atom (Scheme 80). ${ }^{40}$

The dibenzophosphole oxide 129 showed absorption maximum at $\lambda_{\mathrm{abs}}=340 \mathrm{~nm}$ and emission at $\lambda_{\mathrm{em}}=382 \mathrm{~nm}$, for the $\mathrm{CH}_{2} \mathrm{Cl}_{2}$ solution. The absorption and emission maxima of the dibenzophospholes 131-anti and 133-syn were red-shifted compared to the derivative 129 related to $\pi$-expansion through the $\sigma^{*}-\pi^{*}$ conjugation of the $\pi$-framework to the $\sigma^{*}$ orbital of the exocyclic $\mathrm{P}-\mathrm{C}$ bonds. The dibenzophosphole oxides 131-anti and 133-syn exhibited high fluorescence quantum yields of 0.89 and 0.79 , in solution. In the solid state, the quantum yields of both compounds were somewhat lower. In this state, the quantum yield of 133-syn $\left(\phi_{\mathrm{F}}=0.63\right)$ was larger than that of 131-anti $\left(\phi_{\mathrm{F}}=0.46\right)$, indicating that interactions in the solid state were different for both diastereomers due to conformational difference.

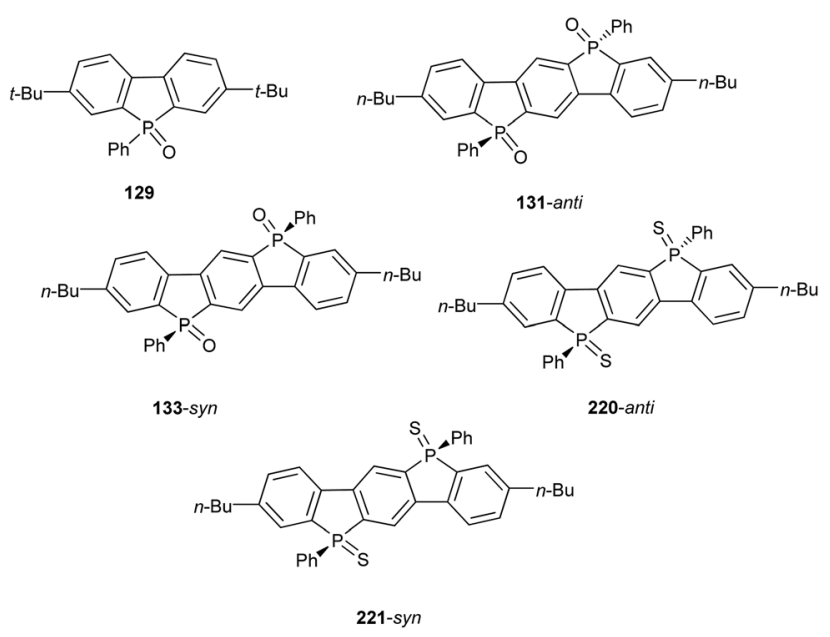

Scheme 80 
Table 7 The values of absorption and fluorescence maxima of the compounds 129, 131-anti, 133-syn, 220-anti and 221-syn, in $\mathrm{CH}_{2} \mathrm{Cl}_{2}$

\begin{tabular}{|c|c|c|c|c|c|c|}
\hline Compound & \multicolumn{2}{|c|}{ UV-Vis absorption } & \multicolumn{4}{|l|}{ Fluorescence } \\
\hline 131-anti & 391 & 3.68 & 426,438 & 0.89 & 454 & 0.46 \\
\hline 133-syn & 391 & 3.61 & 426,438 & 0.79 & 476 & 0.63 \\
\hline 220-anti & 385 & 3.73 & 430 & 0.004 & $437,471,501$ & 0.12 \\
\hline
\end{tabular}

${ }^{a}$ Absolute quantum yield determined by an integrating sphere system.

The dibenzophosphole sulfides 220-anti and 221-syn revealed different photophysical properties compared with the dibenzophosphole oxides 131-anti and 133-syn. The absorption maxima of the sulfides had almost the same values of $\lambda_{\mathrm{abs}}=$ $385 \mathrm{~nm}(\log \varepsilon=3.73)$ and $\lambda_{\mathrm{abs}}=386 \mathrm{~nm}(\log \varepsilon=3.72)$ for 220anti and 221-syn, respectively. These electronic properties led to blue-shifted absorption maxima of the dibenzophospholes sulfides in comparison with those of the dibenzophosphole oxides. The fluorescence quantum yields of the sulfides 220-anti and 221-syn, in solution dramatically dropped down to 0.004 in comparison to oxides 131-anti and 133-syn, but in the solid state increased to 0.12 and 0.04 for 220-anti and 221-syn, respectively. The selected photophysical properties of the investigated compounds are summarized in Table $7 .^{40}$

The linearly fused dibenzophospholes 195 and 196 are also promising for optoelectronics devices, in which optical properties were highly dependent on the combination of benzo $[b]$ (thiophene or pyrrole) subunits (Scheme 81). ${ }^{\mathbf{5 0}}$

The UV-Vis absorption and emission spectra of the dibenzophospholes 195 and 196 were significantly blue shifted relative to the corresponding non-fused biaryl substrates 193 (see subsection 2.11). The Stokes shifts of the rigid fused structures of $195\left(3829 \mathrm{~cm}^{-1}\right)$ and $196\left(4810 \mathrm{~cm}^{-1}\right)$ were smaller than those of the biaryl substrates $193(\mathrm{R}=\mathrm{S})\left(4250 \mathrm{~cm}^{-1}\right)$ and $193(\mathrm{R}=$ $\mathrm{NMe})\left(7000 \mathrm{~cm}^{-1}\right)$.

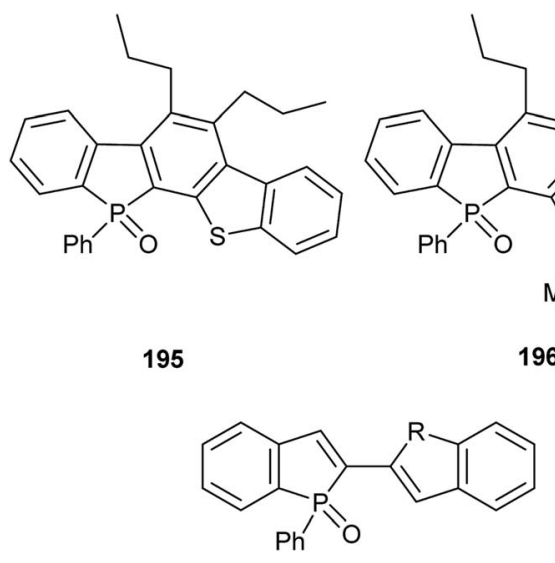

$193 \mathrm{R}=\mathrm{S}, \mathrm{NMe}$

Table 8 The optical characterisation of the compounds 195 and 196 and their precursors 193 ( $\mathrm{R}=\mathrm{S}, \mathrm{NMe}$ ), in $\mathrm{CH}_{2} \mathrm{Cl}_{2}$ (ref. 50)

\begin{tabular}{llllll}
\hline & \multicolumn{2}{l}{ UV-Vis absorption } & & \multicolumn{2}{l}{ Fluorescence } \\
\cline { 2 - 3 } Compound & $\lambda_{\text {abs }}[\mathrm{nm}]$ & $\log \varepsilon$ & & $\lambda_{\mathrm{em}}[\mathrm{nm}]$ & $\phi_{\mathrm{F}}{ }^{a}$ \\
\hline $193(\mathrm{R}=\mathrm{S})$ & 377 & 4.31 & & 450 & 0.17 \\
$193(\mathrm{R}=\mathrm{NMe})$ & 393 & 4.07 & & 542 & 0.44 \\
195 & 344 & 3.96 & 396 & 0.13 \\
196 & 355 & 4.08 & 431 & 0.24
\end{tabular}

${ }^{a}$ Excited at $\lambda_{\mathrm{abs}} 400 \mathrm{~nm}$ for the $\phi_{\mathrm{F}}$ measurements.

Density functional theory (DFT) calculations at the B3LYP/6$31 \mathrm{G}^{*}$ level showed widening of the HOMO-LUMO gap upon acetylene fusion. The energy gaps were changed from 3.53/ $3.34 \mathrm{eV}$ for $193(\mathrm{R}=\mathrm{S}, \mathrm{NMe})$ to $4.10 / 3.85 \mathrm{eV}$, for 195 and 196, respectively.

The fluorescence decay curves of the compounds 195 and 196 in $\mathrm{CH}_{2} \mathrm{Cl}_{2}$ were fitted as a single exponential with lifetimes of 2.2 and 7.9 ns. More photophysical properties of 195 and 196 including quantum yields are displayed in Table $8 .^{50}$

4.2.2. Thiophene modified fused dibenzophospholes. The compounds 186 and 187 obtained from $185(\mathrm{Y}=\mathrm{S}, \mathrm{O})$ possess<smiles>[Y]P1(c2cccs2)=C(c2ccsc2)C(c2ccsc2)=C(c2ccsc2)C1c1ccsc1</smiles>

$185 \mathrm{Y}=\mathrm{S}, \mathrm{O}$<smiles>S=P1(c2ccccc2)c2ccsc2-c2sccc21</smiles>

186<smiles>O=P1(c2ccccc2)c2ccsc2-c2c1c1ccsc1c1sccc21</smiles>

187

Scheme 82 
a considerable dibenzophospholes character based on optical properties in the solid state (Scheme 82). ${ }^{48}$

The dibenzophospholes 186 and 187 compared to the respective nonfused precursors $185(\mathrm{Y}=\mathrm{S}, \mathrm{O})$ showed blue-shift absorption maxima, higher oxidation and lower reduction potential values, which indicated the less efficient electron $\pi$ delocalization over the $\mathrm{sp}^{2}$-C atoms of 186 and 187 and typical for the dibenzophospholes, increased localization of the $\pi$ electrons within aromatic subunits. Although, the dibenzophospholes 186 and 187 were emissive materials with $\lambda_{\max }=$ 475 and $477 \mathrm{~nm}$, respectively, their quantum yields oscillated at around 1\%. Photophysical properties of these compounds are presented in Table $9 .^{48}$

Table 9 The optical data of the dibenzophospholes 186 and 187 and their precursors $185(\mathrm{Y}=\mathrm{S}, \mathrm{O})$ in $\mathrm{CH}_{2} \mathrm{Cl}_{2}$

\begin{tabular}{|c|c|c|c|}
\hline \multirow[b]{2}{*}{ Compound } & \multicolumn{2}{|c|}{ UV-Vis absorption } & \multirow{2}{*}{$\frac{\text { Fluorescence }}{\lambda_{\mathrm{em}}[\mathrm{nm}]}$} \\
\hline & $\lambda_{\max }[\mathrm{nm}]$ & $\log \varepsilon$ & \\
\hline $185(\mathrm{Y}=\mathrm{S})$ & 413 & 3.48 & 484 \\
\hline $185(\mathrm{Y}=\mathrm{O})$ & 411 & 3.83 & - \\
\hline 186 & 391 & 3.56 & 475 \\
\hline 187 & 389 & 3.63 & 477 \\
\hline
\end{tabular}

4.2.3. Benzene modified fused dibenzophospholes. Fused benzene modified dibenzophospholes 190-192, 209, 235 and 263, which have the same fused aromatic $\mathrm{C}$ skeleton but different $\mathrm{P}$ moieties, have been successfully utilized as organic materials for optoelectronics (Scheme 83). ${ }^{\mathbf{4 9}}$

The optical and electrochemical properties of these dibenzophospholes were investigated to evaluate the impact of the $\mathrm{P}$ modifications on their electronic properties. The absorption spectra of the all investigated fused dibenzophospholes 190192, 209, 235 and 263 varied over a wide range covering the entire visible spectrum. In the absorption spectrum of the dibenzophosphole 192, an intense characteristic band at $\lambda_{\max }=$ $472 \mathrm{~nm}$ was observed. The absorption maxima of the $\sigma^{4}-\mathrm{P}$ derivatives 190, 209 and 235 were shifted towards higher wavelengths. A larger bathochromic shift was observed for Palkyl and P-S phospholium salts 263 and 191. Addition of a phenyl group to phosphorus in the dibenzophosphole 192 resulted in a shift of its maximum absorption towards higher wavelengths. All of these dibenzophospholes were fluorescent in solution, with gradual red shifts of the $\lambda_{\mathrm{em}}$ in the compounds 190-192 and 263. The Stokes shifts for rigid structures in the compounds 192, 190, and 263 were relatively small $(737,1072$, $1355 \mathrm{~cm}^{-1}$, respectively). Furthermore, the emission bands indicated a small rearrangement of these molecules upon photoexcitation and for this reason their quantum yields were<smiles>COC1=CC(OC)=C2C=c3c2cccc2c4cccc5c(OC)cc(OC)cc5c3c(c24)P1(=S)c1ccccc1</smiles>

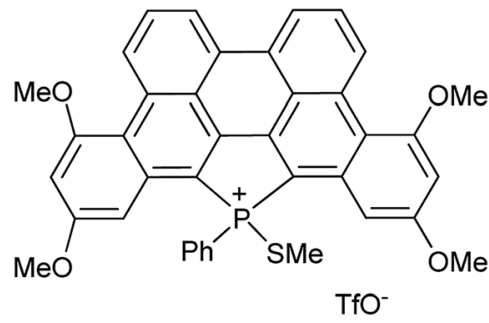

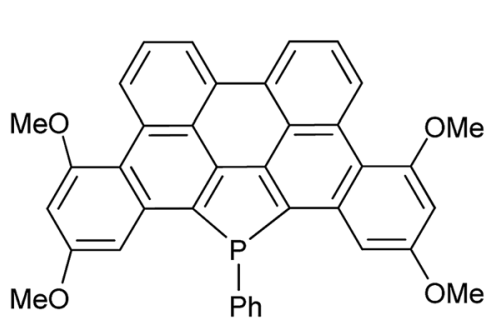

192

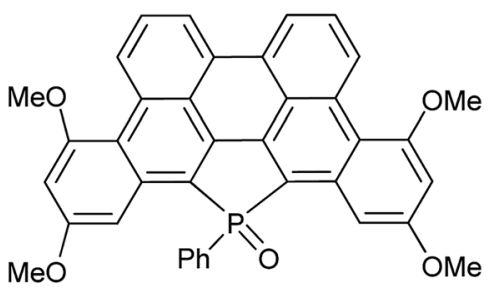

209

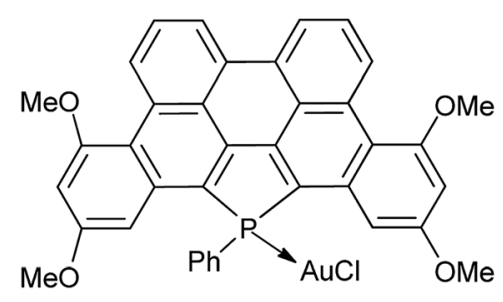

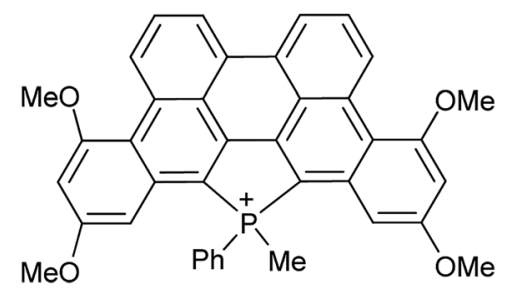

$\mathrm{TfO}^{-}$ 
Table 10 Wavelengths of absorption maxima $\left(\lambda_{\text {abs }}\right)$, logarithm of the molar absorption coefficient ( $\log \varepsilon$ ), wavelength of emission maxima $\left(\lambda_{\mathrm{em}}\right)$, fluorescence quantum yields $\left(\phi_{\mathrm{F}}\right)$, oxidation potentials $\left(E_{1}^{\text {ox }}\right)$, reduction potentials $\left(E_{1}^{\text {red }}\right)$

\begin{tabular}{|c|c|c|c|c|c|c|}
\hline \multirow[b]{2}{*}{ Compound } & \multicolumn{2}{|c|}{ UV-Vis absorption } & \multicolumn{2}{|c|}{ Fluorescence } & \multicolumn{2}{|c|}{$\begin{array}{l}\text { Redox } \\
\text { potentials }\end{array}$} \\
\hline & $\lambda_{\mathrm{abs}}{ }^{a}[\mathrm{~nm}]$ & $\log \varepsilon^{a}$ & $\lambda_{\mathrm{em}}{ }^{a}[\mathrm{~nm}]$ & $\phi_{\mathrm{F}}^{a, b}$ & $E_{1}^{\mathrm{ox} b}$ & $E_{1}^{\mathrm{red} c}$ \\
\hline 190 & 514 & 4.04 & 544 & 0.21 & 0.71 & -1.70 \\
\hline 191 & 569 & 3.95 & 669 & 0.03 & 1.01 & $-1.04^{d}$ \\
\hline 192 & 472 & 4.34 & 489 & 0.80 & 0.44 & $-2.10^{d}$ \\
\hline 209 & 524 & 4.11 & 549 & 0.52 & 0.77 & $-1.71^{d}$ \\
\hline 235 & 508 & 4.14 & 537 & 0.08 & 0.75 & $-1.67^{d}$ \\
\hline 263 & 554 & 4.00 & 599 & 0.19 & 0.97 & $-1.31^{d}$ \\
\hline
\end{tabular}

${ }^{a}$ In dichloromethane $\left(10^{-5} \mathrm{M}\right) .{ }^{b}$ Measured relative to fluorescein $\left(\mathrm{NaOH}, 0.1 \mathrm{M}, \phi_{\mathrm{F}}=0.9\right) .{ }^{c}$ In dichloromethane and $\mathrm{Bu}_{4} \mathrm{~N}^{+} \mathrm{PF}_{6}{ }^{-}(0.2$ M). ${ }^{d}$ Reversible process.

relatively high $(>0.20)$, as opposed to the derivative 191, which presented a larger Stokes shift $\left(2875 \mathrm{~cm}^{-1}\right)$ accompanied by a decrease in the fluorescence quantum yield to 0.03 .

Cyclic voltammetry measurements of these compounds showed that the chemical functionalisation of the $\mathrm{P}$ center in the dibenzophospholes 190-192 and 263 led to a gradual increase in the oxidation and reduction potentials as well as indicated that the phospholium salts 191 and 263 had high electron affinities. Moreover, the dibenzophospholes 190, 209, 235 and 263 presented reversible reduction waves, which suggested stability in their reduced state, under the measurement conditions. It is noteworthy that the evolution of the redox potentials within the compounds 190-192 and 263 were consistent with the decrease in the optical gap. Accurate photophysical and electrochemical data of these compounds are presented in Table 10 and Fig. 5. $^{49}$

Time-dependent density functional theory (TD-DFT) calculations were performed to gain more insight into the electronic properties of the dibenzophospholes 190-192, 209, 235 and 263. These results showed that the long-wavelength UV-Vis absorption of these dibenzophospholes resulted from HOMO-LUMO transitions. The frontier molecular orbitals were comparable in 190-192, 209 and 263. These $\pi$ molecular orbitals were delocalized on the $\mathrm{sp}^{2}$-carbon skeletons with a contribution of the respective orbitals of the phosphole ring.

The HOMO with a nodal plane on the $\mathrm{P}^{\mathrm{III}}$ was influenced by the inductive effects of the substituents on the phosphorus atom. Additionally, both experimental and theoretical data showed that the local chemical modifications around $\mathrm{P}$ had a great significance on the gap fine-tuning. ${ }^{49}$

4.2.4. Bridged dibenzophospholes. Notable organic compounds for optoelectronic devices are bridged dibenzophospholes 17-18, 20 and 21, which were obtained by Yamaguchi and Studer et al. These compounds exhibited electronaccepting character and could find many applications as building blocks in molecular electronics (Scheme 84). ${ }^{27}$

The UV-Vis absorption spectra of the dibenzophospholes 17cis and 18-trans showed an absorption band with the maxima a)

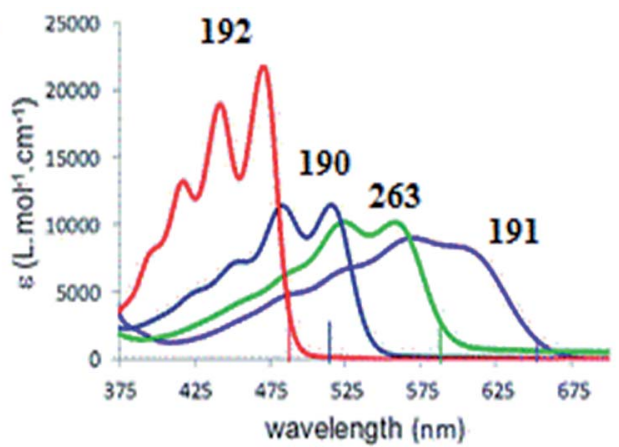

b)

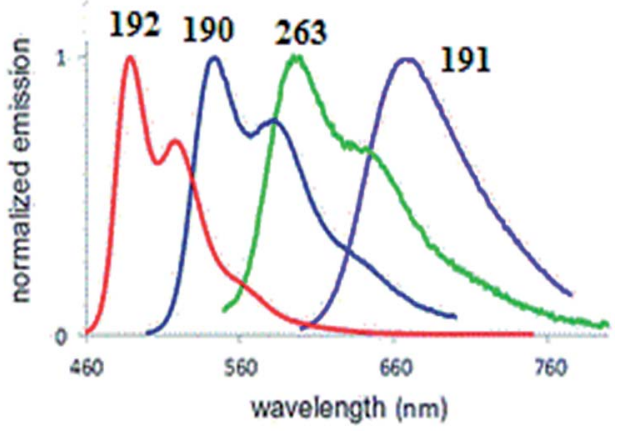

Fig. 5 UV-Vis absorption spectra (a), normalised emission spectra (b) of the compounds $190-192$ and 263 in dichloromethane $\left(10^{-5} \mathrm{M}\right)^{49}$ (reprinted with permission from the American Chemical Society).

wavelength at $\lambda_{\mathrm{abs}}=347 \mathrm{~nm}$ and logarithms of the molar absorption coefficient 2.52 and 2.56 for 17-cis and 18-trans, respectively. Additionally, both isomers presented essentially identical spectra irrespective of the stereochemistry. The fluorescence spectra of 17-cis and 18-trans showed a violet fluorescence with the maximum wavelength at $\lambda_{\mathrm{em}}=387 \mathrm{~nm}$ in both cases, whereas the quantum yield was low $\left(\phi_{\mathrm{F}}=0.03\right)$.

Notably, the absorption and fluorescence spectra of 17-cis and 18-trans were in the longer wavelength range, than those of the dibenzophosphole oxide 66 . These results were attributable to the small HOMO-LUMO gap of isomers 17-cis and 18-trans. The compounds 20-trans and 21-trans showed absorption at $\lambda_{\text {abs }}$ $=375$ and $399 \mathrm{~nm}$, and fluorescence bands at $\lambda_{\mathrm{em}}=422$ and $547 \mathrm{~nm}$, respectively, which were related to the effective extension of $\pi$ conjugation. Whereas the dibenzophospholes 17-cis and 18-trans showed only a faint fluorescence, the $\pi$-extended derivatives 20-trans and 21-trans presented more intense emission with $\phi_{\mathrm{F}}$ values of 0.20 and 0.34 , respectively. Remarkably, the $\lambda_{\mathrm{em}}$ value of the dibenzophosphole 21-trans was longer than that of compound 20-trans in $\mathrm{CHCl}_{3}$. To compare the electronaccepting properties of the bridged compounds 20-trans and 21-trans, the non-bridged dibenzophosphole 273 was also prepared and measured in various solvents. For the compounds 21-trans and 273, the fluorescence spectra presented considerable bathochromic shifts with increasing polarity of a solvent, whereas the absorption maxima showed small solvent dependence. These facts demonstrate that the compounds 21-trans and $\mathbf{2 7 3}$ had more polar structures in the excited state than in the ground state. The use of the Lippert-Mataga equation to 

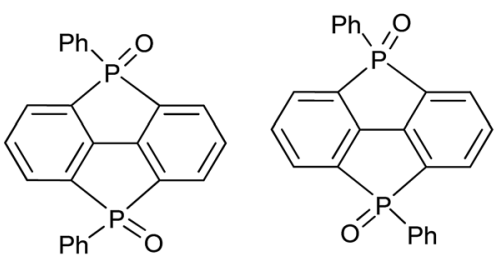<smiles>O=[PH]1c2cc(-c3ccccc3)cc3c2-c2c1cc(-c1ccccc1)cc2P3(=O)c1ccccc1</smiles>

17-cis

18-trans

20-trans

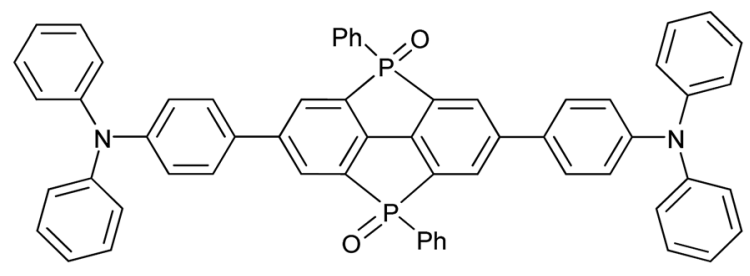

21-trans

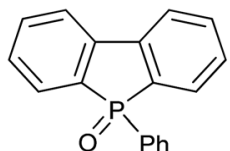

66

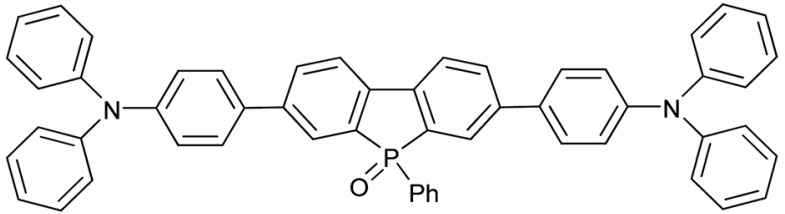

273

Scheme 84

compare the degree of polarity of the structures in the excited state, showed that extension of the electron-accepting character of the bridged dibenzophospholes 20 and 21-trans was larger than the non-bridged dibenzophosphole analogue 273. Noteworthy is that the dibenzophosphole 21-trans retained fluorescence quantum yield in the solid state of $\phi_{\mathrm{F}}=0.30$, in contrast to the non-bridged analogue 273 which exhibited a much smaller fluorescence quantum yield than in solution $\left(\phi_{\mathrm{F}}=0.18\right.$ for solid, 0.89 for solution). Individual results of the investigated compounds are summarized in Table $11 .^{27}$

Yamaguchi and Studer et al. presented the cyclic voltammograms of the dibenzophospholes 21-trans and 273, showing

Table 11 UV-Vis absorption and fluorescence characterisation of the compounds 17-cis, 18-trans, 20-trans, 21-trans, 66, 273, in $\mathrm{CH}_{2} \mathrm{Cl}_{2}$

\begin{tabular}{llllll}
\hline & \multicolumn{2}{l}{ UV-Vis absorption } & & \multicolumn{2}{l}{ Fluorescence } \\
\cline { 2 - 3 } Compound & $\lambda_{\text {abs }}{ }^{a}[\mathrm{~nm}]$ & $\log \varepsilon$ & & $\lambda_{\mathrm{em}}{ }^{b}[\mathrm{~nm}]$ & $\phi_{\mathrm{F}}{ }^{c}$ \\
\hline 17-cis & 347 & 2.52 & 387 & 0.03 \\
18-trans & 347 & 2.56 & 387 & 0.03 \\
20-trans & 375 & 3.54 & 422 & 0.20 \\
21-trans & 399 & 4.57 & 547 & $0.34(0.30)$ \\
$\mathbf{6 6}$ & 332 & 2.89 & 366 & 0.042 \\
$\mathbf{2 7 3}$ & 396 & 4.63 & 499 & $0.89(0.18)$
\end{tabular}

${ }^{a}$ Only absorption maxima at the longest wavelengths were shown. ${ }^{b}$ Emission maxima upon excitation at the absorption maximum wavelengths. ${ }^{c}$ Absolute fluorescence quantum yields determined by a calibrated integrating sphere system within $\pm 3 \%$ errors. the first reversible reduction waves with reduction potentials of -2.15 and $-2.36 \mathrm{~V}$, respectively. These observations indicated that the dibenzophosphole 21-trans might serve as a material to enhance the electron-accepting character.

\section{Application of dibenzophospholes for organic electronic devices}

We believe that dibenzophospholes, as organic $\pi$-conjugated compounds, have enormous potential as optoelectronic materials for example in light-emitting diodes, organic field-effect transistors, nonlinear optical devices and organic solar cells. ${ }^{39}$ However, in the years 2001-2016, only limited testing of dibenzophospholes and their derivatives as materials in these types of device took place. In the 15 years since the review by Aitken ${ }^{11}$ in 2001, only two simple dibenzophospholes 66 and 212 were used in Organic Light-Emitting Diodes (OLEDs) in various configurations. These devices were fabricated in typical layered structures on indium-tin-oxide (ITO)-coated glass substrates $(\leq 15 \Omega)$ with multiple organic layers between the transparent bottom ITO anode and the top metal cathode. The organic and metal layers were deposited by thermal evaporation under high vacuum conditions with a base pressure of $<10^{-6}$ Torr. The active areas of the devices were $2 \times 2 \mathrm{~mm}^{2}$ as defined by the shadow mask for cathode deposition.

Chi, Chou and Chang et al. applied the dibenzophosphole 212 in the three layer OLEDs with $4 \mathrm{wt} \%$ of Os complex as an emitter. The dibenzophosphole $\mathbf{2 1 2}$ served as a bipolar host material with electron-donor properties due to the carbazole 


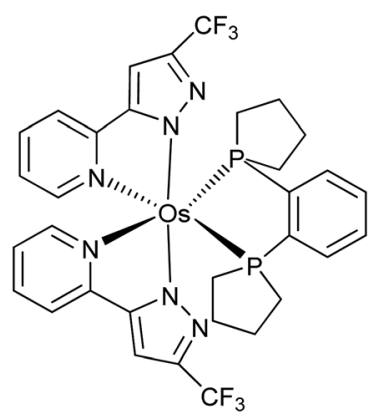

A

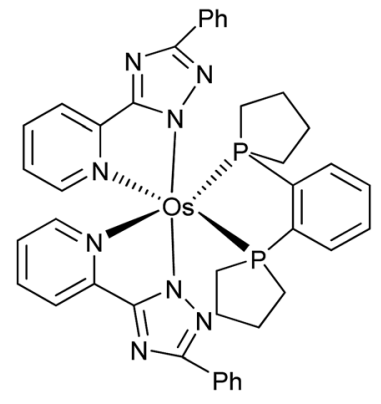

B
Scheme 85

moiety, as well as electron-acceptor properties by reason of the presence of phosphoryl moiety. The configurations of these devices were as follows: ITO/3DTAPBP-[2,2'-bis(3-( $N, N$-di- $p$-tolylamino)phenyl)biphenyl] (40 nm)/the dibenzophosphole 212 with Os complexes A or B (Scheme 85) (30 nm)/BP4mPy$\left[3,3^{\prime}, 5,5^{\prime}\right.$-tetra[(3-pyridyl)-phen-3-yl $]$ biphenyl $\left.(40 \mathrm{~nm})\right] / \mathrm{LiF}(0.8$ $\mathrm{nm}) / \mathrm{Al}(150 \mathrm{~nm})$ (Fig. 6). ${ }^{55}$

3DTAPBP with a wide triplet gap of around $2.68 \mathrm{eV}$, was employed as the hole-transport or a host material in redemitting OLEDs. The second material BP4mPY served as an electron transport layer. These devices exhibited a bright

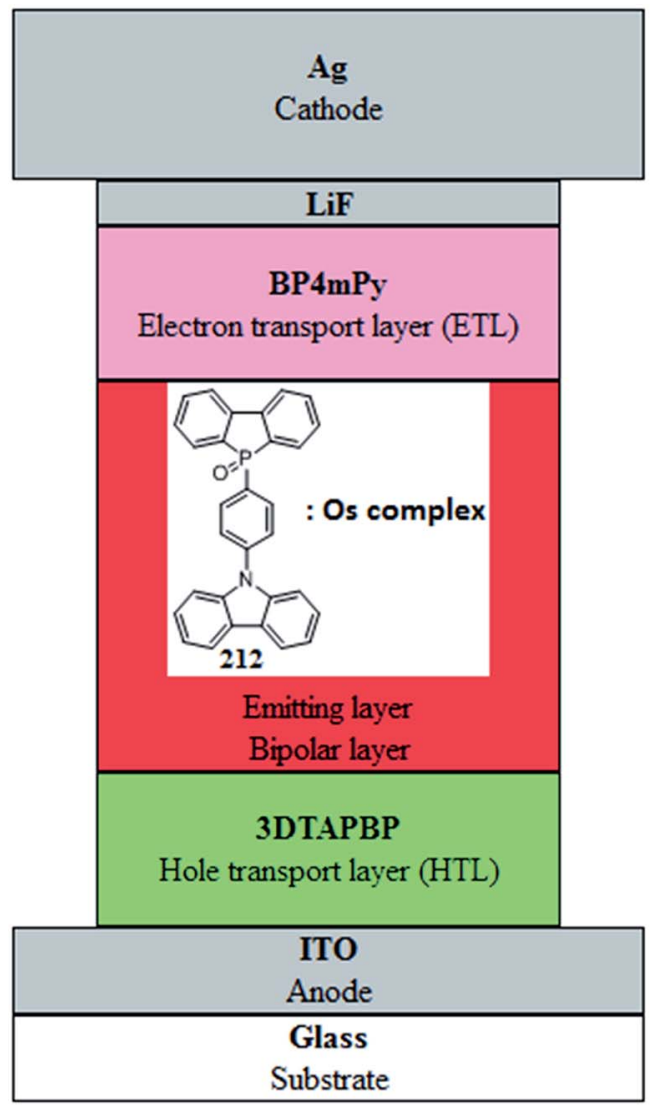

Fig. 6 Three-layer OLED emission of dopants due to good transfer energy between the host and guest materials. Below are presented the Os(II) complexes used in these red-emitting OLEDs (Scheme 85).

The efficiencies of OLEDs in this configuration were as follows: $c f$. $14.3 \%, 34.8 \mathrm{~cd} \mathrm{~A}^{-1}$ and $45.2 \mathrm{~lm} \mathrm{~W}^{-1}$ for the complex A and $9.9 \%, 15.7 \mathrm{~cd} \mathrm{~A}^{-1}$ and $20.5 \mathrm{~lm} \mathrm{~W}^{-1}$ for the complex B. The luminance maxima of 52.6 and $23.7 \mathrm{~cd} \mathrm{~m}^{-2}$ were achieved for the complexes $\mathbf{A}$ and $\mathbf{B}$, through applying relatively low voltages of 2.5 and $2.6 \mathrm{~V}$, respectively. Moreover, the internal quantum efficiency amounted to nearly $100 \%$ in both devices.

The resulting device parameters for the phosphorescent OLED containing as host dibenzophosphole 212 can be compared to the parameters of an OLED containing the standard bipolar host material CBP-4, $4^{\prime}-N, N^{\prime}$-dicarbazolebiphenyl in the following configuration: ITO/3DTAPBP (40 nm)/CBP (or dibenzophosphole 212) doped with $4 \%$ Os complexes A, B (30 $\mathrm{nm}) / \mathrm{BP} 4 \mathrm{mPy}(40 \mathrm{~nm}) / \mathrm{LiF}(0.8 \mathrm{~nm}) / \mathrm{Al}(150 \mathrm{~nm})$ or with other commercial materials, such as BP4mPy/3DTAPBP in the following configurations: ITO/3DTAPBP (40 nm)/3DTAPBP doped with $4 \%$ Os complexes A, B (10 nm)/BP4mPy doped with $4 \%$ of Os complexes A, B $(20 \mathrm{~nm}) / \mathrm{BP} 4 \mathrm{mPy}(40 \mathrm{~nm}) / \mathrm{LiF}(0.8$ $\mathrm{nm}) / \mathrm{Al}(150 \mathrm{~nm})$.

The parameters obtained for the standard host material (CBP, BP4mPy/3DTAPBP) doped with Os complexes A and B were lower than those obtained for the host dibenzophosphole 212 doped with the Os complex A (14.3\%, $34.8 \mathrm{~cd} \mathrm{~A}^{-1}$ and 45.2

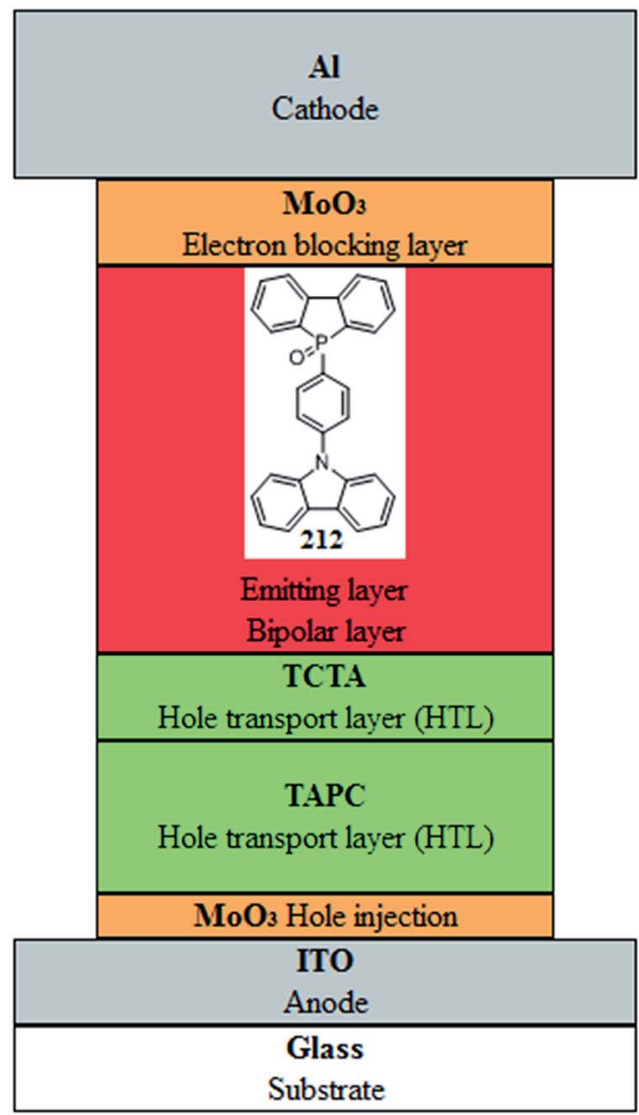

Fig. 7 The hole-only device. 
$\left.\operatorname{lm} \mathrm{W}^{-1}\right)$ : for CBP, efficiencies of $10.9 \%\left(21.7 \mathrm{~cd} \mathrm{~A}^{-1}\right.$ and $11.9 \mathrm{~lm}$ $\mathrm{W}^{-1}$ ) and $10.1 \%$ (13.7 $\mathrm{cd} \mathrm{A}^{-1}$ and $10.0 \mathrm{~lm} \mathrm{~W}^{-1}$ ) for the Os complexes $\mathbf{A}$ and $\mathbf{B}$ were achieved, respectively, whereas, efficiencies for the devices with BP4mPy/3DTAPBP in the second configuration of $12.9 \%$ (27.9 $\mathrm{cd} \mathrm{A}^{-1}$ and $21.8 \mathrm{~lm} \mathrm{~W}^{-1}$ ) for the complex $\mathbf{A}$ and $10.7 \%\left(18.5 \mathrm{~cd} \mathrm{~A}^{-1}\right.$ and $\left.19.3 \mathrm{~lm} \mathrm{~W}^{-1}\right)$ for the complex B, were obtained. ${ }^{55}$

The compound $\mathbf{2 1 2}$ was also used in the only-hole device in the following configuration: ITO/ $\mathrm{MoO}_{3}(1 \mathrm{~nm}) / \mathrm{TAPC}-[\mathrm{di}-[4-(N, N-$

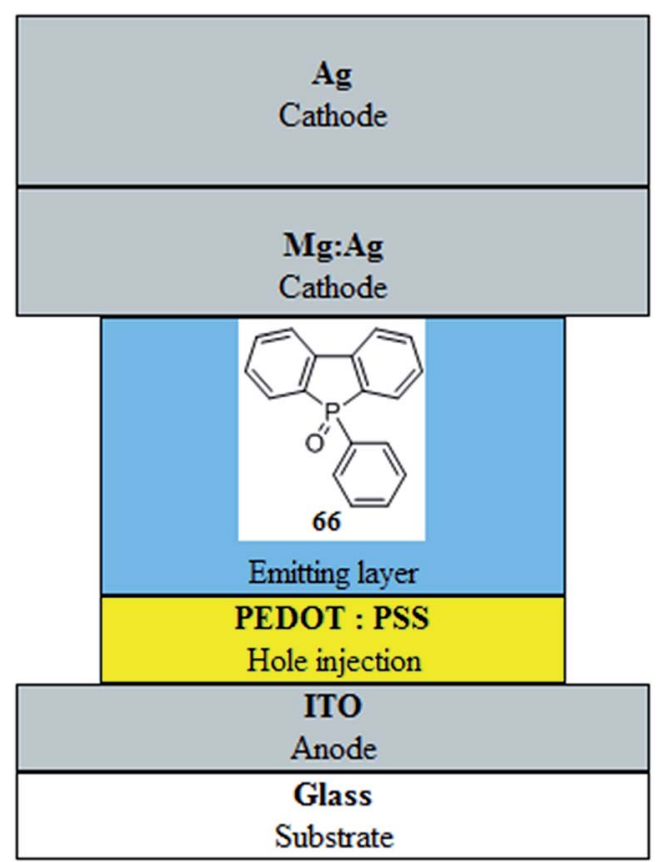

Fig. 8 Single-layer OLEDs. ditholylamino)-phenyl $]$ cyclohexane $\quad(30 \quad \mathrm{~nm}) /$ TCTA-[4, $4^{\prime}, 4^{\prime \prime}$ tris(carbazol-9-yl)-triphenylamine] (30 nm)/the compound 212 $(100 \mathrm{~nm}) / \mathrm{MoO}_{3}(20 \mathrm{~nm}) / \mathrm{Al}(110 \mathrm{~nm})$, for which $\mathrm{MoO}_{3}$ was applied as a hole injection/electron blocking layer, while TAPC and TCTA were used as dual hole-transport layers for providing a smooth hole-injection into the tested material as shown in Fig. $7 .^{55}$

Analogously, an only-electron device was also prepared in the following configuration: $\mathrm{ITO} / \mathrm{Al}(20 \mathrm{~nm}) /$ the dibenzophospholes $212(100 \mathrm{~nm}) /$ TmPyPB-[1,3,5-tri[(3-pyridyl)-phen-3-yl]benzene] $(10 \mathrm{~nm}) / \mathrm{TmPyPB}$ doped with $10 \mathrm{wt} \%$ of n-type cesium carbonate $\mathrm{Cs}_{2} \mathrm{CO}_{3}(10 \mathrm{~nm}) / \mathrm{Al}(110 \mathrm{~nm})$, where TmPyPB was used as the electron transport layer.

Current density-voltage $(J-V)$ characteristics of the only-hole and only-electron devices exhibited the excellent hole and electron transport capability of the dibenzophosphole $\mathbf{2 1 2}$. Summarizing, the dibenzophosphole 212 possesses superior carrier transport properties for both positive and negative charges.

In contrast, the dibenzophosphole 66, which was used in 2006 by $\mathrm{Wu}$ and Réau et al. as an electron transport layer, hole transport layer as well as an ambipolar material for OLEDs, turned out to be an unsuitable component for single- and two-layer OLEDs. The configuration of the single-layer OLED used was the following: ITO/PEDOT:PSS (poly(3,4-ethylenedioxythiophene):polystyrene sulfonate) (25 nm)/organic layer (100 nm)/Mg:Ag (80 nm)/Ag (150 $\mathrm{nm}$ ) as shown in Fig. 8. ${ }^{12}$

Light emission was observed for a turn-on voltage of $4 \mathrm{~V}$. However, the device was unstable and its electroluminescence characteristics (brightness, emission wavelength) varied rapidly with applied driving current.

The dibenzophosphole 66 was also tested in the two-layer OLEDs as an electron-transporting material (n-type) as well as hole-transporting material (p-type) in the two following
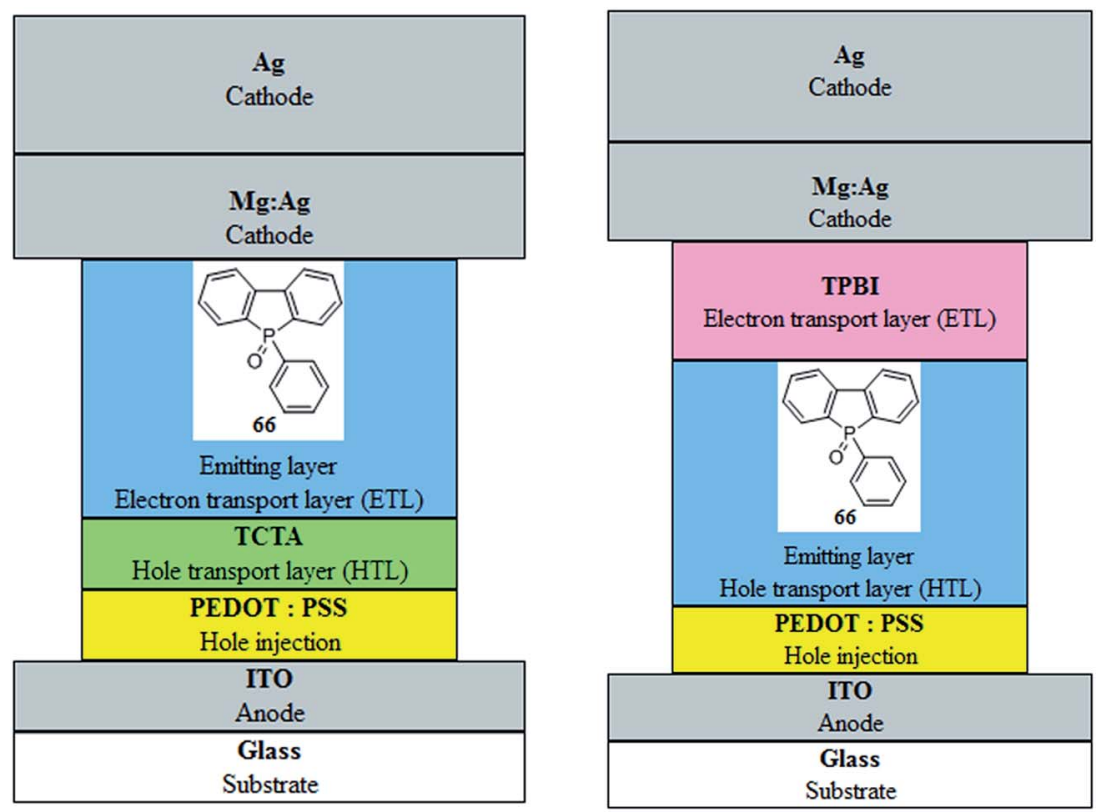

Fig. 9 Two-layer OLEDs. 
configurations: ITO/PEDOT/TCT-[tris(4-carbazoyl-9-ylphenyl) amine]/the compound 66/Mg:Ag/Ag and ITO/PEDOT/dibenzophosphole 66/TPBI-[2,2',2"-(1,3,5-benzinetriyl)-tris(1-phenyl$1 H$-benzimidazole)]/Mg:Ag/Ag. Thus, the compound 66 was mixed with the known p-type hole-transporting material TCTA[tris(4-carbazoyl-9-ylphenyl)amine and with the commonly known n-type electron transporting material TPBI- $\left[2,2^{\prime}, 2^{\prime \prime}\right.$ (1,3,5-benzenetriyl)-tris(1-phenyl-1 $H$-benzimidazole)] to provide two unstable bulk-hetero junctions, respectively (Fig. 9). ${ }^{12} \mathrm{~A}$ comparison of the opposite results obtained with dibenzophospholes 66 and 212 as materials for OLEDs, shows that more intensive investigations should be undertaken in this area with other representatives of dibenzophospholes, as reviewed in this article.

\section{Conclusions}

Dibenzophosphole and its derivatives are an underestimated group of heterorganic compounds which may serve as electroluminescent materials for optoelectronic devices due to easy synthesis (subsection 2) and functionalization (subsection 3), high thermal stability and the possibility of fine-tuning their electronic properties through various structural modifications both on phosphorus and the benzene rings (subsections 3.1 and 3.2). Other areas of optoelectronics are open for exploration of dibenzophospholes and their derivatives. The ${ }^{31} \mathrm{P}-\mathrm{NMR}$ technique may be a very useful tool for the rapid monitoring of progress in chemical synthesis and in testing chemical purity and stability of these compounds. Since, so far, only two dibenzophospholes 66 and 212 were used in construction of emitting diodes, ${ }^{12,65}$ more intensive research with other dibenzophosphole representatives should certainly be investigated in the future.

This review shows the great potential of both simple and functionalized dibenzophospholes that should be tested more intensely as single materials, as well as in structural combinations with other $\pi$-extended conjugated aromatic and heteroaromatic systems containing phosphorus, nitrogen, silicon or sulfur atoms. The promising results obtained so far with closely related phospholes ${ }^{12}$ may outline possible directions of further improvements in optoelectronic materials based on organophosphorus compounds.

\section{Acknowledgements}

This work was financed by the National Science Centre (NCN), Poland on the basis of the grant number 2013/11/B/ST5/01610 and by Statutory Funds from the Ministry of Science and Higher Education in Poland.

\section{References}

1 H. Shirakawa, E. J. Louis, A. MacDiarmid, C. Chiang and A. J. Heeger, J. Chem. Soc., Chem. Commun., 1977, 16, 578.

2 U. Mitschke and P. Bauerle, J. Mater. Chem., 2000, 10, 1471. 3 M. J. S. Dewar and N. Trinajstic, J. Am. Chem. Soc., 1970, 92, 1453.
4 B. El Hamaoui, L. Zhi, J. Wu, J. Li, N. T. Lucas, Z. Tomovic, U. Kolb and K. Mllen, Adv. Funct. Mater., 2007, 17, 1179.

5 T. Baumgartner and R. Reau, Chem. Rev., 2006, 106, 4681.

6 M. G. Hobbs and T. Baumgartner, Eur. J. Inorg. Chem., 2007, 23, 3611.

7 T. Baumgartner, Acc. Chem. Res., 2014, 47, 1613.

8 D. Joly, P.-A. Bouit and M. Hissler, J. Mater. Chem. C, 2016, 4, 3686.

9 M. P. Duffy, W. Delaunay, P.-A. Bouit and M. Hissler, Chem. Soc. Rev., 2016, 45, 5296.

10 K. Fourmy, D. Nguyen, O. Cabaret and M. Gouygou, Catal. Sci. Technol., 2015, 5, 4289.

11 R. A. Aitken, Sci. Synth., 2001, 10, 817.

12 H. Su, O. Fadhel, C. Yang, T. Cho, C. Fave, M. Hissler, C. Wu and R. Réau, J. Am. Chem. Soc., 2006, 128, 983.

13 T. Baumgartner, T. Neumann and B. Wirges, Angew. Chem., Int. Ed., 2004, 43, 6197.

14 T. Baumgartner, W. Bergmans, T. Karpati, T. Neumann, M. Nieger and L. Nyulászi, Chem.-Eur. J., 2005, 11, 4687.

15 S. Durben, Y. Dienes and T. Baumgartner, Org. Lett., 2006, 8, 5893.

16 Y. Dienes, S. Durben, T. Karpati, T. Neumann, U. Englert, L. Nyulászi and T. Baumgartner, Chem.-Eur. J., 2007, 13, 7487.

17 Y. Matano and H. Imahori, Org. Biomol. Chem., 2009, 7, 1258. 18 C. Romero-Nieto and T. Baumgartner, Synlett, 2013, 24, 920.

19 G. Wittig and G. Geissler, Justus Liebigs Ann. Chem., 1953, 44, 580.

20 S. Ogawa, Y. Tajiri and N. Furukawa, Bull. Chem. Soc. Jpn., 1991, 64, 3182.

21 G. Wittig and A. Maercker, Chem. Ber., 1964, 97, 747.

22 S. Affandi, R. L. Green, B. T. Hsieh, M. S. Holt, J. H. Nelson and E. C. Alyea, Synth. React. Inorg. Met.-Org. Chem., 1987, $17,307$.

23 G. Wittig and E. Kochendoerfer, Chem. Ber., 1964, 97, 741.

24 G. Wittig and E. Benz, Chem. Ber., 1959, 92, 1999.

25 D. Hellwinkel, Chem. Ber., 1966, 99, 3642.

26 O. Herd, D. Hoff, K. W. Kottsieper, C. Liek, K. Wenz, O. Stelzer and W. S. Sheldrick, Inorg. Chem., 2002, 41(20), 5034.

27 A. Bruch, A. Fukazawa, E. Yamaguchi, S. Yamaguchi and A. Studer, Angew. Chem., Int. Ed., 2011, 50, 12094.

28 Q. Ruan, L. Zhou and B. Breit, Catal. Commun., 2014, 53, 87. 29 J. A. Macor, J. L. Brown, J. N. Cross, S. R. Daly, A. J. Gaunt, G. S. Girolami, M. T. Janicke, S. A. Kozimor, M. P. Neu, A. C. Olson, S. D. Reilly and B. L. Scott, Dalton Trans., 2015, 44, 18923.

30 H. Kalkeren, S. Leenders, C. Hommersom, F. Rutjes and F. Delft, Chem.-Eur. J., 2011, 17, 11290.

31 A. Oukhrib, L. Bonnafoux, A. Panossian, S. Waifang, D. H. Nguyen, M. Urrutigoity, F. Colobert, M. Gouygou and F. R. Leroux, Tetrahedron, 2014, 70, 1431.

32 T. Agou, M. D. Hossain, T. Kawashima, K. Kamada and K. Ohta, Chem. Commun., 2009, 44, 6762.

33 K. Yavari, P. Retailleau, A. Voituriez and A. Marinetti, Chem.Eur. J., 2013, 19, 9939. 
34 A. S. Ionkin and W. J. Marshall, Heteroat. Chem., 2003, 14(4), 360.

35 A. A. Diaz, J. D. Young, M. A. Khan and R. J. Wehmschulte, Inorg. Chem., 2006, 45, 5568.

36 V. Diemer, A. Berthelot, J. Bayardon, S. Juge, F. R. Leroux and F. Colobert, J. Org. Chem., 2012, 77, 6117.

37 K. Baba, M. Tobisu and N. Chatani, Angew. Chem., Int. Ed., 2013, 52, 11892.

38 Y. Unoh, T. Satoh, K. Hirano and M. Miura, ACS Catal., 2015, $5,6634$.

39 Y. Kuninobu, T. Yoshida and K. Takai, J. Org. Chem., 2011, 76, 7370 .

40 S. Furukawa, S. Haga, J. Kobayashi and T. Kawashima, Org. Lett., 2014, 16, 3228.

41 Y. Cui, L. Fu, J. Cao, Y. Deng and J. Jiang, Adv. Synth. Catal., 2014, 356, 1217.

42 S. Ishikawa and K. Manabe, Tetrahedron, 2010, 66, 297.

43 M. Stankevič, J. Pisklak and K. Włodarczyk, Tetrahedron, 2016, 72, 810.

44 N. Fukawa, T. Osaka, K. Noguchi and K. Tanaka, Org. Lett., 2010, $12(6), 1324$.

45 E. Martinez-Arripe, F. Jean-Baptiste-dit-Dominique, A. Auffrant, X. F. Le Goff, J. Thuilliez and F. Nief, Organometallics, 2012, 31, 4854.

46 S. Shah, M. Cather Simpson, R. C. Smith and J. D. Protasiewicz, J. Am. Chem. Soc., 2001, 123, 6925.

47 X. Wei, Z. Lu, X. Zhao, Z. Duan and F. Mathey, Angew. Chem., Int. Ed., 2015, 54, 1583-1586.

48 O. Fadhel, D. Szieberth, V. Deborde, C. Lescop, L. Nyulászi, M. Hissler and R. Réau, Chem.-Eur. J., 2009, 15, 4914.

49 P. Bouit, A. Escande, R. Szucs, D. Szieberth, C. Lescop, L. Nyulászi, M. Hissler and R. Réau, J. Am. Chem. Soc., 2012, 134, 6524.

50 Y. Hayashi, Y. Matano, K. Suda, Y. Kimura, Y. Nakao and H. Imahori, Chem.-Eur. J., 2012, 18, 15972.

51 H. Kalkeren, S. Leenders, C. Hommersom, F. Rutjes and F. Delft, Chem.-Eur. J., 2011, 17, 11290.
52 K. Geramita, J. McBee and T. D. Tilley, J. Org. Chem., 2009, 74, 820 .

53 Y. J. Ahn, R. J. Rubio, T. K. Hollis, F. S. Tham and B. Donnadeiu, Organometallics, 2006, 25, 1079.

54 N. Dubrovina, H. Jiao, V. Tararov, A. Spannenberg, R. Kadyrov, A. Monsees, A. Christiansen and A. Borner, Eur. J. Org. Chem., 2006, 11, 3412.

55 C. H. Lin, C. W. H. Su, J. L. Liao, Y. M. Cheng, Y. Chi, T. Y. Lin, M. W. Chung, P. T. Chou, G. H. Lee, C. H. Chang, C. Y. Shih and C. L. Ho, J. Mater. Chem., 2012, 22, 10684.

56 H. A. van Kalkeren, C. Grotenhuis, F. S. Haasjes, C. A. Hommersom, F. P. J. T. Rutjes and F. L. van Delft, Eur. J. Org. Chem., 2013, 31, 7059.

57 H. A. Kalkeren, J. J. Bruins, F. P. J. T. Rutjes and F. L. Delft, Adv. Synth. Catal., 2012, 354, 1417.

58 E. Durán, E. Gordo, J. Granell, M. Font-Bardía, X. Solans, D. Velasco and F. López-Calahorra, Tetrahedron: Asymmetry, 2001, 12, 1987.

59 J. G. L. Cortés, S. Vincendeau, J. C. Daran, E. Manoury and M. Gouygou, Acta Crystallogr., Sect. C: Cryst. Struct. Commun., 2006, 62, m188.

60 A. Decken, M. Neil, C. Dyker and F. Bottomley, Can. J. Chem., 2002, 80, 55.

61 A. Decken, M. Neil, C. Dyker and F. Bottomley, Can. J. Chem., 2001, 79, 1321.

62 D. H. Nguyen, H. Lauréano, S. Jugé, P. Kalck, J. C. Daran, Y. Coppel, M. Urrutigoity and M. Gouygou, Organometallics, 2009, 28, 6288.

63 C. Thoumazet, L. Ricard, H. Gruützmacherb and P. Le Floch, Chem. Commun., 2005, 12, 1592.

64 E. Duran, D. Valasco, F. Lopez-Calahorra and H. Finkelmann, Mol. Cryst. Liq. Cryst., 2010, 381, 43.

65 J. Yin, R. F. Chen, S. L. Zhang, Q. D. Ling and W. Huang, J. Phys. Chem. A, 2010, 114, 3655.

66 R. Kabe, V. M. Lynch and P. Anzenbacher, CrystEngComm, 2011, 13, 5423. 